\section{Pacific Northwest}

National Laboratory

Operated by Battelle for the

U.S. Department of Energy

\title{
C-200 Series Tanks Vacuum Retrieval System Aerosol Test Results
}

\author{
J. L. Huckaby \\ J. A. Glissmeyer \\ P. E. Grey
}

September 2003

Prepared for the U.S. Department of Energy under Contract DE-AC06-76RL01830 


\title{
DISCLAIMER
}

This report was prepared as an account of work sponsored by an agency of the United States Government. Neither the United States Government nor any agency thereof, nor Battelle Memorial Institute, nor any of their employees, makes any warranty, express or implied, or assumes any legal liability or responsibility for the accuracy, completeness, or usefulness of any information, apparatus, product, or process disclosed, or represents that its use would not infringe privately owned rights. Reference herein to any specific commercial product, process, or service by trade name, trademark, manufacturer, or otherwise does not necessarily constitute or imply its endorsement, recommendation, or favoring by the United States Government or any agency thereof, or Battelle Memorial Institute. The views and opinions of authors expressed herein do not necessarily state or reflect those of the United States Government or any agency thereof.

\author{
PACIFIC NORTHWEST NATIONAL LABORATORY \\ operated by \\ BATTELLE \\ for the \\ UNITED STATES DEPARTMENT OF ENERGY \\ under Contract DE-ACO6-76RLO183O
}

Printed in the United States of America

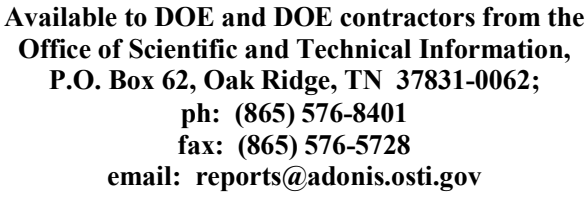

Available to the public from the National Technical Information Service, U.S. Department of Commerce, 5285 Port Royal Rd., Springfield, VA 22161

ph: (800) 553-6847

fax: $(703) 605-6900$

email: orders@ntis.fedworld.gov

online ordering: http://www.ntis.gov/ordering.htm 


\title{
C-200 Series Tanks Vacuum Retrieval System Aerosol Test Results
}

\author{
J. L. Huckaby \\ J. A. Glissmeyer \\ P. E. Gray
}

September 2003

Prepared for

the U.S. Department of Energy

under Contract DE-AC06-76RL01830

Pacific Northwest National Laboratory

Richland, Washington 


\section{Executive Summary}

The radioactive wastes stored in tanks 241-C-201, 241-C-202, 241-C-203, and 241-C-204 (C-200 series tanks) are to be retrieved with the C-200 vacuum retrieval system (VRS). The VRS will use high-volume, liquid-ring vacuum pumps (LRVPs) to suck the wastes up through an articulated mast system, separate it from the suspending air, collect and transfer it to a receiver batch tank, and return the air as exhaust to the waste tank being retrieved. Analysis of potential accidents has indicated that a break in the line used to return the VRS exhaust to the waste tank might release unacceptable quantities of suspended radioactive material to the environment.

To estimate the quantity of suspended material in the VRS exhaust line and allow a more definitive determination of accident risks, the contractor responsible for the C-200 series tanks waste retrieval, CH2M HILL Hanford Group, Inc. (CH2M HILL), and staff from Pacific Northwest National Laboratory (PNNL) conducted a series of tests with the VRS using nonradioactive waste simulants at the Hanford Cold Test Facility. The test plan and procedures are given by Baide and Huckaby (2003). This report describes the tests conducted and presents and discusses the results.

The goal of the C-200 VRS aerosol tests was to collect sufficient information to make a conservative estimate of particulate and aerosol mass concentrations in the VRS exhaust line under actual operating conditions. Because the potential exists to accumulate waste in the VRS between the batch tank (where the bulk of the waste is collected) and the exhaust line, and the accumulation of waste in this section of the VRS directly affects the exhaust aerosol concentration, it is important to be able to estimate the rate of waste accumulation and relate it to the exhaust aerosol concentration. Consequently, the tests were designed to evaluate the collection efficiency of the batch tank, the rate at which waste accumulated in the LRVP seal water, and the rate at which the LRVP seal water separator released materials to the exhaust line.

Tests were conducted with the VRS retrieving two different waste simulants; one was intended to represent aqueous wastes conservatively and the other to examine system performance on a dry material. Aqueous wastes were simulated by water and dry wastes by graded dry sand in the tests, which used the same process equipment as, under conditions similar to, the actual retrievals from the $\mathrm{C}-200$ series tanks. The aqueous waste simulant was tagged with trace levels of nonradioactive Cs, and the LRVP seal water was tagged with trace levels of $\mathrm{Rb}$.

Testing consisted of collecting air samples from the VRS exhaust line while the VRS was applied to collect full-scale batches of waste simulant. The exhaust air sample was heated to evaporate the liquid water portion of the aerosol and then filtered to collect essentially all the

solid particles in the sample air. Samples of the LRVP seal water were collected at the beginning and end of each test run to establish initial and final conditions of this key process fluid. Also, the liquid that tended to collect and run along the inside of the exhaust line was sampled during 
the test runs. All samples were subsequently analyzed for chemical tracers (when tests involved the aqueous waste simulant) or mass and particle size distribution (when tests involved the dry waste simulant).

Not all tests planned by Baide and Huckaby (2003) were conducted; all the planned aqueous waste simulant tests were completed, but, after the first dry waste simulant test run, testing was interrupted and two planned test runs were not conducted. The lack of data from these final two test runs was determined to be acceptable by the CH2M HILL test coordinator.

Table ES.1 lists the aqueous waste simulant aerosol concentrations measured in the VRS exhaust line. As indicated in the table, the first test run was performed with a single LRVP operating, and subsequent test runs were performed with both LRVPs. The aerosol concentration was expected to increase with each successive test run (because waste simulant concentrations in the LRVP seal water increase), but the approximately geometric increases observed were larger than expected. The anomalously high aerosol concentration observed during the $\mathrm{CsCl} 4$ test run may be due to the re-entrainment of droplets from the thin streams of liquid running along the inside wall of the exhaust line.

Table ES.1. Aqueous Waste Simulant Test Aerosol Mass Concentrations

\begin{tabular}{|c|l|c|}
\hline Test Run & \multicolumn{1}{|c|}{ Description } & $\begin{array}{c}\text { VRS Exhaust Aqueous Waste Simulant } \\
\text { Aerosol Mass Concentration } \\
\left(\mathbf{m g} / \mathbf{m}^{\mathbf{3}}\right)\end{array}$ \\
\hline $\mathrm{CsCl} 1$ & Test run with one LRVP & 2.5 \\
\hline $\mathrm{CsCl} 2$ & Test run with two LRVPs & 6.6 \\
\hline $\mathrm{CsCl} 3$ & Test run with two LRVPs & 25 \\
\hline $\mathrm{CsCl} 4$ & Test run with two LRVPs & 102 \\
\hline
\end{tabular}

The VRS exhaust was estimated to contain from 0.07 to $0.7 \mathrm{~mL} / \mathrm{m}^{3}$ of LRVP seal water as an aerosol, based on measured tracer concentrations in the LRVP seal water and quantities of the tracers on the aerosol filters. Higher concentrations of seal water aerosol in the exhaust were associated with increased LRVP operating temperatures and the use of two LRVPs instead of one. Informal testing performed subsequent to the aerosol tests indicates entrainment of LRVP seal water is strongly affected by the amount of seal water introduced to the LRVPs. The amount of condensate and entrained seal water was reduced by approximately a factor of five by reducing the seal water flowrate.

The VRS batch tank collection efficiency was calculated from the accumulation of aqueous waste simulant tracer (Cs) in the LRVP seal water. Collection efficiency was markedly higher for the test conducted with one LRVP than for the three tests conducted with two LRVPs. The calculated batch tank efficiency with one LRVP was 99.98\%; with two LRVPs the average was about $98.3 \%$. The reason for this difference was not established but could be explained by a nonrepresentative sample of LRVP seal water or an error in its chemical analysis. Because it is 
inconsistent with subsequent test runs, we recommend that the batch efficiency calculated for the first test run not be used for safety-related analyses and that the batch tank collection efficiency be assumed to be $98.3 \%$ regardless of whether one or two LRVPs are used.

The single test run using dry waste simulant was determined to produce an exhaust aerosol with approximately $9.8 \mathrm{mg} / \mathrm{m}^{3}$ of simulant. Particle size analysis indicated the aerosol was composed predominantly of particles smaller than about $50 \mu \mathrm{m}$ and about $80 \%$ of the aerosol mass was due to particles greater than about $10 \mu \mathrm{m}$.

\section{Reference}

Baide DG and JL Huckaby. 2003. C-200 Series Retrieval Project - Test Implementation Plan for Measurement of Particulate and Aerosol Discharge for the Vacuum Retrieval System. RPP-17356 Rev. 1, CH2M HILL Hanford Group, Inc., Richland, WA. 


\section{Acknowledgments}

The authors would especially like to thank John Schofield for his contributions to the understanding of the retrieval system, the test conditions and results, and for various other help with the report itself. 


\section{Acronyms and Abbreviations}

$\begin{array}{ll}\text { AMS } & \text { articulated mast system } \\ \text { CH2M HILL } & \text { CH2M HILL Hanford Group, Inc. } \\ \text { CTF } & \text { Cold Test Facility } \\ \text { g } & \text { grams } \\ \text { ICP-MS } & \text { inductively coupled plasma mass spectrometry } \\ \text { L } & \text { liters } \\ \text { LRVP } & \text { liquid ring vacuum pump } \\ \text { mg } & \text { milligrams } \\ \text { mL } & \text { milliliters } \\ \text { PNNL } & \text { Pacific Northwest National Laboratory } \\ \text { psi } & \text { pounds per square inch } \\ \text { VRS } & \text { vacuum retrieval system } \\ \text { wt } \% & \text { weight percent } \\ \mu \mathrm{g} & \text { micrograms } \\ \mu \mathrm{m} & \text { micrometers }\end{array}$




\section{Contents}

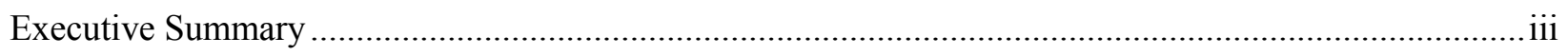

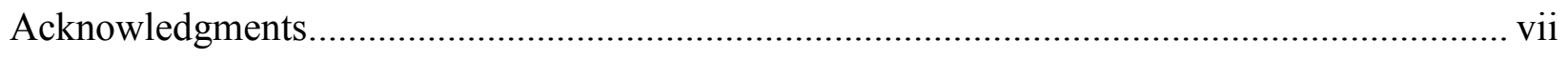

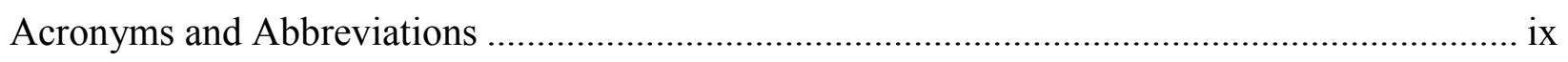

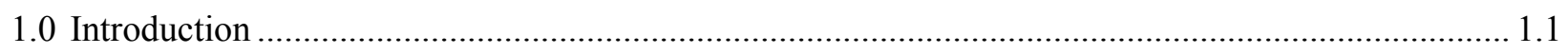

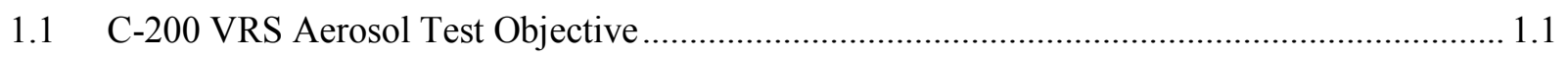

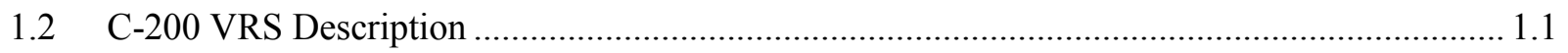

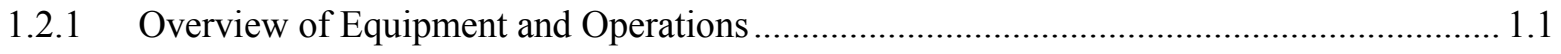

1.2.2 Aerosol Separation Processes Within the VRS ................................................................ 1.2

1.2.3 Operating Conditions that Maximize Exhaust Aerosols ................................................. 1.3

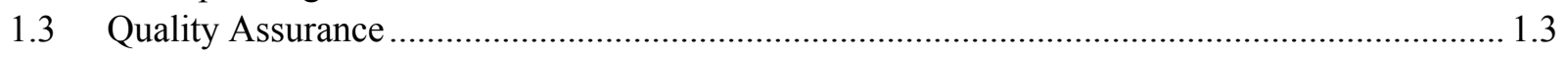

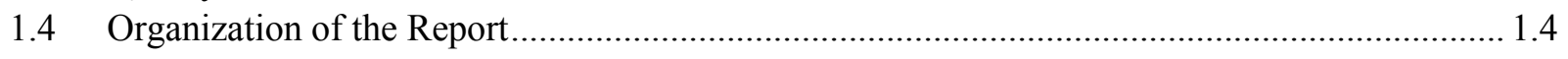

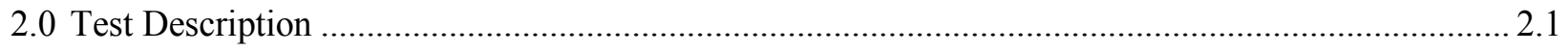

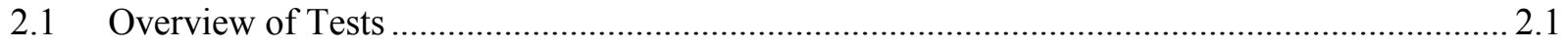

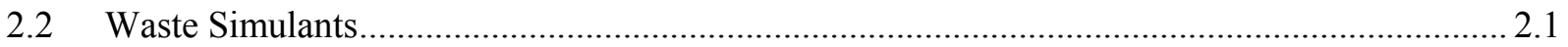

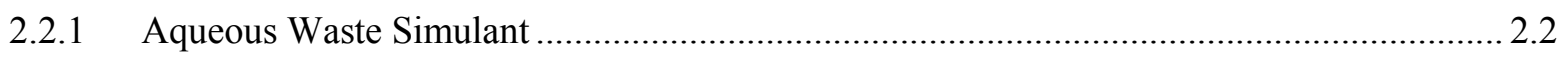

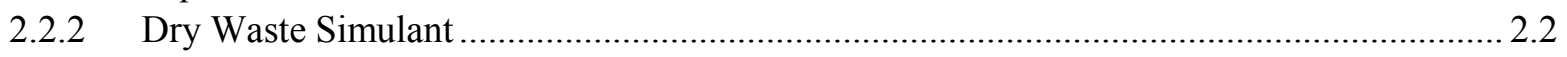

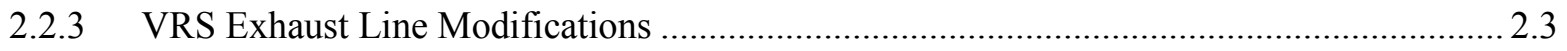

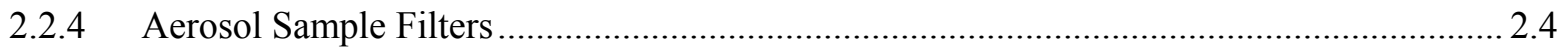

2.2.5 Sample and Total Airflow Control and Measurement ................................................ 2.5

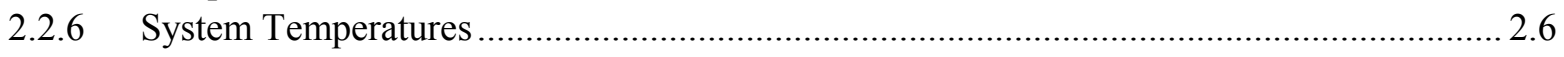

2.3 Test Sequence and Deviations from the Test Plan ........................................................... 2.7

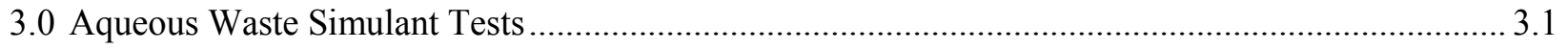

3.1 Aqueous Waste Simulant and LRVP Water Tracers ….......................................................... 3.1

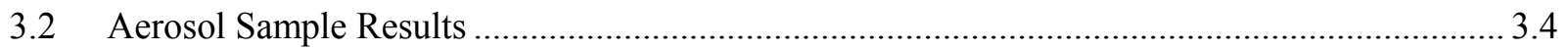

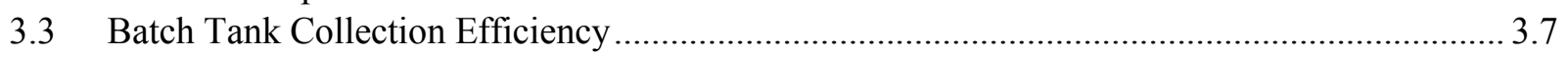

3.4 LRVP Seal Water Aerosol in the Exhaust Air Stream........................................................... 3.8

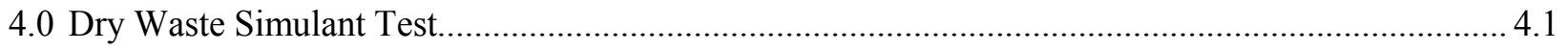

4.1 Aerosol Sample Analyses and Results ........................................................................... 4.1

4.2 Particulates in Exhaust Line Liquid Samples..................................................................... 4.3

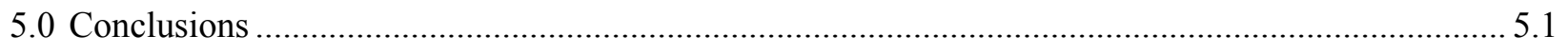

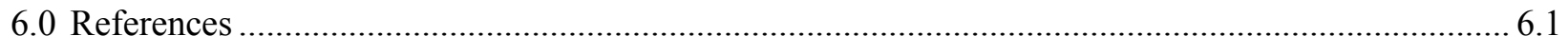

Appendix: Particle Size Analysis Results.................................................................. 


\section{Figures}

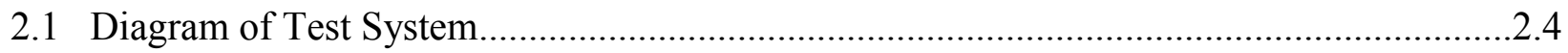

4.1 Total Mass of Particles as a Function of Particle Size .......................................................4.2

\section{Tables}

ES.1 Aqueous Waste Simulant Test Aerosol Mass Concentrations ....................................... iv

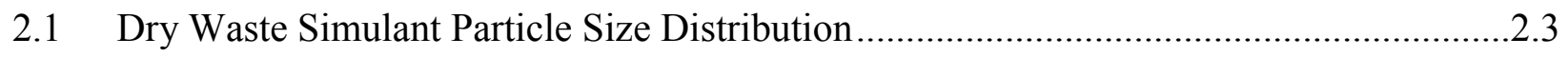

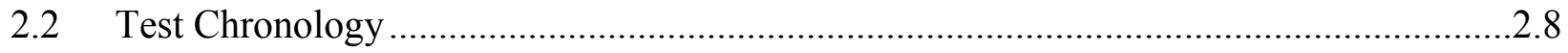

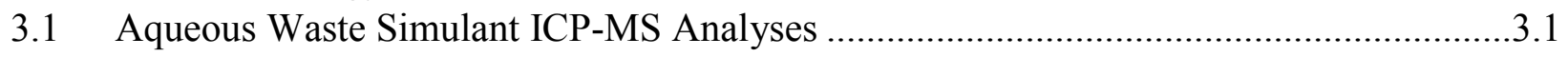

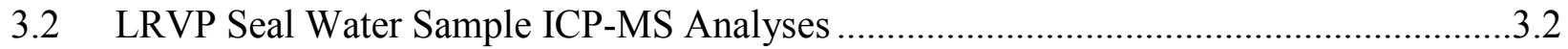

3.3 VRS Exhaust Line Liquid Volumes and Sample Analyses ..........................................2

3.4 Comparison of Exhaust Line Liquid and LRVP Seal Water..........................................3.3

3.5 Aqueous Waste Simulant Test Aerosol Sample Volumes and Flow Rates ......................3.4

3.6 Tracer Masses Measured in Filter Assemblies .................................................................. 3.5

3.7 Aqueous Waste Simulant Test Aerosol Mass Concentrations ..........................................6

3.8 Batch Tank Efficiency Calculation Inputs and Results...............................................

3.9 LRVP Seal Water Aerosol Concentration in Exhaust Air Stream ....................................10

4.1 Dry Waste Simulant Filter Sample Gravimetric Analysis Results.................................4.1

4.2 Dry Waste Simulant Filter Sample Particle Size Analyses ........................................... 4.2

4.3 Size Analyses of Particles in Exhaust Line Liquid .....................................................3 


\subsection{Introduction}

The radioactive wastes stored in tanks 241-C-201, 241-C-202, 241-C-203, and 241-C-204 (the $\mathrm{C}-200$ series) are to be retrieved with the $\mathrm{C}-200$ vacuum retrieval system (VRS). The VRS will use high-volume vacuum pumps to draw the wastes up through an articulated mast system (AMS), separate it from the suspending air, collect and transfer it to a receiver tank, and return the air as exhaust to the waste tank being retrieved. Analysis of potential accidents has indicated that a break in the line used to return the VRS exhaust to the waste tank could release unacceptable quantities of suspended radioactive material to the environment.

To estimate the quantity of suspended material in the VRS exhaust line and allow a more definitive determination of accident risks, the contractor responsible for the C-200 series tank waste retrieval, CH2M HILL Hanford Group, Inc. (CH2M HILL), and staff from Pacific Northwest National Laboratory (PNNL) conducted a series of tests with the VRS using nonradioactive waste simulants at the Hanford Cold Test Facility (CTF). The test plan and procedures are given by Baide and Huckaby (2003). This report describes the tests conducted and presents and discusses the results.

\subsection{C-200 VRS Aerosol Test Objective}

The goal of the C-200 VRS aerosol tests was to collect sufficient information to conservatively bound the particulate and aerosol mass loading in the VRS exhaust line under actual operating conditions. Based on criteria developed by $\mathrm{CH} 2 \mathrm{M}$ HILL safety analysts, the tests were to provide an aerosol detection limit of about $1 \mathrm{mg} / \mathrm{m}^{3}$.

\subsection{C-200 VRS Description}

This section provides background information on the C-200 VRS and its operational conditions during the tests.

\subsubsection{Overview of Equipment and Operations}

The C-200 VRS consists of the AMS, a batch tank and two waste transfer pumps, two liquid ring vacuum pumps (LRVPs), the LRVP liquid/air separator vessel, a monitoring and control system, a portable exhauster, and hose-in-hose transfer lines. The AMS is installed through a riser on the tank to be retrieved and extended so that its inlet reaches within several inches of the waste surface. Compressed air is injected at the inlet of the AMS to lower the density of the waste inside the AMS, and assist the vacuum retrieval of waste vertically into the batch tank. Water can also be added at the inlet of the AMS as a lubricant for collecting dry wastes. The 
AMS is also equipped with high-pressure "scarifier" jets (1,500 psi) that can be used to break up and mobilize the waste.

The bulk of the waste drawn up through the AMS is separated from the entraining air in the batch tank. Waste is collected at the bottom of the batch tank while air exits the top of the tank. The batch tank has a maximum capacity of approximately 1,200 L, with a working volume of approximately $950 \mathrm{~L}$. Progressive cavity pumps are used to transfer wastes from the batch tank to the designated waste receipt tank.

The vacuum system consists of two liquid ring vacuum pumps (LRVPs), a seal water/air separator vessel, and a seal water cooler. The two pumps may be operated one at a time or simultaneously. The LRVPs use water as the sealing and heat removal medium. The seal water/air separator vessel performs two functions. It acts as a cyclone to collect particulate and aerosols entrained in the LRVP discharge stream, and it serves as the reservoir of seal water. Seal water collected in the LRVP separator vessel flows through a heat exchanger (to remove the heat generated by the LRVPs) and back into the LRVPs. High- and low-level switches in the seal water/air separator vessel maintain proper level for pump operation. The air leaving the LRVP separator vessel is routed back to the waste tank being retrieved to complete a closed-loop air recirculation system. More detailed descriptions of the C-200 VRS are given by Baide and Huckaby (2003).

\subsubsection{Aerosol Separation Processes Within the VRS}

The VRS uses a sequence of three separation processes to separate retrieved waste from the exhaust air. These are 1) the bulk separation of waste from air in the batch tank, 2) the mixing and centrifugal separation of air and waste aerosol with water in the LRVPs, and 3) the cyclonic separation of LRVP seal water from air in the LRVP separator vessel.

The air and entrained waste enter the batch tank via a side inlet into the top of the tank that directs the waste and air downward. Gravity and inertia cause the bulk of the waste to accumulate at the bottom of the batch tank while the air is removed via a vertical pipe in the top of the tank.

Air and any entrained waste leaving the batch tank enter the LRVPs. The LRVPs use violent mixing of the incoming air with water and centrifugal forces inside the LRVPs to effect the removal of particulates from the air. This results in the collection of virtually the entire waste aerosol that enters the LRVPs by the seal water. However, some of the seal water is itself entrained as droplets in the air leaving the LRVPs, and to the extent that these droplets contain dissolved or suspended waste and pass through the LRVP separator vessel, waste can be reentrained in the VRS exhaust. Thus, the waste aerosol mass concentration in the VRS exhaust line is expected to be a strong function of the concentration of waste in the LRVP seal water. 
The mixture of air and LRVP seal water pumped out of the LRVPs enters the LRVP separator vessel. It is a cyclone separator, and the LRVP separator vessel tends to be very efficient at removing all particles above a cut size and allows most particles below the cut size to pass through. The cut size will vary with the velocity of incoming air, the extent to which the vessel is filled with material (seal water), and the density and aerodynamic properties of the particles.

Because the concentration of waste in the LRVP water increases steadily as waste aerosol enters from the batch tank, the waste aerosol mass concentration in the VRS exhaust will also continue to rise (other things being equal) until the LRVP water is drained and replaced with fresh water.

\subsubsection{Operating Conditions that Maximize Exhaust Aerosols}

According to Baide and Huckaby (2003), the bounding conditions that result in the maximum aerosol concentration in the VRS exhaust line are the following:

- No scarifier or lube water running. Any water addition at the AMS inlet nozzle will enhance removal in the batch vessel.

- Batch vessel full. A full vessel reduces the available space for inertial or settling effects and supports resuspension of material.

- Both vacuum pumps operating. Maximum airflow and volume enhances turbulence in the batch vessel and seal water/air separator vessel, which supports resuspension of material and short-circuits inertial or settling effects.

- Normal liquid level in the seal water/air separator vessel. Maximum vacuum pump efficiency creates highest pass-through.

Informal testing performed subsequent to the aerosol tests indicates entrainment of LRVP seal water is strongly affected by the amount of seal water introduced to the LRVPs. The amount of condensate and entrained seal water observed during the aerosol tests was reduced by approximately a factor of five by reducing the seal water flowrate. Based on operating experience with the VRS, the manufacturer has confirmed that the listed conditions represent worst-case pass-through into the exhaust stream (Baide and Huckaby 2003).

\subsection{Quality Assurance}

The quality assurance requirements applied to the testing are described by Baide and Huckaby (2003). Chemical analyses of the liquid and filter samples were conducted by the 222-S Laboratory in compliance with the DOE's Hanford Analytical Services Quality Assurance Document. Sample chain of custody records, calibration certificates, and test exceptions are documented in the field copy of the test plan and procedures (Baide 2003). 


\subsection{Organization of the Report}

Descriptions of the tests, waste simulants, the test apparatus and instrumentation, the sequence of events, and deviations from the test plan are given in Section 2 of this report. Sections 3 and 4 provide the test data, sample analyses, and detailed results for the aqueous and dry waste simulant tests, respectively. Conclusions from the test results are given in Section 5 and cited references in Section 6. 


\subsection{Test Description}

Testing of the C-200 VRS for exhaust aerosols was governed by C-200 Series Retrieval Project - Test Implementation Plan for Measurement of Particulate and Aerosol Discharge from the Vacuum Retrieval System (Baide and Huckaby 2003), which provides both the test plan and test procedure. The field copy of that test plan, with instrument calibration records, completed data sheets, and a record of test exceptions, has been released as Baide (2003).

This section summarizes the testing, test apparatus and instrumentation, the sequence of events, and deviations from the test plan.

\subsection{Overview of Tests}

Tests were conducted using the same process equipment that will be used to retrieve wastes from the C-200 series tanks under conditions similar to those of the actual retrievals. Test conditions, waste simulants, and sample locations were also chosen to provide the information needed to develop reasonably conservative estimates of waste aerosol concentrations in the VRS exhaust line.

Tests were conducted using the C-200 VRS as it was installed at the Hanford CTF in July 2003. Two waste simulants were tested. Aqueous wastes were simulated by water containing a chemical tracer, and dry wastes were simulated by \#70 sand (see Section 2.2). Testing consisted of collecting air samples from the VRS exhaust line while the VRS was applied to collect fullscale batches of waste simulant. The exhaust air sample was heated to evaporate the liquid water portion of the aerosol, then filtered to collect essentially all the solid particles in the sample air. The collected filter samples were subsequently analyzed for chemical tracers (when tests involved the aqueous waste simulant) or mass and particle size distribution (when tests involved the dry waste simulant).

To establish the rate at which the aqueous wastes accumulate in the LRVP seal water, samples were collected after each aqueous waste simulant test run and analyzed for the waste simulant tracer. A second chemical tracer was added to the LRVP seal water to independently track the LRVP seal water in the exhaust aerosol.

\subsection{Waste Simulants}

Tests were conducted with the VRS retrieving two different waste simulants, one intended to conservatively represent aqueous wastes and the other to examine system performance on a dry material. Aqueous wastes were simulated in the tests by water, and dry wastes were simulated in the tests by graded dry sand. 


\subsubsection{Aqueous Waste Simulant}

Water is a conservative simulant of aqueous wastes because it has a lower density and the efficiencies of the VRS separation processes tend to increase as the density of the aerosol particles increases. The cyclonic separation of LRVP separator vessel and the centrifugal action of the LRVPs both rely on the inertia of the aerosol particles to effect their separation from air, and higher density particles (other things being equal) are preferentially separated. A small amount of cesium chloride $(\mathrm{CsCl})$ was added to the water (i.e., the waste simulant) to allow the simulant to be tracked through the VRS process and quantitatively measured in the VRS exhaust line. Cs was selected as a tracer because it is not normally present at significant concentrations in water and can be accurately measured by standard laboratory techniques at very low concentrations. ${ }^{(\text {a) }}$ The $\mathrm{CsCl}$ was added strictly as a chemical tracer. At the concentration that was used it was not expected to modify the physical properties of the water.

\subsubsection{Dry Waste Simulant}

In an attempt to simulate worst-case performance of the VRS on C-200 series waste, preliminary testing was conducted in late July using a silicon dioxide powder having a mean particle size of about $3.5 \mu \mathrm{m}$. By comparison, Creze and Jewett (2002) estimated the C-200 series wastes had a median particle size of $7.5 \mu \mathrm{m}$ (i.e., $50 \%$ of all waste particles have an equivalent diameter of $7.5 \mu \mathrm{m}$ or less), and a $95^{\text {th }}$ percentile particle size of $140 \mu \mathrm{m}$ (i.e., $95 \%$ of all particles are smaller than $140 \mu \mathrm{m}$ ). The preliminary testing conducted in late July with $3.5 \mu \mathrm{m}$ simulant was performed without the benefit of lubrication water at the entrance of the AMS and with both LRVPs operating. Under these operating conditions, a significant fraction of the extremely fine powder was passed through the batch tank and collected in the LRVP seal water. The wetted powder accumulated and eventually fouled portions of the LRVP heat exchanger, causing the temperature of the LRVP system to rise.

While much of the waste to be retrieved with the VRS contains fine particles, it is expected to be agglomerated and have much larger effective particle sizes than the extremely fine, loose, dry $\mathrm{SiO}_{2}$ powder used in the preliminary tests. Consequently, the dry waste simulant chosen for the tests discussed in this report was not intended to be a direct simulant of the C-200 series tank wastes. These tests were conducted with commercially available \#70 sand. The vendor-supplied particle size distribution determined using screen filtration ${ }^{(b)}$ is given in Table 2.1, with comparable results from light scattering particle size analysis ${ }^{(\mathfrak{c})}$ performed by PNNL. More detailed particle size analyses by both screen analysis and light scattering are given in Appendix A.

(a) An informal analysis by PNNL of a CTF process water sample indicated Cs to be present at about $0.014 \mathrm{ng} / \mathrm{mL}$.

(b) Lane Mountain Company, Valley, WA.

(c) Analyses conducted on two grab samples of the simulant using a Horiba LA-920 particle size analyzer. 
Table 2.1. Dry Waste Simulant Particle Size Distribution

\begin{tabular}{|c|c|c|c|}
\hline $\begin{array}{c}\text { Particle Size }^{(\mathbf{a})} \\
d \\
(\mu \mathrm{m})\end{array}$ & $\begin{array}{c}\text { Vendor Analysis }^{(\mathbf{b})} \\
(\mathbf{w t} \%)\end{array}$ & $\begin{array}{c}\text { Particle Size } \\
d \\
(\mu \mathrm{m})\end{array}$ & $\begin{array}{c}\text { Light-Scattering } \\
\text { Analysis (average) } \\
(\mathbf{w t} \%)\end{array}$ \\
\hline$d \leq 74$ & 5.0 & $d \leq 77$ & 0.00 \\
\hline $74<d \leq 105$ & 10.5 & $77<d \leq 101$ & 0.02 \\
\hline $105<d \leq 147$ & 18.0 & $101<d \leq 152$ & 0.35 \\
\hline $147<d \leq 208$ & 31.0 & $152<d \leq 229$ & 2.0 \\
\hline $208<d \leq 297$ & 32.0 & $229<d \leq 301$ & 3.3 \\
\hline $297<d$ & 3.5 & $301<d$ & 94 \\
\hline \multicolumn{4}{|c|}{$\begin{array}{l}\text { (a) Particle size is the effective particle diameter. } \\
\text { (b) Vendor analysis was conducted by screening a sample, and particle sizes correspond to screen mesh sizes. } \\
\text { (c) Two samples of the sand in the waste simulant trough were analyzed by light-scattering. Results from the } \\
\text { two samples were averaged by first converting the size distribution (see Appendix A) to a mass distribution, and } \\
\text { then averaging the fractions of mass in each size bin from the two samples. }\end{array}$} \\
\hline
\end{tabular}

The large difference between the particle size distributions from the vendor (based on shaking the sand through screens of different mesh size) and from light-scattering analysis is not understood. Some settling of the finer particles in the waste simulant trough (prior to sample collection) and in the sample vials (prior to sub-sampling for the light-scattering analyses) may have occurred, but this does not completely explain the large differences in reported size distributions. The sand itself was supplied in 80-pound bags, and it is possible that the two analyses were based on samples from different portions of a much larger supply of sand.

\subsubsection{VRS Exhaust Line Modifications}

The VRS exhaust aerosol sampling apparatus is illustrated in the lower half of Figure 2.1. It consisted of a 48 -in. long section of clear 4-in. inside-diameter Plexiglas pipe with a $45^{\circ}$ wye, blind flange, and long-radius pipe elbow; a sampling probe inserted into the Plexiglas pipe, an aerosol filter holder with two filters, valves for controlling airflows, and associated instruments for measuring airflows and temperatures. As indicated in the figure, this apparatus was connected to the exhaust of the LRVP separator vessel. Because the LRVP separator vessel is housed in a steel Connex box and room within the Connex box is limited, the sampling apparatus was installed outside the Connex box, connected to the VRS in place of the VRS exhaust line (a 4-in. inside diameter hose). The exhaust air passed through the sampling apparatus and was directed downward into a bucket to collect the bulk of condensate and entrained liquid from the LRVP separator vessel. 


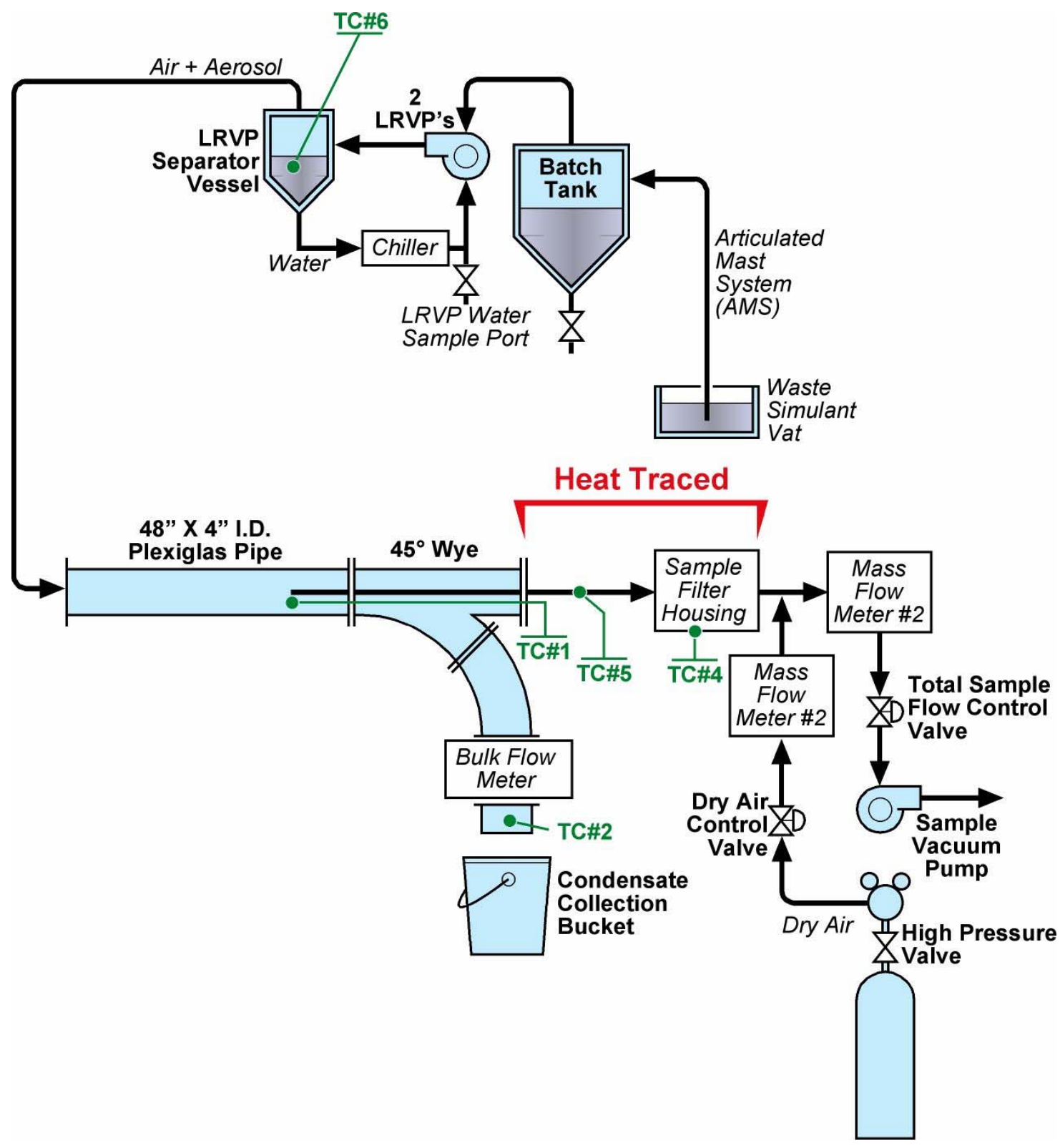

Figure 2.1. Diagram of Test System

\subsubsection{Aerosol Sample Filters}

The aerosol sample filter assemblies were composed of commercially available $47 \mathrm{~mm}$ filter holders ${ }^{(\text {a) }}$ modified to include a 34.25-in.-long, 0.245-in.-inside diameter straight stainless steel tubes with a beveled (knife-edge) inlet. As depicted in Figure 2.1, the aerosol filter holder was located outside the plastic sampling manifold and accessed the exhaust air via a straight sampling probe. Each filter sample was collected with a dedicated sampling probe and filter holder, so that aerosol particles collected on the inner wall of the sampling probe could be rinsed from the

(a) Model 2220, Paul Gelman, East Hill, New York. 
probe and included in the sample. The sampling probe was inserted at a marked location approximately 40 in. (10 pipe diameters) away from the entrance of the Plexiglas pipe and 8 in. ( 2 pipe diameters) upstream of the $45^{\circ}$ wye. The probe location was chosen to provide fully developed flow profile.

The filter holder and the sampling probe between the blind flange and the filter holder were wrapped with heat tape and heated when samples were collected to evaporate any water droplets in the air stream and protect the filters from becoming wet. ${ }^{\text {(a) }}$ Because the VRS exhaust air was hot $\left(105^{\circ}\right.$ to $\left.140^{\circ} \mathrm{F}\right)$ and essentially saturated with water vapor from the LRVPs, precautions were necessary to prevent the condensation of water in the sample air mass flow meter. For this purpose, the sample air was mixed with a measured stream of dry air that effectively reduced its dewpoint to below the ambient temperature.

Two filters were used for each sample to demonstrate that the first (upstream) filter had indeed collected essentially all the aerosols and had not been wetted. In the event that either filter exhibited water spots (nonuniform coloration of deposits) or breakage, the second (downstream) filter would also be analyzed. Two glass fiber filters ${ }^{(b)}$ were installed in the filter

holder when the aqueous waste simulant was tested, and two mixed cellulose membrane filters ${ }^{(c)}$ were installed in the filter holder when the dry particulate waste simulant was used. The glass fiber filters were considered less likely to break during sample collection and were easily analyzed for the chemical tracers. The mixed cellulose membrane filters were used for tests of the dry waste simulant (sand) because, unlike the glass fiber filters, they could be incinerated to recover the simulant.

\subsubsection{Sample and Total Airflow Control and Measurement}

The total VRS exhaust flow rate was measured using an Annubar meter installed about 8 in. (two pipe diameters) from the exhaust outlet. Total exhaust flow rate was not a critical measurement of the tests, but was needed to adjust sample airflow rates to an isokinetic velocity. Because the Annubar meter proved unreliable in the wet exhaust conditions and insensitive to low flow rates, two hand-held flow rate instruments were also used. These were a thermal anemometer $^{(\mathrm{d})}$ and a vane anemometer. ${ }^{(\mathrm{e})}$

(a) Collection efficiency of the filters would be significantly reduced if the filters were allowed to become wetted.

(b) Type A/E $47 \mathrm{~mm}$ diameter, Pall Corporation, Ann Arbor, MI.

(c) Type SMWP04700, Millipore Corporation, Bedford, MA.

(d) Model TA4, AIRFLOW Technical Products, Netcong, NJ.

(e) Model AV6, AIRFLOW Technical Products, Netcong, NJ. 
The Annubar meter was calibrated by Dick Munns Company ${ }^{(a)}$ for a range from 235 to $1,130 \mathrm{scfm}$. A copy of the calibration certificate is included in the field copy of the test plan (Baide 2003). Both the thermal anemometer and the vane anemometer were outside their allowed calibration periods. These instruments were used for indication purposes only during the tests.

Sample airflow rates were measured with two mass flow meters. ${ }^{(b)}$ Each of these had its own digital readout, calibrated for 0 to $3 \mathrm{scfm}$. Both sample air mass flow meters were also connected to a datalogger for electronic recording of data on a laptop computer. Dry air was supplied from a standard high-pressure air cylinder equipped with a pressure regulator. Metering and shut-off (quarter-turn ball) valves were used to control dry air and sample airflow rates. A rotary vane vacuum pump was used to draw sample air through the sampling probe, filters, and sample flow meter.

The sample air and dry air mass flow meters, datalogger, and dedicated laptop computer were calibrated as a unit by the PNNL Instrument Calibration Facility. A copy of the calibration certificate is included in the field copy of the test plan (Baide 2003).

Condensate and entrained liquid in the VRS exhaust was collected in a plastic bucket and measured using either a 500- or 2,000-mL plastic graduated cylinder.

\subsubsection{System Temperatures}

Key VRS and sampling apparatus temperatures were measured using Type $J$ thermocouples ${ }^{(c)}$ connected to a thermocouple reader. ${ }^{\text {(d) }}$ The LRVP separator vessel temperature was monitored to establish an approximate water vapor concentration in the exhaust, which was in turn used to establish the ratio of dry air to sample air needed to prevent condensation in the sample air mass flow meter. The VRS exhaust air temperature was measured in two locations: in the air stream itself via a port in the sampling apparatus blind flange and at the outlet of the sampling apparatus. Two other thermocouples were inserted under the heat tape of the filter sample probe and filter holder to ensure their temperatures were adequate to prevent water droplets from wetting the filters.

The Omega thermocouples and thermocouple reader were calibrated as a unit by the PNNL Instrument Calibration Facility. Readings were established as $\pm 2{ }^{\circ} \mathrm{C}$. A copy of the calibration certificate is included in the field copy of the test plan (Baide 2003).

(a) Dick Munns Company, Los Alamitos, CA.

(b) Model 826-NX-OV1-PV1-VT, Sierra Instruments, Monterey, CA.

(c) Model SA 1-J, Omega Engineering Inc., Stamford, CT.

(d) Model CN1507-TC, Omega Engineering Inc., Stamford, CT. 


\subsection{Test Sequence and Deviations from the Test Plan}

Tests were conducted on August 6 and 7, 2003. The sequence of events is given in Table 2.2. Of the seven planned test runs using waste simulant, only five were actually performed. All four tests runs using the aqueous waste simulant were successfully performed, and all planned samples associated with these runs were collected. Only one of the three planned dry waste simulant runs was performed because of operability problems with the sample air mass flow meters. Issues encountered during the tests include the following:

1. Aerosol droplets in the VRS exhaust were apparently causing the Annubar airflow meter to give questionable readings. In addition, airflow rates in the VRS during waste retrieval were expected to be in the 75 to $250 \mathrm{cfm}$ range, and the Annubar was neither calibrated for (nor did it respond to) flow rates less than $200 \mathrm{cfm}$. For indication of the exhaust flow rate, an Airflow TA4 thermal anemometer (serial number 087556, last calibrated in 1998) was used.

The exhaust airflow rate data were originally specified as necessary for the tests because they were to be used to establish isokinetic sample airflow rates. ${ }^{\text {(a) }}$ To compensate for the lack of accurate exhaust airflow rate data, the sample airflow rates were set to ensure subisokinetic sampling. When an air stream is sampled for aerosol particles using subisokinetic sampling rates, the sampling tends to collect more aerosol particles per unit volume of sampled air than are actually in the air stream being sampled. This ensures a conservatively high estimate of the aerosol concentration in the exhaust stream. The size distribution of particles collected on the filter is also biased by the disproportionate collection of larger particles.

2. A gradual rise in the temperature of the LRVP separator vessel from $35^{\circ}$ to $59^{\circ} \mathrm{C}$ was observed during the tests conducted on August 6, 2003. This coincided with an increase in the amount of liquid (condensate and entrained seal water) in the VRS exhaust line.

3. After completion of test runs on August 6, the LRVP separator vessel was drained, and the LRVP seal water from the aqueous waste simulant tests was replaced with fresh water. This maintenance related event was not a planned test event. It effectively eliminated the $\mathrm{CsCl}$ and $\mathrm{RbCl}$ chemical tracers from the system and negated the value of collecting further LRVP seal water samples. Only ancillary data were lost.

4. Field observations of the initial dry waste simulant test run on August 7 caused the run to be stopped before a complete batch of simulant had been collected. The appearance of fine suspended particulates in the exhaust line liquid, the increasing temperature of the LRVP separator vessel, and the relatively large quantities of exhaust line liquid collected all contributed to the decision by the test coordinator to abort the test run. Approximately $1,900 \mathrm{lb}$ of dry waste simulant were collected; a complete batch would be 2,000 lb.

(a) Sampling of an air stream is isokinetic when the velocity of air entering the sampling probe matches the velocity of air flowing past the probe. 
Table 2.2. Test Chronology

\begin{tabular}{|c|c|c|}
\hline Date & Time & Event \\
\hline \multirow[t]{42}{*}{ 6-Aug-03 } & \multirow[t]{2}{*}{$14: 25$} & One LRVP started for system warmup \\
\hline & & 15-min warmup run performed \\
\hline & $14: 43$ & LRVP stopped \\
\hline & $15: 16$ & Filter sample air started \\
\hline & \multirow[t]{2}{*}{$15: 17$} & One LRVP started \\
\hline & & Collected system blank "Filter1" \\
\hline & $15: 36$ & LRVP stopped \\
\hline & \multirow[t]{5}{*}{$15: 36$} & Filter sample air stopped \\
\hline & & Collected LRVP seal water sample "LRVP1" \\
\hline & & Added $\mathrm{RbCl}$ solution to LRVP seal water \\
\hline & & Added $\mathrm{CsCl}$ solution to simulant trough and mixed \\
\hline & & Collected aqueous waste simulant sample "CsCl1" \\
\hline & $16: 17$ & Started filter sample airflow \\
\hline & \multirow[t]{2}{*}{$16: 19$} & Started one LRVP \\
\hline & & Collected aerosol filter assembly sample "FilterCs1" \\
\hline & $16: 27$ & Stopped LRVP \\
\hline & \multirow[t]{3}{*}{$16: 27$} & Stopped filter sample airflow \\
\hline & & Collected LRVP seal water sample "LRVP2" \\
\hline & & Collected aqueous waste simulant sample "CsCl2" \\
\hline & $16: 59$ & Started filter sample airflow \\
\hline & \multirow[t]{2}{*}{$17: 01$} & Started two LRVPs \\
\hline & & Collected aerosol filter assembly sample "FilterCs2" \\
\hline & $17: 08$ & Stopped LRVPs \\
\hline & \multirow[t]{4}{*}{$17: 08$} & Stopped filter sample airflow \\
\hline & & Collected exhaust line liquid sample "Cond1" \\
\hline & & Collected LRVP seal water sample "LRVP3" \\
\hline & & Collected aqueous waste simulant sample "CsCl3" \\
\hline & $17: 32$ & Started filter sample airflow \\
\hline & \multirow[t]{2}{*}{$17: 36$} & Started two LRVPs \\
\hline & & Collected aerosol filter assembly sample "FilterCs3" \\
\hline & $17: 42$ & Stopped LRVPs \\
\hline & \multirow[t]{4}{*}{$17: 42$} & Stopped filter sample airflow \\
\hline & & Collected exhaust line liquid sample "Cond2" \\
\hline & & Collected LRVP seal water sample "LRVP4" \\
\hline & & Collected aqueous waste simulant sample "CsCl4" \\
\hline & 18:09 & Started filter sample airflow \\
\hline & \multirow[t]{2}{*}{$18: 10$} & Started two LRVPs \\
\hline & & Collected aerosol filter assembly sample "FilterCs4" \\
\hline & $18: 18$ & Stopped LRVPs \\
\hline & \multirow[t]{3}{*}{$18: 18$} & Stopped filter sample airflow \\
\hline & & Collected exhaust line liquid sample "Cond3" \\
\hline & & Collected LRVP seal water sample "LRVP5" \\
\hline \multirow[t]{7}{*}{ 7-Aug-03 } & 11:08 & Started filter sample airflow \\
\hline & \multirow[t]{2}{*}{$11: 09$} & Started one LRVP \\
\hline & & Collected aerosol filter assembly sample "Filter2" \\
\hline & $11: 33$ & Collected exhaust line liquid sample "Cond4" \\
\hline & $11: 38$ & Stopped LRVPs \\
\hline & \multirow[t]{2}{*}{$11: 39$} & Stopped filter sample airflow \\
\hline & & Collected exhaust line liquid sample "Cond5" \\
\hline
\end{tabular}


The decision was also made at that time to drain the LRVP seal water, flush the LRVP separator vessel, and change the test sequence to include a test run using lubricating water in the AMS inlet nozzle. However, during the transfer of waste simulant from the VRS batch tank to the CTF spent simulant pond, a vent line overflowed with water, and the Sierra sample air and dry air mass flow meters were sprayed with water. The mass flow meters were briefly tested with dry air, and found to be inconsistent with each other. Based on their key role in the tests, the tests were stopped. 


\subsection{Aqueous Waste Simulant Tests}

Four tests were run using water as an aqueous waste simulant. This section discusses the test conditions and presents the results of these test runs.

\subsection{Aqueous Waste Simulant and LRVP Water Tracers}

Four tests were run using water as an aqueous waste simulant. In each of these runs the VRS was used to "retrieve" about 240 gal of water from an open trough. About $500 \mathrm{~mL}$ of an aqueous

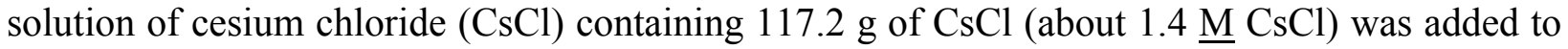
the trough of water, and the trough of water was stirred to mix in the $\mathrm{CsCl}$. The $\mathrm{CsCl}$ was added strictly as a tracer that could be identified and quantitatively measured in samples collected and did not alter the physical properties of the water significantly. $\mathrm{CsCl}$ was selected as a convenient source of ionic Cs, which could be measured at very low concentrations by standard analytical methods and was otherwise present at very low levels in the CTF process water.

Samples of the $\mathrm{CsCl}$ waste simulant were collected before each test run (see Table 2.2) and analyzed for Cs by inductively coupled plasma mass spectrometry (ICP-MS). Each sample consisted of four $25-\mathrm{mL}$ vials of the waste simulant; two of these were combined and analyzed, and the remaining two were set aside for possible duplicate analysis. Table 3.1 lists the results of these analyses. The initial sample analyses are higher than subsequent analyses because the batch tank and waste transfer pumps contained a heel of water that was not mixed with the initial batch of waste simulant water.

Table 3.1. Aqueous Waste Simulant ICP-MS Analyses

\begin{tabular}{|c|l|c||}
\hline Sample Name & \multicolumn{1}{|c|}{ Sample Collection Time } & $\begin{array}{c}\text { Cs Concentration } \\
(\boldsymbol{\mu g} / \mathbf{m L} \mathbf{~})\end{array}$ \\
\hline $\mathrm{CsCl} 1$ & Prior to CsCl1 aerosol sample test run & 103 \\
\hline $\mathrm{CsCl} 2$ & Prior to CsCl2 aerosol sample test run & 73.8 \\
\hline $\mathrm{CsCl} 3$ & Prior to CsCl3 aerosol sample test run & 71.8 \\
\hline $\mathrm{CsCl} 4$ & Prior to CsC14 aerosol sample test run & 72.0 \\
\hline
\end{tabular}


As discussed in Section 2, a chemical tracer was added to the LRVP seal water. About $50 \mathrm{~mL}$ of an aqueous solution of rubidium chloride $(\mathrm{RbCl})$ containing $14.08 \mathrm{~g}$ of $\mathrm{RbCl}$ (about $2.3 \underline{\mathrm{M}}$ ) was added to the LRVP seal water tank before the first aqueous waste simulant test started. As with $\mathrm{Cs}, \mathrm{Rb}$ was selected because it could be measured at very low concentrations

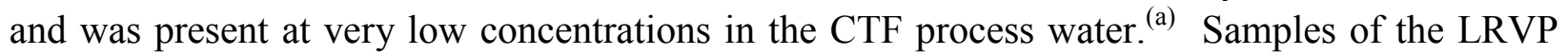
seal water were collected from the LRVP separator vessel drain prior to the addition of the $\mathrm{RbCl}$ solution, and after each of the aqueous simulant batch test runs (see Table 2.2). Samples were collected by first flushing the piping upstream of the sampling port with several line volumes (a minimum of about $2 \mathrm{~L}$ ) of seal water and then collecting the sample from the running stream. Each sample consisted of four 25-mL vials of the LRVP seal water; two of these were combined and analyzed, and the remaining two were set aside for possible duplicate analysis. The samples were analyzed for $\mathrm{Rb}$ and $\mathrm{Cs}$. Analytical results are presented in Table 3.2.

Table 3.2. LRVP Seal Water Sample ICP-MS Analyses

\begin{tabular}{|c|l|c|c||}
\hline $\begin{array}{c}\text { Sample } \\
\text { Name }\end{array}$ & \multicolumn{1}{|c|}{ Sample Collection Time } & $\begin{array}{c}\text { Rb Concentration } \\
(\mu \mathbf{g} / \mathbf{m L})\end{array}$ & $\begin{array}{c}\text { Cs Concentration } \\
(\mu \mathbf{g} / \mathbf{m L} \mathbf{)}\end{array}$ \\
\hline LRVP1 & $\begin{array}{l}\text { Prior to CsCl1 aerosol sample test run } \\
\text { and prior to addition of } \mathrm{RbCl}\end{array}$ & $9.62 \times 10^{-4}$ & $<2.06 \times 10^{-6}$ \\
\hline LRVP2 & After CsCl1 aerosol sample test run & 75.8 & 0.135 \\
\hline LRVP3 & After CsCl2 aerosol sample test run & 49.0 & 14.9 \\
\hline LRVP4 & After CsCl3 aerosol sample test run & 40.4 & 17.0 \\
\hline LRVP5 & After CsCl4 aerosol sample test run & 33.1 & 22.7 \\
\hline
\end{tabular}

In addition to the aerosol present, the exhaust line generally had droplets and thin streams of liquid running along the inside of the pipe. This was due both to condensation of water vapor downstream of the LRVP separator vessel, and the collection of entrained LRVP seal water droplets by the exhaust line wall. During the $\mathrm{CsCl}$, $\mathrm{CsCl}$, and $\mathrm{CsCl} 4$ test runs, this liquid was collected in a plastic bucket, its volume was estimated, and samples were collected and analyzed. (No exhaust line liquid sample was collected during the $\mathrm{CsCl1}$ test run because there was very little of the liquid present.) Table 3.3 summarizes the available data.

Table 3.3. VRS Exhaust Line Liquid Volumes and Sample Analyses

\begin{tabular}{|c|l|c|c|c|}
\hline $\begin{array}{c}\text { Sample } \\
\text { Name }\end{array}$ & Description & $\begin{array}{c}\text { Estimated } \\
\text { Volume } \\
(\mathbf{m L} \mathbf{L})\end{array}$ & $\begin{array}{c}\mathbf{R b} \\
\text { Concentration } \\
(\boldsymbol{\mu g} / \mathbf{m} \mathbf{L})\end{array}$ & $\begin{array}{c}\text { Cs } \\
\text { Concentration } \\
(\boldsymbol{\mu} \mathbf{g} / \mathbf{m} \mathbf{L})\end{array}$ \\
\hline Cond1 & Liquid collected during CsCl2 test run & 450 & 1.98 & 0.00529 \\
\hline Cond2 & Liquid collected during CsCl3 test run & 550 & 10.6 & 3.16 \\
\hline Cond3 & Liquid collected during CsCl4 test run & 950 & 12.3 & 5.33 \\
\hline
\end{tabular}

(a) An informal analysis conducted by PNNL prior to the aerosol tests indicated the background concentration of $\mathrm{Rb}$ in the CTF process water to be about $0.85 \mathrm{ng} / \mathrm{mL}$. 
Comparison of the exhaust line liquid $\mathrm{Rb}$ and $\mathrm{Cs}$ concentrations with the LRVP seal water concentrations suggests that the exhaust line liquid was composed predominantly of condensed water vapor and that entrained LRVP seal water accounted for less than $40 \%$ of the liquid in the exhaust line. Specific values are given in Table 3.4, where the concentration of each tracer in the liquid samples has been divided by the corresponding concentration in the LRVP seal water samples collected before and after each test run. Assuming that the $\mathrm{Rb}$ seal water concentration decreased linearly with time during each test run and that the Cs seal water concentration increased linearly, the average concentrations of each tracer in the seal water during a test run can be approximated by averaging their concentrations before and after the test run. This ratio corresponds to the fraction of entrained seal water in the exhaust line liquid sample.

Table 3.4. Comparison of Exhaust Line Liquid and LRVP Seal Water

\begin{tabular}{|c|c|c|c|c|}
\hline $\begin{array}{l}\text { Test } \\
\text { Run }\end{array}$ & Concentration Ratio & $\begin{array}{c}\text { Rb } \\
\text { Ratio }\end{array}$ & $\begin{array}{c}\text { Cs } \\
\text { Ratio }\end{array}$ & $\begin{array}{l}\text { Test Run } \\
\text { Average }\end{array}$ \\
\hline \multirow{6}{*}{$\mathrm{CsCl} 2$} & Concentration in Cond1 & & & \multirow{6}{*}{0.027} \\
\hline & $\overline{\text { Concentration in LRVP2 }}$ & 0.026 & 0.039 & \\
\hline & Concentration in Cond 1 & & & \\
\hline & $\overline{\text { Concentration in LRVP3 }}$ & 0.040 & 0.0004 & \\
\hline & Concentration in Cond 1 & 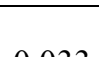 & م & \\
\hline & Average Concentration in LRVP2 and LRVP3 & 0.033 & 0.020 & \\
\hline \multirow{6}{*}{$\mathrm{CsCl} 3$} & Concentration in Cond2 & & & \multirow{6}{*}{0.22} \\
\hline & $\overline{\text { Concentration in LRVP3 }}$ & 0.22 & 0.21 & \\
\hline & Concentration in Cond 2 & & & \\
\hline & $\overline{\text { Concentration in LRVP4 }}$ & 0.26 & 0.19 & \\
\hline & Concentration in Cond2 & & & \\
\hline & $\overline{\text { Average Concentration in LRVP3 and LRVP4 }}$ & 0.24 & 0.20 & \\
\hline \multirow{6}{*}{$\mathrm{CsCl4}$} & Concentration in Cond3 & & & \multirow{6}{*}{0.31} \\
\hline & $\overline{\text { Concentration in LRVP4 }}$ & 0.30 & 0.31 & \\
\hline & Concentration in Cond3 & & & \\
\hline & $\overline{\text { Concentration in LRVP5 }}$ & 0.37 & 0.23 & \\
\hline & Concentration in Cond 3 & & & \\
\hline & $\overline{\text { Average Concentration in LRVP4 and LRVP5 }}$ & 0.34 & 0.27 & \\
\hline
\end{tabular}

Note that the estimated fraction of seal water in the exhaust line liquid samples is consistently smaller when calculated using the Cs data. The reason for this is not clear. If some if the Cs in the waste simulant was passed through the LRVPs without being collected in the seal water, the exhaust line liquid samples would have been enriched in $\mathrm{Cs}$, but the opposite was observed. 


\subsection{Aerosol Sample Results}

Aerosol samples from the VRS exhaust air stream were collected during the entire time that the VRS was used to collect the aqueous waste simulant. Sample airflow through the aerosol filters began before the LRVPs started and not turned off until after the LRVPs had been stopped. Sample airflow volumes were calculated for the period that the LRVPs were running and did not include the short times before and after LRVP operation that sample air was being drawn through the filters. This is justified because before the LRVPs were started the exhaust was relatively free of aerosols, and the time span between the LRVPs stopping and sampling itself stopping was relatively short. The errors associated with this treatment of the data tend to increase the calculated aerosol mass concentration, giving a conservatively large value. Table 3.5 lists the calculated sample air volumes for the system blank run (Filter1) and four aqueous waste simulant runs (FilterCs1, FilterCs2, FilterCs3, and FilterCs4).

Table 3.5. Aqueous Waste Simulant Test Aerosol Sample Volumes and Flow Rates

\begin{tabular}{||l|c|c|c|c||}
\hline $\begin{array}{c}\text { Sample } \\
\text { Name }\end{array}$ & $\begin{array}{c}\text { Sample Volume } \\
\left(\mathbf{( m}^{\mathbf{3}}\right)\end{array}$ & $\begin{array}{c}\text { Estimated Total Exhaust } \\
\text { Flow Rate } \\
\mathbf{( c f m})\end{array}$ & $\begin{array}{c}\text { Isokinetic Sample } \\
\text { Airflow Rate } \\
\mathbf{( c f m})\end{array}$ & $\begin{array}{c}\text { Average Sample } \\
\text { Airflow Rate } \\
\text { (cfm) }\end{array}$ \\
\hline Filter1 & 0.31 & 370 & 1.37 & 0.58 \\
\hline FilterCs1 & 0.088 & Not Measured & -- & 0.34 \\
\hline FilterCs2 & 0.067 & 156 & 0.58 & 0.34 \\
\hline FilterCs3 & 0.050 & 245 & 0.91 & 0.29 \\
\hline FilterCs4 & 0.079 & 225 & 0.83 & 0.35 \\
\hline
\end{tabular}

Because total exhaust airflow rates were not accurately measured and appeared to fluctuate with time, no attempt was made to collect the aerosol samples at isokinetic flow rates. Sample airflow rates were further constrained by the ranges of the sample air and dry air mass flow meters and the need to mix relatively large amounts of dry air with the sample air to prevent condensation of water in the meters. To address these issues, the aerosol sampling was conducted at sub-isokinetic airflow rates. Sub-isokinetic sampling tends to cause the collection of additional particles with a bias favoring larger particles. The effect is negligible (on the order of $3 \%$ ) for $1 \mu \mathrm{m}$ water droplets, and becomes potentially significant (on the order of a factor of three) for droplets larger than about $35 \mu \mathrm{m}$. ${ }^{\text {(a) }}$ This has the effect of 1) collecting a greater than representative aerosol mass on the filter and 2) skewing the particle size distribution towards larger particles.

As discussed in Section 2.2.4, the filter samples were collected with dedicated sampling probe, filter holder, and two filters (in series) for each sample. The entire filter assembly was sealed after sampling and sent to 222-S Laboratory for analysis. Each filter assembly was then dismantled to remove the filters, leach the filters to remove the Cs and $\mathrm{Rb}$, and rinse any

(a) Based on the correlation of Belyaey and Levin (1974) as presented by Brockman (1993). 
particulate material attached to the inner wall of the sampling probe. The procedures for sample preparation and analysis are described by Callaway (2003a). Probe rinsate and filter leachate from each sample were combined and analyzed by ICP-MS. Table 3.6 lists the results in $\mu \mathrm{g}$ of each analyte per filter assembly; Callaway (2003b) provide further details and the results of laboratory quality assurance samples.

Table 3.6. Tracer Masses Measured in Filter Assemblies

\begin{tabular}{|l|l|c|c||}
\hline $\begin{array}{c}\text { Sample } \\
\text { Name }\end{array}$ & \multicolumn{1}{|c|}{ Description } & $\begin{array}{c}\text { Rb Mass on Filter } \\
(\boldsymbol{\mu g})\end{array}$ & $\begin{array}{c}\text { Cs Mass on Filter } \\
(\mu \mathbf{g})\end{array}$ \\
\hline Filter1 & System blank & 0.0130 & 0.00197 \\
\hline FilterCs1 & Run with one LRVP & 0.931 & 0.0232 \\
\hline FilterCs2 & Run with two LRVPs & 1.09 & 0.0330 \\
\hline FilterCs3 & Run with two LRVPs & 0.613 & 0.0918 \\
\hline FilterCs4a & $\begin{array}{l}\text { Run with two LRVPs, primary } \\
\text { (upstream) filter }\end{array}$ & 1.88 & 0.582 \\
\hline FilterCs4b & Breakthrough (downstream) filter & 0.00980 & 0.00765 \\
\hline
\end{tabular}

Inspection of the primary (upstream) and breakthrough (downstream) filters indicated no water spots or other evidence that any of the filters had been damaged or failed in any way (Callaway 2003b). To further verify that the upstream filters had indeed collected essentially all the aerosol material in the air stream, the downstream filter of FilterCs 4 was analyzed for Rb and Cs. Results of this analysis are given in the last row of Table 3.6. Comparison of masses of $\mathrm{Rb}$ and Cs measured on the downstream filter with the masses measured on the upstream filters confirms that the upstream filter caught essentially the entire aerosol. The mass of $\mathrm{Rb}$ on the downstream filter is about $0.5 \%$ of the $\mathrm{Rb}$ mass on the upstream filter, and the mass of Cs on the downstream filter is about $1.3 \%$ of the Cs mass on the upstream filter. Note that the masses of $\mathrm{Cs}$ and $\mathrm{Rb}$ measured on the downstream filter (FilterCs4b) are also approximately the same as on the system blank (Filter1).

The mass of Cs measured in each filter assembly is directly related to the concentration of aqueous waste simulant aerosol present in the exhaust. The formula used to calculate aqueous aerosol concentration, $C_{\text {Waste Aerosol }}$, in units of $\mathrm{mg} / \mathrm{m}^{3}$ is

$$
C_{\text {Waste Aerosol }}=\frac{1000 \rho_{\text {Waste }}}{C_{C s} V_{\text {Sample }}}\left(m_{C s}-\frac{V_{\text {Sample }}}{V_{\text {blank }}} m_{\text {Cs blank }}\right)
$$

where $\rho_{\text {Waste }}$ is the density of the waste simulant $(\mathrm{g} / \mathrm{mL}) ; m_{C s}$ and $m_{C s \text { blank }}$ are the masses of Cs measured in the filter assembly and system blank, respectively $(\mu \mathrm{g}) ; C_{C s}$ is the mass concentration of Cs in the waste simulant $(\mu \mathrm{g} / \mathrm{mL})$; and $V_{\text {Sample }}$ and $V_{\text {blank }}$ are the volumes of the aerosol sample and system blank, respectively $\left(\mathrm{m}^{3}\right)$. Assuming $\rho_{\text {Waste }}=1.0$, Eq. (3.1) has been 
applied to the sample air volumes (Table 3.5), filter assembly Cs masses (Table 3.6), and the Cs concentrations in the waste simulant (Table 3.1) to calculate the waste aerosol concentrations for each sample. Results are listed in Table 3.7. As expected, the aerosol concentration of waste simulant in the exhaust increased with each successive test run, presumably for reasons described in Section 1.2.2.

Table 3.7. Aqueous Waste Simulant Test Aerosol Mass Concentrations

\begin{tabular}{||c|l|c|}
\hline Test Run & \multicolumn{1}{|c|}{ Description } & $\begin{array}{c}\text { VRS Exhaust Aqueous Waste Simulant } \\
\text { Aerosol Mass Concentration } \\
\left(\mathbf{m g} / \mathbf{m}^{\mathbf{3}}\right)\end{array}$ \\
\hline $\mathrm{CsCl1}$ & Test run with one LRVP & 2.5 \\
\hline $\mathrm{CsCl} 2$ & Test run with two LRVPs & 6.6 \\
\hline $\mathrm{CsCl} 3$ & Test run with two LRVPs & 25 \\
\hline $\mathrm{CsCl} 4$ & Test run with two LRVPs & 102 \\
\hline
\end{tabular}

Note that the results in Table 3.7 are specific to an aqueous waste (simulant) having a density of $1.0 \mathrm{~g} / \mathrm{mL}$. Ignoring the small increases (decreases) in batch tank and LRVP separator vessel aerosol removal efficiencies associated with denser (less dense) materials, the aerosol concentrations given in Table 3.7 can be adjusted to any specific liquid waste density by multiplying the value in Table 3.7 by the specific gravity of the waste.

The aerosol mass concentration measured for test run $\mathrm{CsCl} 4$ is anomalously high, based on the expectation that increases in aerosol masses between test runs $\mathrm{CsCl1}, \mathrm{CsCl}$, $\mathrm{CsCl}$, and $\mathrm{CsCl} 4$ should approximately follow the successive increases in LRVP seal water Cs concentrations given in Table 3.2. The reason for the high $\mathrm{CsCl} 4$ result was not clearly established, but it appears to be related to the increased temperature of the LRVP system. The volume of condensate and entrained seal water (Table 3.3) collected from the exhaust line during the $\mathrm{CsCl} 4$ test had increased, and it is possible the re-entrainment of relatively large droplets from the exhaust line wall resulted in the high aerosol mass concentration measured for this test run. $^{\text {(a) }}$

(a) Informal testing conducted since these tests were performed included several test runs with the blind flange at the end of the aerosol sampling wye removed (see Figure 2.1). It was noticed that, as the amount of liquid in the exhaust line increased, there was a disproportionate increase in the number of large droplets in the exhaust. These droplets were large enough to feel as individual drops on one's hand, and too large to have passed directly from the LRVP separator to the sampling apparatus. It was presumed that they were produced by resuspension of the liquid as it passed over the connection between the elbow and the Plexiglas pipe just upstream of the sampling point. Because such droplets are also too big to remain suspended if accidentally released from the exhaust line, they would not contribute to the exposure of an individual more than a few feet away. 


\subsection{Batch Tank Collection Efficiency}

The batch tank collection efficiency was estimated by dividing the amount of Cs transferred from the batch tank to the LRVP seal water by the total amount of Cs collected by the AMS during the run. The amount of Cs transferred from the batch tank was calculated by performing a mass balance on the $\mathrm{Rb}$ in the LRVP system to establish the amount of aqueous waste simulant added to the LRVP system.

$$
m_{C s \text { Batch }}=C_{C s \text { LRVP f }} V_{\text {LRVP } f}-C_{C s L R V P 0} V_{L R V P 0}+C_{C s \text { Cond }} V_{\text {Cond }}+C_{C s \text { Drain }} V_{\text {Drain }}
$$

Where $m_{C s \text { Batch }}$ is the total mass of Cs transferred from the batch tank to the LRVP seal water during the test run (mg), $C_{C S L R V P f}$ and $V_{\text {LRVP } f}$ are the LRVP seal water Cs concentration and total volume at the end of the test run $\left(\mu \mathrm{g} / \mathrm{mL}\right.$ and L, respectively), $C_{C S L R V P 0}$ and $V_{\text {LRVP } 0}$ are the LRVP seal water Cs concentration and total volume at the start of the test run $(\mu \mathrm{g} / \mathrm{mL}$ and $\mathrm{L}$, respectively), $C_{C S \text { Cond }}$ and $V_{\text {Cond }}$ are the exhaust line liquid Cs concentration and total volume ( $\mu \mathrm{g} / \mathrm{mL}$ and $\mathrm{L}$, respectively), and $C_{C s \text { Drain }}$ and $V_{\text {Drain }}$ are the LRVP drained liquid Cs concentration and volume ( $\mu \mathrm{g} / \mathrm{mL}$ and $\mathrm{L}$, respectively).

Samples of the LRVP seal water collected before and after the test runs establish $C_{C s \text { LRVP f }}$ and $C_{C S L R V P 0}{ }^{\text {(a) }}$ Exhaust line liquid was collected and analyzed (giving both $C_{C S \text { Cond }}$ and $V_{\text {Cond }}$ ) for each test run except the first, which had markedly less liquid in the exhaust than subsequent test runs. To establish estimates for $V_{\text {LRVP } f}, V_{\text {LRVP } 0}$, and $V_{\text {Drain }}$, a material balance on the $\mathrm{Rb}$ in the LRVP system is used. Analogous to Eq. (3.2), the Rb material balance is given by

$$
0=C_{R b L R V P f} V_{\text {LRVP } f}-C_{R b L R V P 0} V_{\text {LRVP } 0}+C_{R b \text { Cond }} V_{\text {Cond }}+C_{R b \text { Drain }} V_{\text {Drain }}
$$

where the left side is now zero because there is no $\mathrm{Rb}$ being introduced from the batch tank during the run.

Note that during the aqueous simulant tests, the amount of aqueous simulant passed through the batch vessel to the LRVP system was significantly greater than the amount of liquid lost via the exhaust line. The accumulation of liquid in the LRVP system was consequently handled by the system by automatic opening of the drain valve. Specifically, when the seal water level reached the high-level switch (i.e., when the seal water volume reaches about $140 \mathrm{~L}$ ), the drain valve is automatically opened and seal water is drained out until the liquid level reaches the low-

(a) No LRVP sample was collected before the first test run because the $\mathrm{RbCl}$ solution had not been mixed throughout the LRVP system at that time. 
level switch (i.e., when the seal water volume reaches about $85 \mathrm{~L}$ ). Based on this description of the LRVP system, the following additional restraints are imposed:

$$
\begin{gathered}
85 \mathrm{~L} \leq V_{\text {LRVP } f} \leq 140 \mathrm{~L}, \\
85 \mathrm{~L} \leq V_{\text {LRVP } 0} \leq 140 \mathrm{~L}, \\
V_{\text {Drain }}=0 \text { or } 55 \mathrm{~L}
\end{gathered}
$$

Only one LRVP was used in the first test run, with the result that the $\mathrm{RbCl}$ added to the LRVP seal water prior to this run was not mixed with the reservoir of water in the second LRVP. This effectively decreased the working volume of seal water during this run by an estimated $20 \mathrm{~L}$. Therefore, for the first test run,

$$
\begin{gathered}
65 \mathrm{~L} \leq V_{\text {LRVPf }} \leq 120 \mathrm{~L} \\
65 \mathrm{~L} \leq V_{\text {LRVP } 0} \leq 120 \mathrm{~L} \\
V_{\text {Drain }}=0 \text { or } 55 \mathrm{~L}
\end{gathered}
$$

Eq. (3.2) and (3.3) were solved for each of the test runs, with the restrictions given in Eq. (3.5) imposed on test run $\mathrm{CsCl} 1$, and Eq. (3.4) imposed on test runs $\mathrm{CsCl} 2, \mathrm{CsCl} 3$, and $\mathrm{CsCl} 4$. Table 3.8 lists the input values and results. Values not directly obtained from sample analyses or test measurements are given in brackets and their origin explained in the table endnotes.

The calculated batch tank collection efficiencies given at the bottom of Table 3.8 indicate that Test Run CsCl1, conducted with a single LRVP, caused the least amount of aqueous waste simulant to be passed through the batch tank. Test runs $\mathrm{CsCl} 2, \mathrm{CsCl} 3$, and $\mathrm{CsCl} 4$, each conducted with two LRVPs operating, had an average batch tank collection efficiency of 0.983 , and allowed an average of $1.7 \mathrm{wt} \%$ of the waste simulant to pass through the batch tank.

\subsection{LRVP Seal Water Aerosol in the Exhaust Air Stream}

Results given in Tables 3.2 and 3.5 support the premise that the waste aerosol concentration in the exhaust should increase as the concentration of waste in the LRVP seal water increases (see Section 1.2.2). To estimate the likely aerosol concentration in the exhaust line at any time during a retrieval campaign, notably after many batches of waste have been retrieved, it is necessary to establish both the collection efficiency of the batch tank (see Section 3.4) and the amount of LRVP seal water entrained in the exhaust.

If all of the waste particles passing through the batch tank and entering the LRVPs were collected in the LRVP seal water, and the appearance of waste aerosol in the exhaust could be attributed solely to droplets of LRVP seal water entrained in the exhaust, then the waste aerosol concentration in the exhaust should be directly proportional to the concentration of waste in the 
Table 3.8. Batch Tank Efficiency Calculation Inputs and Results

\begin{tabular}{|c|c|c|c|c|c|}
\hline Parameter & Notes & $\begin{array}{c}\text { Test Run } \\
\text { CsCl1 }\end{array}$ & $\begin{array}{c}\text { Test Run } \\
\text { CsCl2 }\end{array}$ & $\begin{array}{c}\text { Test Run } \\
\text { CsCl3 }\end{array}$ & $\begin{array}{c}\text { Test Run } \\
\text { CsCl4 }\end{array}$ \\
\hline Initial Seal Water Volume, $V_{L R V P 0},(\mathrm{~L})$ & (a) & [115] & [69] & [103] & [122] \\
\hline 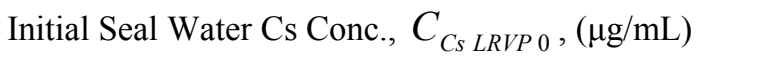 & & 0 & 0.135 & 14.9 & 17.0 \\
\hline Initial Seal Water Rb Conc., $C_{R b L R V P 0}(\mu \mathrm{g} / \mathrm{mL})$ & (a) & [87] & 75.8 & 49.0 & 40.4 \\
\hline Exhaust line liquid volume, $V_{\text {Cond }},(\mathrm{L})$ & (b) & {$[0.45]$} & 0.45 & 0.55 & 0.95 \\
\hline Exhaust line liquid Cs Conc., $C_{C s}$ Cond,$(\mu \mathrm{g} / \mathrm{mL})$ & (b) & {$[0.00529]$} & 0.00529 & 3.16 & 5.33 \\
\hline Exhaust line liquid Rb Conc., $C_{R b \text { Cond }},(\mu \mathrm{g} / \mathrm{mL})$ & (b) & [1.98] & 1.98 & 10.6 & 12.3 \\
\hline Seal Water Drained Volume, $V_{\text {Drain }}$, (L) & & 55 & 0 & 0 & 55 \\
\hline Drained Seal Water Cs Conc., $C_{C s \text { Drain }},(\mu \mathrm{g} / \mathrm{mL})$ & (c) & [0.135] & -- & -- & {$[22.7]$} \\
\hline Drained Seal Water Rb Conc., $C_{R b \text { Drain }},(\mu \mathrm{g} / \mathrm{mL})$ & (d) & 82 & -- & -- & {$[35]$} \\
\hline Final LRVP Seal Water Volume, $V_{L R V P f}$, (L) & & 72 & 107 & 125 & 90 \\
\hline Final Seal Water Cs Conc., $C_{C s L R V P f},(\mu \mathrm{g} / \mathrm{mL})$ & & 0.135 & 14.9 & 17.0 & 22.7 \\
\hline Final Seal Water Rb Conc., $C_{R b L R V P f},(\mu \mathrm{g} / \mathrm{mL})$ & & 75.8 & 49.0 & 40.4 & 33.1 \\
\hline Volume of Seal Water used in sample flush (L) & & 2.7 & 3.3 & 3.7 & \\
\hline Mass of Cs passed from Batch Tank, $m_{C s \text { Batch }},(\mathrm{mg})$ & & 17.1 & 1,580 & 590 & 1,224 \\
\hline Mass of Cs entering Batch Tank (mg) & (e) & {$[93,440]$} & {$[66,950]$} & {$[65,136]$} & {$[65,317]$} \\
\hline Collection Efficiency of Batch Tank & & 0.9998 & 0.976 & 0.991 & 0.981 \\
\hline
\end{tabular}

(a) Just before the start of test run $\mathrm{CsCl1}$ the $\mathrm{RbCl}$ solution, containing 9,950 $\mathrm{mg}$ of $\mathrm{Rb}$, was added to the LRVP seal water. The values of initial seal water volume and initial seal water Rb concentration for this run may vary as long as $C_{\text {CS LRVP } 0} V_{\text {LRVP } 0}=9,950 \mathrm{mg}$. Subsequent initial seal water volumes were calculated by subtracting the volume of seal water used in sample flush (see Section 3.1) from the calculated final seal water volume of the previous test run.

(b) No exhaust line liquid sample was collected during Test Run CsCl1, in part because little was present to collect. It was assumed in calculations that the exhaust line liquid volume and composition were the same that measured in Test Run CsCl2.

(c) LRVP seal water drained automatically was assumed to have the same Cs concentration as the LRVP seal water sample collected at the end of the test run. This tends to overestimate the amount of Cs lost via the automatic drain and decrease the batch tank collection efficiency.

(d) The $\mathrm{Rb}$ concentration in LRVP seal water drained automatically was calculated by assuming the Rb present in the LRVP system was diluted with aqueous waste simulant to a volume of $140 \mathrm{~L}$ (the point at which the automatic drain is activated).

(e) Mass of Cs entering batch tank was calculated by multiplying the measured Cs concentration in the aqueous waste simulant (from Table 3.1) by the total volume of simulant collected during the test run $(907 \mathrm{~L}$ ). 
LRVP seal water. The volume of LRVP seal water entrained ${ }^{(a)}$ in the VRS exhaust $\left(\mathrm{mL} / \mathrm{m}^{3}\right)$ can be calculated with the following equation:

$$
C_{\text {LRVP water aerosol }}=\frac{m_{C S}}{C_{C s ~ L R V P} V_{\text {Sample }}}
$$

where $C_{C s L R V P}$ is the concentration of Cs in the LRVP seal water $(\mu \mathrm{g} / \mathrm{mL})$.

Note that $C_{C S L R V P}$ increased throughout each test run because waste simulant passed through the batch tank and was added to the LRVP seal water (see Table 3.2). Even if the influx of Cs from the batch tank was constant during the run, the change in $C_{C S L R V P}$ would not be linear because the LRVP seal water volume is also gradually increasing. Compounding this is the fact that during testing approximately 14.5 gal of the LRVP seal water was automatically drained from the separator vessel when the liquid level reached the high-level indicator, ${ }^{(b)}$ and no record of these automatic drains is available. In lieu of better data, the measured values of $C_{C S L R V P}$ from LRVP seal water samples collected before and after each run were averaged (see Table 3.2), and used in Eq. (3.6) with $m_{C s}$ values from Table 3.6 and $V_{\text {Sample }}$ from Table 3.5. Results of these calculations are given in the third column of Table 3.9.

Table 3.9. LRVP Seal Water Aerosol Concentration in Exhaust Air Stream

\begin{tabular}{|c|l|c|c|}
\hline \multirow{2}{*}{ Test Run } & \multirow{2}{*}{ Run Description } & \multicolumn{2}{|c|}{$\begin{array}{c}\text { Aerosol Seal Water Concentration in Exhaust Air Stream } \\
\left(\mathbf{m L} / \mathbf{m}^{\mathbf{3}}\right)\end{array}$} \\
\cline { 3 - 4 } & & From Cs Data & From Rb Data \\
\hline CsC11 & Run with one LRVP & 3.9 & 0.13 \\
\hline $\mathrm{CsCl} 2$ & Run with two LRVPs & 0.066 & 0.26 \\
\hline $\mathrm{CsC13}$ & Run with two LRVPs & 0.12 & 0.27 \\
\hline $\mathrm{CsCl} 4$ & Run with two LRVPs & 0.37 & 0.65 \\
\hline
\end{tabular}

The relationship between the mass of $\mathrm{Rb}$ in the filter assembly, $m_{R b}$, and LRVP seal water $\mathrm{Rb}$ concentration, $C_{R b L R V P}$, to the LRVP seal water concentration in the exhaust line is analogous to Eq. (3.6):

(a) Waste or LRVP water that is "entrained" in the exhaust is categorically considered an aerosol here and does not include the droplets and small streams of liquid running along the inside wall of the VRS exhaust line.

(b) The LRVP water level is controlled by adding make-up water when the level drops too low and by draining seal water when the level rises too high. When the seal water reaches the high-level switch, indicating too much seal water present, a drain valve is automatically opened and seal water is drained to a sump until the low-level switch is reached. When the seal water reaches the low-level switch (either during normal operation or when the level was automatically drained) the valve controlling make-up water is automatically opened until the low-level switch is again submerged. 


$$
C_{\text {LRVP water aerosol }}=\frac{m_{R b}}{C_{R b L R V P} V_{\text {Sample }}}
$$

Like the Cs concentration, the $\mathrm{Rb}$ concentration in the LRVP seal water was also changing during the test runs. The $\mathrm{Rb}$ concentration decreased during the run as aqueous waste simulant was carried over from the batch vessel and diluted the $\mathrm{Rb}$. As with $\mathrm{Cs}$, the $\mathrm{Rb}$ concentration would not have changed linearly with time. In lieu of better data, the $\mathrm{Rb}$ concentration was assumed to be approximately linear, and the $C_{R B L R V P}$ for each test run was calculated by averaging the $\mathrm{Rb}$ concentrations measured in the LRVP seal water samples collected before and after the test run. Results of these calculations are given in the last column of Table 3.9.

Results in Table 3.9 from $\mathrm{Cs}$ and $\mathrm{Rb}$ data should agree. The greatest inconsistency occurs for the first test run, where it appears the value for $C_{C S L R V P}$ is anomalously low, resulting in the high calculated aerosol concentration. 


\subsection{Dry Waste Simulant Test}

One test was run using fine sand as a dry waste simulant. This section discusses the test conditions and presents the results of that test run.

\subsection{Aerosol Sample Analyses and Results}

The dry waste simulant test run filter sample and the system blank filter sample were both subjected to gravimetric analysis and particle size analysis. The filter assemblies were disassembled and the particulate sample recovered by 222-S Laboratory. Particles on the inside of the sampling probe and upstream half of the filter holder were rinsed off with de-ionized water and added to the upstream filter sample. The samples were incinerated (to burn off the filter itself), cooled, and weighed. Details of the analyses are given by Callaway (2003b). Table 4.1 lists the results, considered accurate to $\pm 0.5 \mathrm{mg}$, along with the measured weight of an incinerated clean, unused filter.

Table 4.1. Dry Waste Simulant Filter Sample Gravimetric Analysis Results

\begin{tabular}{||l|l|c|c|c||}
\hline Test Run & \multicolumn{1}{|c|}{ Description } & $\begin{array}{c}\text { Mass } \\
\text { (mg) }\end{array}$ & $\begin{array}{c}\text { Sample Air } \\
\text { Volume } \\
\text { (L) }\end{array}$ & $\begin{array}{c}\text { Aerosol } \\
\text { Concentration } \\
\left(\mathbf{m g} / \mathbf{m}^{\mathbf{3}}\right)\end{array}$ \\
\hline Filter1 & System blank & 0.8 & 310 & 2.6 \\
\hline Filter2 & Dry waste simulant test run & 8.7 & 702 & $9.8^{\text {(a) }}$ \\
\hline-- & Clean, unused filter & 0.7 & -- & -- \\
\hline (a) Value includes correction for $2.6 \mathrm{mg} / \mathrm{m}^{3}$ of background particles. \\
\hline
\end{tabular}

Also listed in Table 4.1 are the sample air volumes for each sample, and the calculated aerosol concentration. Note that the aerosol concentration for the dry waste simulant test run has been corrected for the measured background (system blank) aerosol concentration.

The incinerated samples (ash) and sample rinsate were then added to vials of water, agitated, and transferred to PNNL for particle size analysis. Particle size analysis was conducted at PNNL using a Particle size analyzer. ${ }^{\text {(a) }}$ Table 4.2 gives key statistical results for these samples. Numerical results are included in Appendix A.

The aerosol size statistics given in Table 4.2 are based on a count of particles in each size bin of the distribution and indicate that the average particle size is relatively small. However, because the mass of the particles is proportional to the cube of the diameter, the mean particle masses are significantly larger than the mean particle diameters. This is illustrated in Figure 4.1,

(a) Analyses were conducted using a Horiba LA-920 particle size analyzer. 
Table 4.2. Dry Waste Simulant Filter Sample Particle Size Analyses

\begin{tabular}{|l|c|c|c|}
\hline Parameter & $\begin{array}{c}\text { System Blank } \\
\text { (Filter1) }\end{array}$ & $\begin{array}{c}\text { Dry Waste } \\
\text { Simulant Run } \\
\text { (Filter2) }\end{array}$ & $\begin{array}{c}\text { Clean } \\
\text { Unused Filter }\end{array}$ \\
\hline Median particle diameter $(\mu \mathrm{m})$ & 3.4 & 7.9 & 34.9 \\
\hline Mean particle diameter $(\mu \mathrm{m})$ & 4.4 & 9.0 & 34.9 \\
\hline Mode of particle diameters $(\mu \mathrm{m})$ & 8.17 & 12.4 & 42.2 \\
\hline
\end{tabular}

where the total mass of particles as a function of particle size (effective diameter) is plotted for the incinerated dry waste simulant sample (Filter2) and the system blank sample assuming all particles are spherical and have a nominal density of $2.5 \mathrm{~g} / \mathrm{mL}$. This figure illustrates that about $80 \%$ of aerosol particle mass collected during the dry waste simulant test run was associated with particles greater than $10 \mu \mathrm{m}$ in diameter. Also, because the system blank and Filter2 samples have comparable aerosol masses below $10 \mu \mathrm{m}$, much of the mass of particles smaller than $10 \mu \mathrm{m}$ in the Filter2 sample is attributable to materials present in the system before dry waste simulant was introduced.

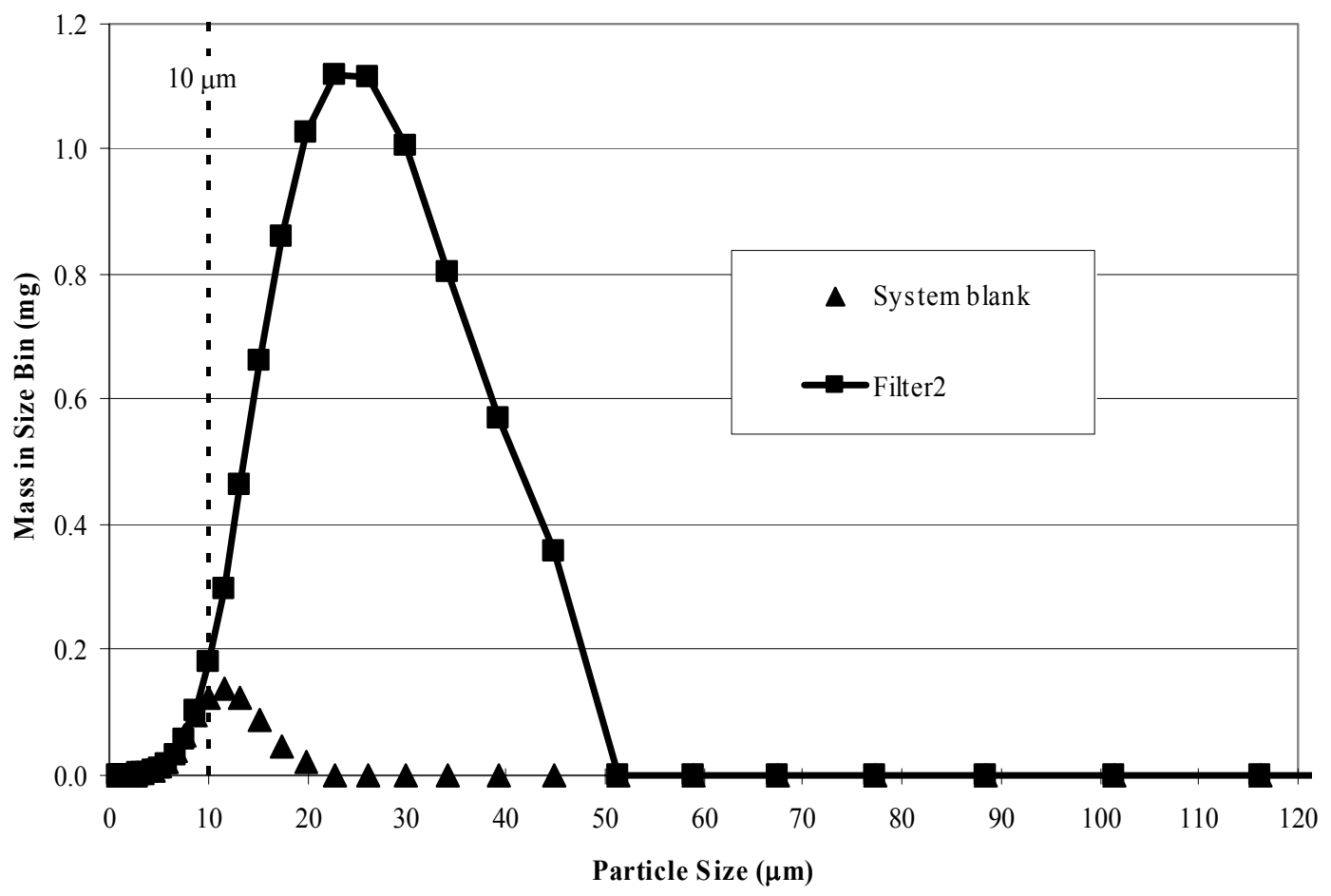

Figure 4.1. Total Mass of Particles as a Function of Particle Size 


\subsection{Particulates in Exhaust Line Liquid Samples}

The fluid running along the inside of the exhaust line during the dry waste simulant test run was collected in a catch container. Two samples were collected. Approximately $23 \mathrm{~L}$ of fluid was collected during the 29-minute test run. The samples were collected by first vigorously stirring the fluid catch container to resuspend any settled particles and then submerging the sample vials to flush and fill them. The sample labeled "Cond4" was collected from the initial $15 \mathrm{~L}$ of fluid, and the sample labeled "Cond5" was collected from the final $8 \mathrm{~L}$ of fluid.

The 222-S Laboratory conducted a gravimetric analysis of sample Cond5 and determined it had a solids content of $25 \mathrm{~g} / \mathrm{L}$ (Callaway 2003b). As part of the analytical procedure, the Cond5 sample was centrifuged and the liquid decanted to a separate container. It was noted by the analyst that even prolonged centrifugation did not completely remove all suspended particles from the liquid portion of Cond5. Particle size analyses were conducted on Cond4 and both the Cond5 solids and decanted liquid. Table 4.3 lists key statistical parameters from the particle size analyses. Complete analyses are given in Appendix A.

Table 4.3. Size Analyses of Particles in Exhaust Line Liquid

\begin{tabular}{||l|c|c|c||}
\hline Parameter & $\begin{array}{c}\text { Cond4 Sample } \\
\text { Particles }\end{array}$ & $\begin{array}{c}\text { Cond5 Sample } \\
\text { Centrifuged Solid } \\
\text { Particles }\end{array}$ & $\begin{array}{c}\text { Cond5 Sample } \\
\text { Decanted Liquid } \\
\text { Suspended Particles }\end{array}$ \\
\hline Median particle diameter $(\mu \mathrm{m})$ & 10.3 & 8.9 & 13.3 \\
\hline Mean particle diameter $(\mu \mathrm{m})$ & 12.7 & 10.5 & 13.2 \\
\hline Mode of particle diameters $(\mu \mathrm{m})$ & 12.4 & 12.4 & 16.3 \\
\hline
\end{tabular}

A comparison of results in Tables 4.2 and 4.3 (as well as the more detailed analyses given in Appendix A) indicates that the particles collected by the aerosol filter sample had a size distribution very similar to that of the two exhaust line liquid samples, suggesting that the loss of aerosol particles to the exhaust line wall between the outlet of the LRVP separator vessel and the aerosol sampling point did not strongly affect the aerosol sample particle size distribution. 


\subsection{Conclusions}

The tests described in this report have characterized the efficiency with which waste simulants are removed from the entraining air stream in the C-200 VRS under various conditions. The important conclusions from the tests are

1. As expected, operation of the VRS causes a gradual increase in the concentration of aqueous waste simulant in the LRVP seal water. Comparison of the amounts of $\mathrm{Rb}$ and Cs tracers in the exhaust line liquid samples suggests that nearly all the aqueous simulant passed through the batch tank to the LRVPs was collected by the LRVP seal water. The LRVPs appear to be highly effective at scrubbing waste particles from the air leaving the batch tank for aqueous waste.

2. Also as expected, aqueous waste simulant aerosol mass concentrations in the exhaust line increased in each successive test run. However, the increases in aerosol concentration were expected to be about proportional to the increases in LRVP seal water waste simulant concentration, and they were not. Instead, the aerosol concentrations increased much faster than the LRVP simulant waste concentrations. This has not been definitively explained, but it is thought to be due to the gradually increasing temperature of the LRVP system and secondary phenomena (e.g., reentrainment of droplets from exhaust line walls).

3. The dry waste simulant particles collected by the filter samples tended to range in size (effective diameter) from about 1 to $50 \mu \mathrm{m}$, and about $80 \%$ of the aerosol mass was due to particles greater than $10 \mu \mathrm{m}$. The dry waste simulant itself was determined to be composed primarily of much larger particles, having a mean particle size of about $280 \mu \mathrm{m}$ based on an average of four measurements (see Appendix A). This indicates that the VRS is very effective at collecting waste particles larger than about $50 \mu \mathrm{m}$. Visual inspection of the LRVP seal water drained after the tests indicated larger particles were being collected by the LRVP seal water, implying that the $50 \mu \mathrm{m}$ particle size was essentially the cut size of the LRVP separator vessel. This is supported by similar particle size analyses of the solid particles in the exhaust line liquid samples (Cond4 and Cond5).

4. Batch tank aqueous waste simulant collection efficiency was markedly higher for the test conducted with one LRVP than for the three tests conducted with two LRVPs. The calculated batch tank efficiency with one LRVP was $99.98 \%$, and with two LRVPs the average was about 98.3\%. The reason for this difference was not established but could be explained by a nonrepresentative LRVP2 sample or an error in its chemical analysis. Because it is inconsistent with subsequent test runs, it is recommended that the batch efficiency calculated for the $\mathrm{CsCl1}$ test run not be used for safety-related analyses and that the batch tank collection efficiency be assumed to be $98.3 \%$ regardless of whether one or two LRVPs are used. 
5. The VRS exhaust was estimated to contain between 0.07 to $0.7 \mathrm{~mL} / \mathrm{m}^{3}$ of LRVP seal water as an aerosol, excluding a single anomalously high value associated with $\mathrm{Cs}$ measurements in the first test run. 


\subsection{References}

Baide DG. 2003. Field Data from the C-200 Series Retrieval Project Particulate and Aerosol Tests. RPP-18229 Rev. 0, CH2M HILL Hanford Group, Inc., Richland, WA.

Baide DG and JL Huckaby. 2003. C-200 Series Retrieval Project - Test Implementation Plan for Measurement of Particulate and Aerosol Discharge for the Vacuum Retrieval System. RPP-17356 Rev. 1, CH2M HILL Hanford Group, Inc., Richland, WA.

Belyaev SP and LM Levin. 1974. "Techniques for Collection of Representative Aerosol Samples.” J. Aerosol Science, 3:127-140.

Brockman JE. 1993. "Sampling and Transport of Aerosols." Aerosol MeasurementPrinciples, Techniques, and Applications, K Willeke and PA Baron, eds. Van Nostrand Reinhold, New York.

Callaway WS. August 12, 2003a. Test Plan and Procedure: Analytical Support of C-200 Vacuum Retrieval System Testing. Letter FH-0303138 to JL Huckaby, Pacific Northwest National Laboratory, dated August 12), Fluor Hanford, Richland, Washington.

Callaway WS. September 11, 2003b. Preparation and Analysis of C-200 Vacuum Retrieval System Test Samples. Letter report FH-0303567 to DG Baide, CH2M HILL Hanford Group, Inc. Fluor Hanford Inc., Richland, WA.

Creze CM and JR Jewett. 2003. Characteristics of Waste in the C-200 Series of Hanford Underground Waste Tanks. RPP-14627 Rev 0, Numatec Hanford Company, Richland, WA. 


\section{Appendix}

\section{Particle Size Analysis Results}


Vendor (Lane Mountain Company) screen analysis of dry waste simulant (LM\#70)

Chain of Custody form for particulate samples ...............................................................2

Particle size analysis of system blank (Filter1) ..............................................................

Particle size analyses of dry waste simulant aerosol (Filter2) ..............................................4.4

Particle size analyses of exhaust line liquid solids (Cond4) .................................................6

Particle size analyses of exhaust line liquid recovered solids (Cond5) .....................................7

Particle size analyses of solids in decanted exhaust line liquid (Cond5)................................10

Particle size analyses of incinerated clean unused filter (Filter4A) .......................................12

Particle size analyses of dry waste simulant (Sand1) .......................................................13

Particle size analyses of dry waste simulant (Sand2) .........................................................15 


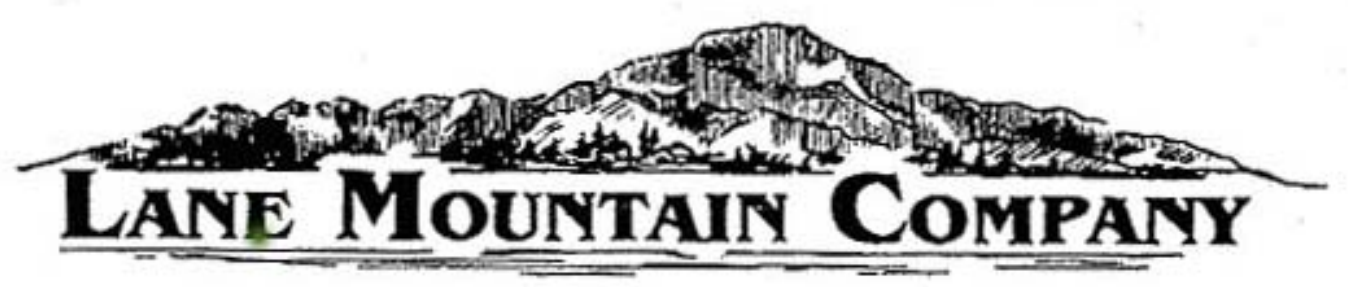

P.O. BOX 127

PLANT: VALLEY, WASMINGTON PQIE1

Phone: 509.937.2221 Fax: 509.937.2523

SCREEN ANALYSIS - \% RETAINED

+ or $-5 \%$

\begin{tabular}{|l|c|c|c|c|c|c|}
\hline U.S. SCREEN SIZE & LM 16 & LM\# 20/30 & LM 30 & LM\# 50 & LME 70 & LME 125 \\
\hline 12 & 0.5 & & & & \\
\hline 16 or $1.168 \mathrm{MM}$ & 11.0 & & & & \\
\hline 20 or $.883 \mathrm{MM}$ & 60.0 & 2.5 & & & & \\
\hline 30 or $.589 \mathrm{MM}$ & 24.0 & 29.0 & 12.0 & & & \\
\hline 40 or $.417 \mathrm{MM}$ & 2.0 & 55.0 & 22.0 & 24.5 & \\
\hline 50 or $.297 \mathrm{MM}$ & & 12.0 & 24.0 & 45.5 & 3.5 & 1.0 \\
\hline 70 or $.208 \mathrm{MM}$ & & & 14.0 & 16.0 & 32.0 & 1.5 \\
\hline 100 or $.147 \mathrm{MM}$ & & & 11.0 & 7.5 & 31.0 & 4.5 \\
\hline 140 or $.105 \mathrm{MM}$ & & & 9.0 & 3.5 & 18.0 & 25.0 \\
\hline 200 or $.074 \mathrm{MM}$ & & & & 1.5 & 10.5 & 39.0 \\
\hline PAN & 2.5 & 1.5 & 8.0 & -1.5 & 5.0 & 29.0 \\
\hline
\end{tabular}

SULICAINGREDIENTS

CHEMICAI ANALYSIS

SILICON DIOXIDE

ALUMINUM OXIDE

IRON OXIDE

TITANIUM DIOXIDE

CALCIUM OXIDE

MAGNESIUM OXIDE

SODIUM OXIDE

POTASSIUM OXIDE

L.O.I. (1200 deg. C)
PERCENI

89.4

0.21

0.035

0.02

0.10

0.00

0.00

0.08

2.20

100.0 


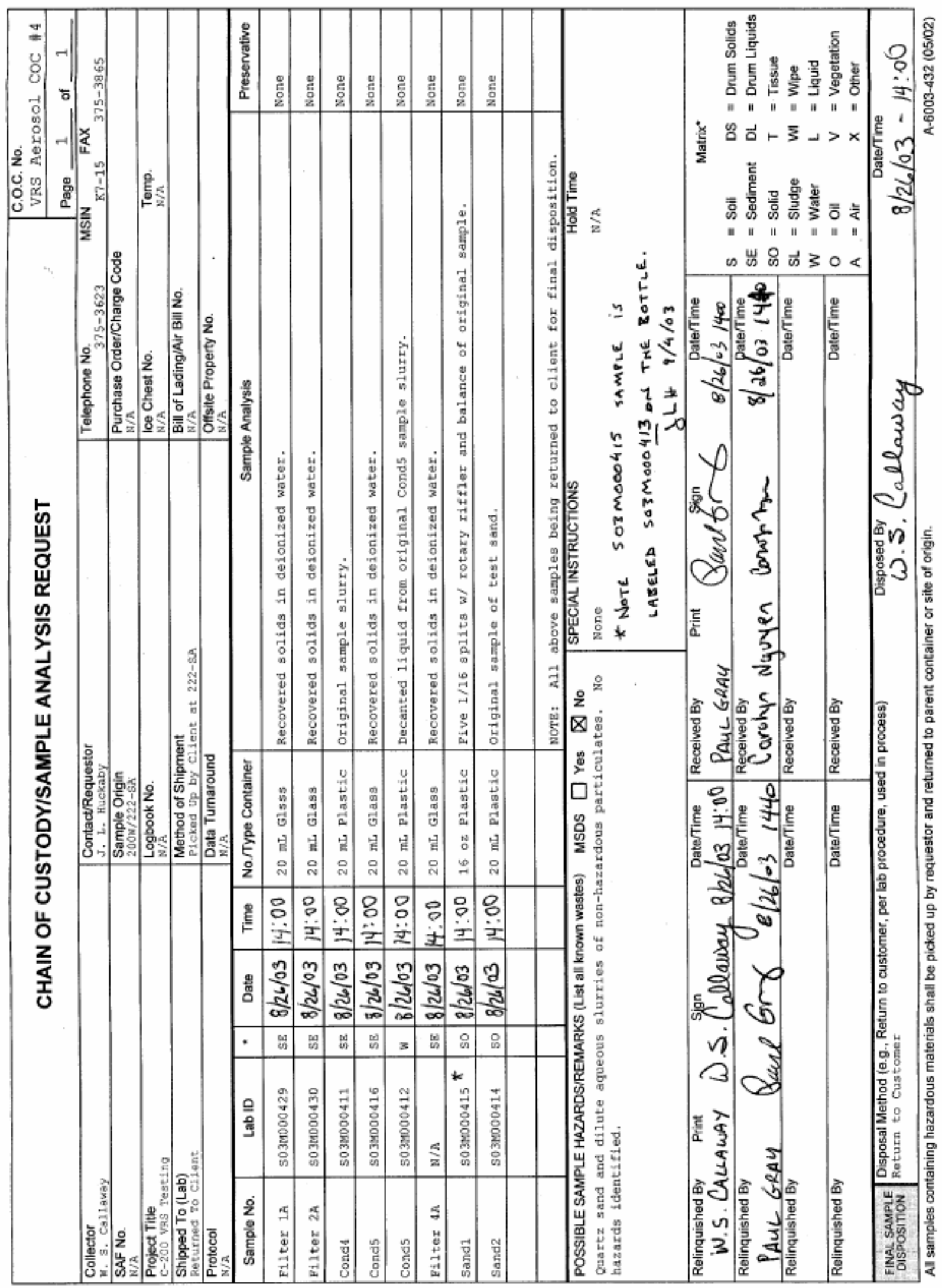


HORIBA LA-920 for Windows(TMD [ WET(LA-920)] Ver.3.25

\section{LA-920 system for Windows}

Filename

ID\#

Sample Name

Material

Source

Lot Number

:200308280816182

:200309020954183

:S03m000429

:S03m000429

:1000 24hr's

Form of Distribution :Standard

Distribution Base :Volume

Sampling Times

$: 10$

S.P. Nrea : $40497\left(\mathrm{~cm}^{2} / \mathrm{cm}^{2}\right)$

Median : $3.4074(\mathrm{um})$

Mean : $4.3962(\mathrm{um})$

Mode : $8.1711(\mathrm{um})$

Span : 2.6931

$\%$ on Diameter

:(1) 5.000 (\%) $\quad 0.374(\mu \mathrm{m})$

(2) $10.00(\%)-0.455(\mu \mathrm{m})$

(3) $20.00(\%)-1.036(\mathrm{um})$

(4) $30.00(\%) \cdot 1.741(u m)$

$(5) 40.00(\%) \cdot 2.458(\mu \mathrm{m})$

Calc. Level $: 30$

Diameter on \%

$(78) .00(\%)-6.114(\mu \mathrm{m})$
Horiba Laboratory

Laboratory Manager

17671 Armstrong Avenue

Irvine, CA 92614

Phone: $(800) 446-7422$

Fax: (949)250-0924

Groulation Speed : 3

Uitra sonic $\quad: 00: 27(7)$

$\begin{array}{ll}\text { Laser T\% } & : 98.8(\%) \\ \text { Lamp T\% } & : 97.6(\%)\end{array}$

R.R.Index : 18000101

Varlance : $12.875\left(\mathrm{um}^{2}\right)$

S.D. : 3.5881(um)

CV : 81.6192

Geo. Mean: 2.7885 (um)

Chi-2 : 0.147233

:850.0 (um)- $100.000 \%$ \%) $150.0(\mu \mathrm{m})-100.000(\%)$

$600.0(\mu \mathrm{m})-100.000 \%) \quad 106.0(\mu \mathrm{m})-100.000(\%)$

425.0 (um)- $100.000(\%) \quad 75.00(\mu \mathrm{m})-100.000(\%)$

300.0 (um)- $100.000(\%) \quad 53.00(\mu \mathrm{m})-100.000(\%)$

$38.00(\mathrm{~mm})-100.000 \%$

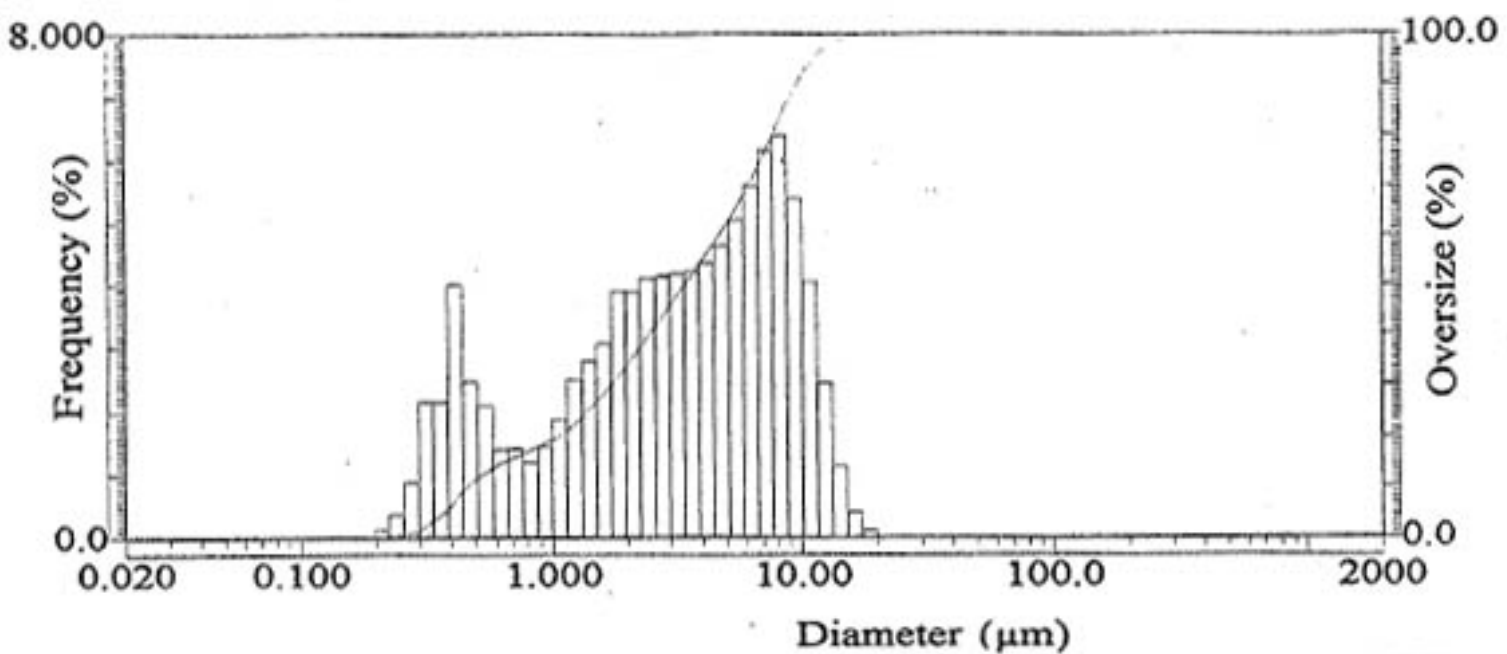

\begin{tabular}{|c|c|c|c|c|c|c|c|c|c|c|c|c|c|c|}
\hline No. & Diameter & & Under $\mathbf{6}$ & No. & Diameter & & Under \%। & iNo. & Diameter & & Under \% & No. & Dismeter & Under $\%$ \\
\hline 1 & 0.022 & 0.000 & 0.000 & 24 & 0.510 & 2,443 & 12.045 & 47 & 11.565 & 4.046 & 85.926 & 70 & 262.376 & 0.000100 .000 \\
\hline 2 & 0.026 & 0.000 & 0.000 & 25 & 0.584 & 2.057 & 14.102 & 48 & 13.246 & 2.410 & 08.345 & 71 & 300.518 & 0.000100 .000 \\
\hline 3 & 0.029 & 0.000 & 0.000 & 26 & 0.669 & 1.407 & 15.510 & 49 & 15.172 & 1.125 & 99.470 & 72 & 344.206 & $0.000 \quad 100,000$ \\
\hline 4 & 0.034 & 0.000 & 0.000 & 27 & 0.766 & 1.416 & 16.025 & 50 & 17.377 & 0.409 & 09.879 & 73 & 394.244 & 0.000100 .000 \\
\hline 5 & 0.039 & 0.000 & 0.000 & 28 & 0.877 & 1.210 & 18.135 & 51 & 19.904 & 0.121 & 100.000 & 74 & 451.556 & 0.000100 .000 \\
\hline 6 & 0.044 & 0.000 & 0.000 & 29 & 1.005 & 1.443 & 10.578 & 52 & 22.797 & 0.000 & 100.000 & 75 & 517.200 & $0.000100,000$ \\
\hline 7 & 0.051 & 0.000 & 0.000 & 30 & 1.151 & 1.886 & 21.464 & 53 & 26,111 & 0.000 & 100.000 & 76 & 592.387 & 0.000100 .000 \\
\hline 8 & 0.058 & 0.000 & 0.000 & 31 & 1.318 & 2.491 & 23.954 & 54 & 29.907 & 0.000 & 100.000 & 77 & 678.504 & 0.000100 .000 \\
\hline 9 & 0.067 & 0.000 & 0.000 & 32 & 1.510 & 2.787 & 26.741 & 55 & 34.255 & 0.000 & 100.000 & 78 & 777.141 & 0.000100 .000 \\
\hline 10 & 0.076 & 0.000 & 0.000 & 33 & 1.729 & 3.058 & 29.790 & 56 & 39.234 & 0.000 & 100.000 & 79 & 890.116 & 0.000100 .000 \\
\hline 11 & 0.087 & 0.000 & 0.000 & 34 & 1.981 & 3.902 & 33.701 & 57 & 44.938 & 0.000 & 100.000 & 80 & 1018.515 & 0.000100 .000 \\
\hline 12 & 0.100 & 0.000 & 0.000 & 35 & 2.269 & 3.878 & 37,580 & 58 & 51.471 & 0.000 & 100.000 & 81 & 1167.725 & 0.000100 .000 \\
\hline 13 & 0.115 & 0.000 & 0.000 & 36 & 2.599 & 4.102 & 41.682 & 59 & 58.953 & 0.000 & 100.000 & 82 & 1337.481 & 0.000100 .000 \\
\hline 14 & 0.131 & 0.000 & 0.000 & 37 & 2.976 & 4.144 & 45.825 & 60 & 67.523 & 0.000 & 100.000 & 83 & 1531.914 & 0.000100 .000 \\
\hline 15 & 0.150 & 0.000 & 0.000 & 38 & 3.409 & 4.189 & 50.014 & 61 & 77.339 & 0.000 & 100.000 & 84 & 1754.613 & 0.000100 .000 \\
\hline 16 & 0.172 & 0.000 & 0.000 & 39 & 3.905 & 4.208 & 54.222 & 62 & 88.583 & 0.000 & 100.000 & 85 & 2000.000 & 0.000100 .000 \\
\hline 17 & 0.197 & 0.000 & 0.000 & 40 & 4.472 & 4.369 & 58.590 & 63 & 101.460 & 0.000 & 100.000 & & & \\
\hline 18 & 0.226 & 0.124 & 0.124 & 41 & 5.122 & 4.639 & 63.230 & 64 & 116.210 & 0.000 & 100.000 & & & \\
\hline 18 & 0.259 & 0.367 & 0.491 & 42 & 5.867 & 5.062 & 68.292 & 65 & 133,103 & 0.000 & 100.000 & & & \\
\hline 20 & 0.286 & 0.872 & 1.383 & 43 & 6.720 & 5.613 & 73.905 & 66 & 152.453 & 0.000 & 100.000 & & & \\
\hline 21 & 0.339 & 2.127 & 3,400 & 44 & 7.697 & 6.165 & 80.070 & 67 & 174.616 & 0.000 & 100.000 & & & \\
\hline 22 & 0.389 & 2.113 & 5.603 & 45 & 8.816 & 6.405 & 86.475 & 68 & 200.000 & 0.000 & 100.000 & & & \\
\hline 23 & 0.445 & 4,000 & 9.602 & 46 & 10.097 & 5.405 & 91.860 & 69 & 229.075 & 0.000 & 100.000 & & & \\
\hline
\end{tabular}


HORIBA LA-920 for Windows(TMD [ WETC.A-920)] Ver.3.25

LA-920 system for Windows

Filename

:200308280816182

ID*

:200309021001184

Sample Name :S03M000430

Material :S03M000430

Source

Lot Number

:1000 24hr's

Form of Distribution :Standard

Distribution Base : :Volume

Sampling Times

S.P. Area : $24668\left(\mathrm{~cm}^{2} / \mathrm{cm}^{3}\right)$

Median : $7.6884($ um)

Mean : $9.0071(\mathrm{um})$

Mode : $12.3628(u \mathrm{~m})$

Span : 2.2890

$\%$ on Diameter

:(1)5.000 (\%). $0.464(\mu \mathrm{m})$ (2) $10.00(\%)-0.791(\mu \mathrm{m})$ (3) $20.00(\%) \cdot 2.056(\mu \mathrm{m})$

(4) $30.00(\%) \cdot 3.581(\mathrm{um})$

(6) $60.00(\%)-9.968(u m)$ (7) $70.00(\%)-12.135(\mu \mathrm{m})$ $(8) 80.00(\%)-14.761(\mu \mathrm{m})$

(5) $40.00(\%) \cdot 5.688(\mathrm{~mm})$

$90.00(\%) \cdot 18.847(u m)$

(10)95.00(\%)-22.583(um)

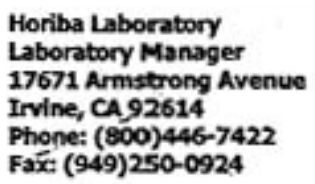

Girculation Speed : 3

Ultra sonic :00:40 (7)

Laser T\% : $\quad: 93.1(\%)$

Lomp T\% :88.2(\%)

Calc. Level : 30

R.R.Index :1800010t

Variance : $52.650\left(\mathrm{um}^{2}\right)$

S.D. : $7.2581(\mathrm{um})$

CV : 80.5822

Geo. Mean : $5.5569(\mu \mathrm{m})$

Chi-2 :0.054840

Diameter on $\%$

850.0 (um)- $100.000(\%) \quad 150.0(\mu \mathrm{m})-100.000 \%)$

600.0 (um)- $100.000(\%) \quad 106.0(\mu \mathrm{m})-100.000 \%)$

425.0 (um)- $100.000(\%) \quad 75.00$ (um)- $100.000 \%$ )

300.0 (um)- $100.000 \%$ ) $\quad 53.00$ (um) $100.000 \%$ )

$212.0(\mathrm{~m})-100.000(\%) \quad 38.00(\mu \mathrm{m})-99.780(\%)$

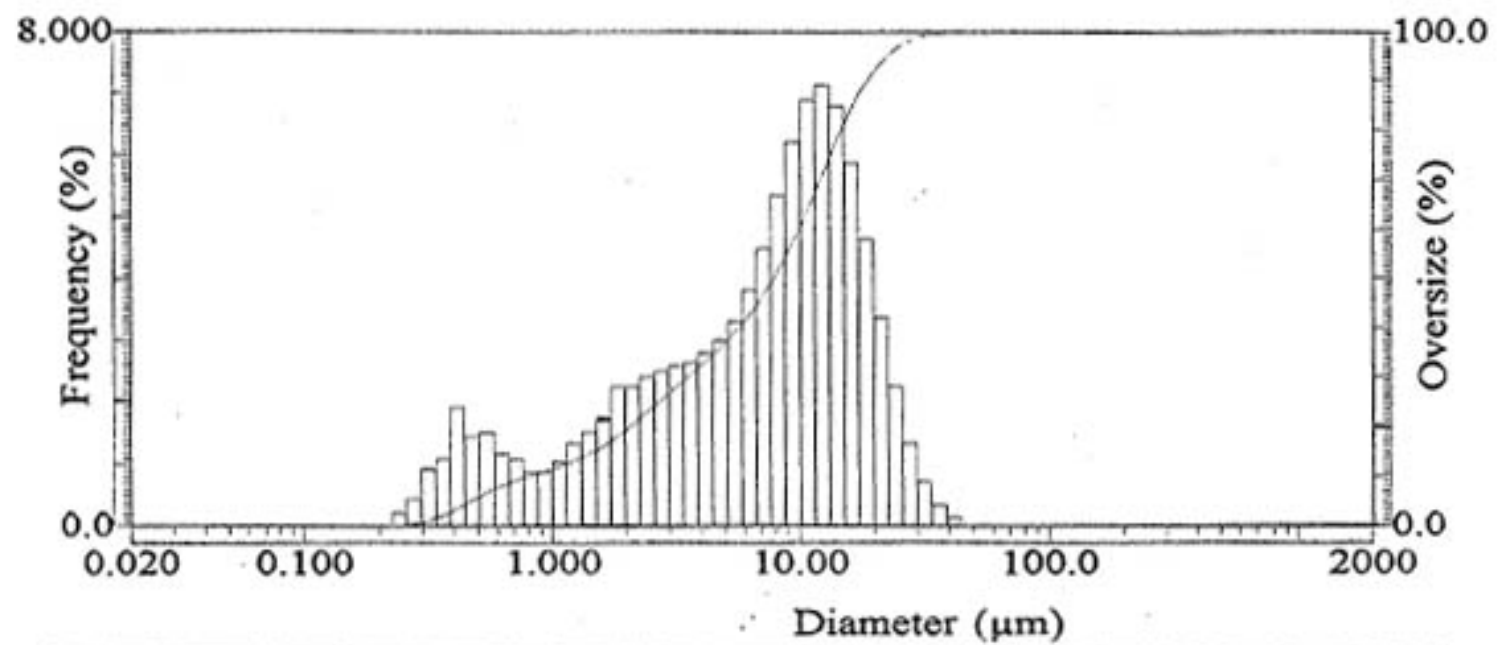

\begin{tabular}{|c|c|c|c|c|c|c|c|c|c|c|c|c|c|c|}
\hline No. & Diameter & & inder $\%$ & No. & Diameter & & Under \% & No. & Diameter & & Under \% & No. & Diameter & Under $\%$ \\
\hline 1 & 0.022 & 0.000 & 0.000 & 24 & 0.510 & 1.458 & 6.021 & 47 & 11.565 & 6.886 & 67,475 & 70 & 262.376 & 0.000100 .000 \\
\hline 2 & 0.026 & 0.000 & 0.000 & 25 & 0.584 & 1.526 & 7,546 & 48 & 13.246 & 7,127 & 74.602 & 71 & 300.518 & 0.000100 .000 \\
\hline 3 & 0.029 & 0.000 & 0.000 & 26 & 0.669 & 1.174 & 8.721 & 49 & 15.172 & 6.766 & 81.368 & 72 & 344.206 & 0.000100 .000 \\
\hline 4 & 0.034 & 0.000 & 0.000 & 27 & 0.766 & 1.078 & 9.798 & 50 & 17.377 & 5.858 & 87.225 & 73 & 394.244 & 0.000100 .000 \\
\hline 5 & 0.039 & 0.000 & 0.000 & 28 & 0.877 & 0.868 & 10.668 & 51 & 19.904 & 4.639 & 01.865 & 74 & 451.556 & 0.000100 .000 \\
\hline 6 & 0.044 & 0.000 & 0.000 & 29 & 1.005 & 0.879 & 11.546 & 52 & 22.797 & 3.369 & 95.234 & 75 & 517.200 & 0.000100 .000 \\
\hline 7 & 0.051 & 0,000 & 0.000 & 30 & 1.151 & 1.047 & 12.593 & 53 & 26.111 & 2.236 & 97,470 & 76 & 592.387 & 0.000100 .000 \\
\hline 8 & 0.058 & 0.000 & 0.000 & 31 & 1.318 & 1.346 & 13.939 & 54 & 29.907 & 1.340 & 98.810 & 77 & 678.504 & 0.000100 .000 \\
\hline 9 & 0.067 & 0.000 & 0.000 & 32 & 1.510 & 1.520 & 15.459 & 55 & 34.255 & 0.714 & 90.524 & 78 & 777.141 & 0.000100 .000 \\
\hline 10 & 0.076 & 0.000 & 0.000 & 33 & 1.729 & 1.711 & 17.170 & 56 & 39.234 & 0.336 & 99.859 & 79 & 890.116 & 0.000100 .000 \\
\hline 11 & 0.087 & 0.000 & 0.000 & 34 & 1.981 & 2220 & 19.390 & 57 & 44.938 & 0.141 & 100.000 & 80 & 1019.515 & 0.000100 .000 \\
\hline 12 & 0.100 & 0.000 & 0.000 & 35 & 2.269 & 2.220 & 21.610 & 58 & 51,471 & 0.000 & 100.000 & 81 & 1167.725 & $0.000,100.000$ \\
\hline 13 & 0.115 & 0.000 & 0.000 & 36 & 2.599 & 2.385 & 23.995 & 59 & 58.953 & 0.000 & 100.000 & 82 & 1337,481 & 0.000100 .000 \\
\hline 14 & 0.131 & 0.000 & 0.000 & 37 & 2.976 & 2.476 & 26.471 & 60 & 67.523 & 0.000 & 100.000 & 83 & 1531.914 & $0.000 \quad 100.000$ \\
\hline 15 & 0.150 & 0.000 & 0.000 & 38 & 3.409 & 2.575 & 29.046 & 61 & 77.339 & 0.000 & 100.000 & 84 & 1754,613 & 0.000100 .000 \\
\hline 16 & 0.172 & 0.000 & 0.000 & 39 & 3.905 & 2.633 & 31.679 & 62 & 88.583 & 0.000 & 100.000 & 85 & 2000.000 & 0.000100 .000 \\
\hline 17 & 0.197 & 0.000 & 0.000 & 40 & 4.472 & 2.780 & 34.459 & 63 & 101.460 & 0.000 & 100,000 & & & \\
\hline 18 & 0.226 & 0.000 & 0.000 & 41 & 5,122 & 2.985 & 37.444 & 64 & 116.210 & 0.000 & 100.000 & & & \\
\hline 19 & 0.259 & 0.219 & 0.219 & 42 & 5.887 & 3.310 & 40.755 & 65 & 133.103 & 0.000 & 100.000 & & & \\
\hline 20 & 0.296 & 0.445 & 0.664 & 43 & 6.720 & 3.795 & 44.549 & 66 & 152.453 & 0.000 & 100.000 & & ? & \\
\hline 21 & 0.339 & 0.923 & 1.592 & 44 & 7.697 & 4.480 & 49.030 & 67 & 174.616 & 0.000 & 100.000 & & & \\
\hline 22 & 0.389 & 1.074 & 2.667 & 45 & 8.816 & 0.352 & 54.382 & 68 & 200.000 & 0.000 & 100.000 & & & \\
\hline 23 & 0.445 & 1.896 & 4.563 & 46 & 10.097 & 6.206 & 60.589 & 69 & 229.075 & 0.000 & 100.000 & & & \\
\hline
\end{tabular}




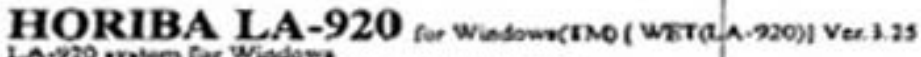

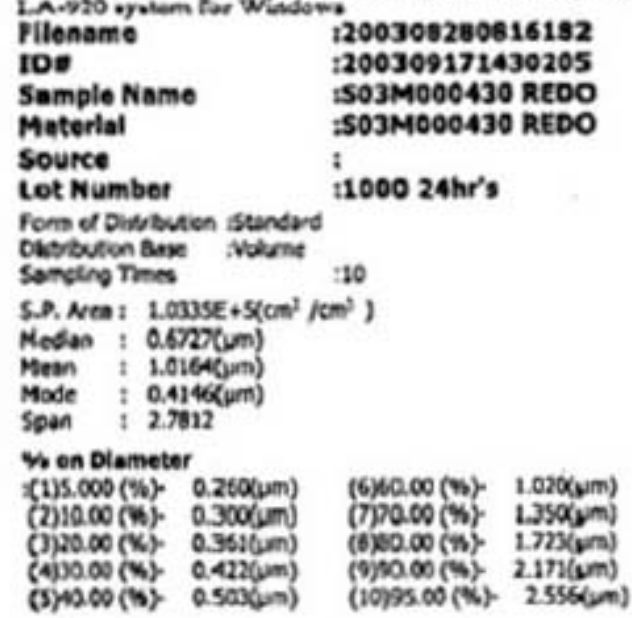

Moriba Laboratory

Loberatery Menaper 17671 Nrmatreng Avenue Irvine, CA 92614 Phene: (600)446-7422 Fox: (949)250-0924

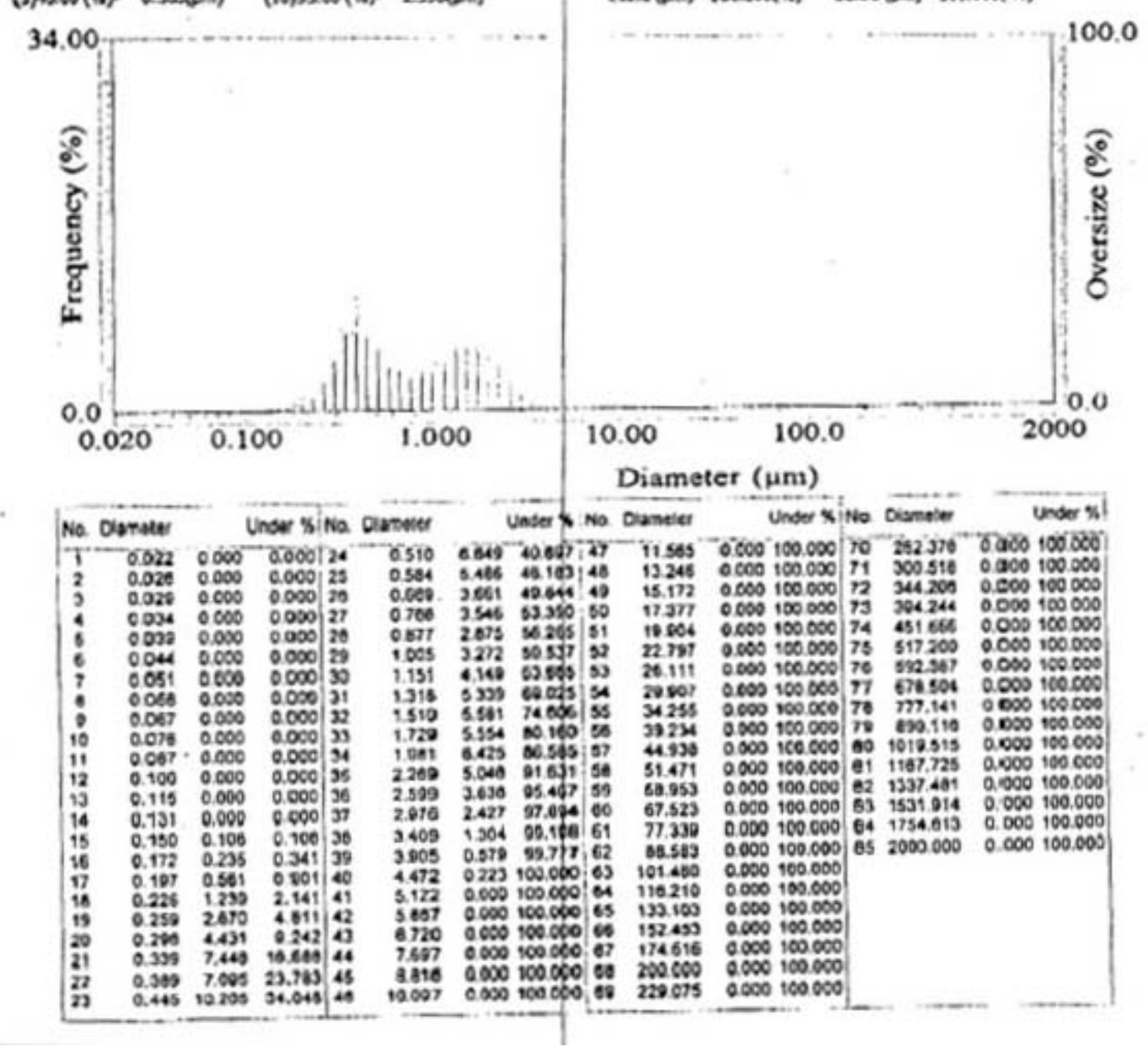

Orabion speres a

Uen sonk 00:14 (7)

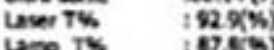

Cotclevel os

Re. inser : 1600010\%

varance : $0.6139\left(4 \mathrm{~m}^{2}\right.$ )

S.D. : $0.763(\mathrm{ym})$

cr : 70074

Geo. Mean : $0.2597(u m)$

oil-2

0.75974
$0.10745)$

Diemeter en $\mathbf{V}$

050.0 (um) $100.000(\mathrm{w}) \quad 150.0$ (um) $\cdot 100.000 \mathrm{x}$ )

600.0 (umt $100.0000 \mathrm{c}) \quad 206.0$ (um) 100.000 (5)

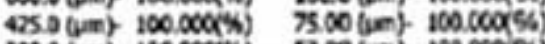

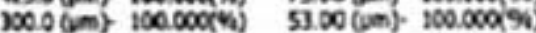

2120 (ba) $100000(\mathrm{~s}), 3800(\mathrm{gn}), 200000 \mathrm{x}$ 
HORIBA LA-920 for Windows(t) [ WBT(L.A-920) ver.3.25

L.A-920 nystem for Windowa

\begin{tabular}{|c|c|}
\hline Filename & $: 200308280816182$ \\
\hline $\mathrm{ID} *$ & 2200309021008185 \\
\hline Sample Name & $2503 M 000411$ \\
\hline Material & : \\
\hline Source & : \\
\hline Lot Number & 11000 24hr's \\
\hline $\begin{array}{l}\text { Form of Distribution :Standard } \\
\text { Distribution Base : Volume } \\
\text { Sampling Times }\end{array}$ & $: 10$ \\
\hline $\begin{array}{l}\text { S.P.Area : } 12872\left(\mathrm{~cm}^{2} / \mathrm{cm}^{2}\right) \\
\text { Median : } 10.2614(\mathrm{um}) \\
\text { Mean : } 12.7316(\mathrm{\mu m}) \\
\text { Mode : } 12.4235(\mathrm{\mu m}) \\
\text { Span : } 2.3659\end{array}$ & \\
\hline
\end{tabular}

$\%$ on Diameter

$:(1) 5.000(\%)-1.272(\mu \mathrm{m})$ (2) $10.00(\%)-1.930(\mu \mathrm{m})$ (3) $20.00(\%)-3.483(\mu m)$ (4) $30.00(\%)-5.683(u m)$ (5) $10.00(4) .8 .034(\mathrm{gm})$
(6) $60.00(\%)-12.613(u m)$ (7) $70.00(\%)-15.389(\mathrm{~mm})$ (8) $80.00(\%)-19.275$ (um) $(9) 90.00(\%)-26.254(\mu m)$ (10) $95.00(\%) \cdot 33.980(1 \mathrm{~m})$
Horiba Laberatery

Laboratory Manager 17671 Armstrong Avenue Irvine, CA 92614 Phone: (800) 446-7422 Faxi (949)2.50-0924

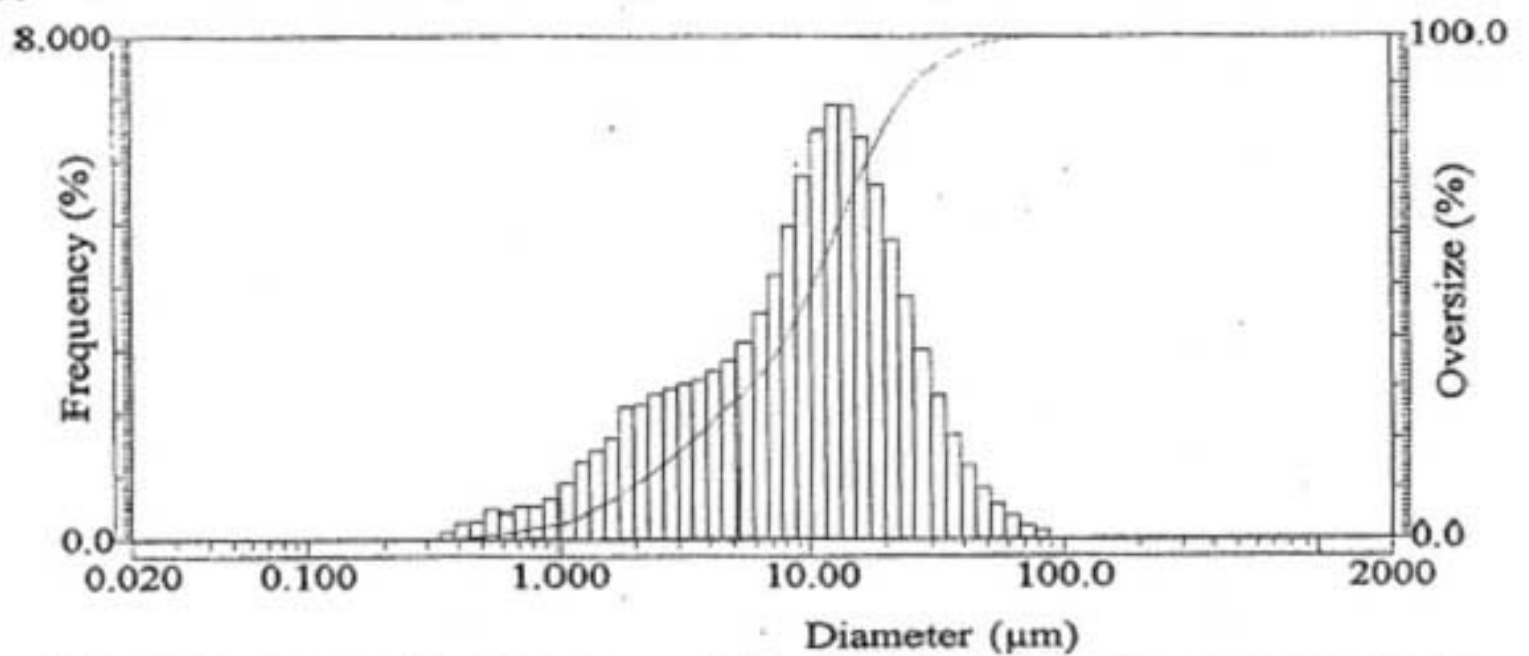

\begin{tabular}{|c|c|c|c|c|c|c|c|c|c|c|c|c|c|c|}
\hline No. & Diancter & & Inder $x$ & No. & Diameter & & Under $\mathbf{w}$ & No. & Diameter & & Under \% & No. & Dianeter & Under \% \\
\hline 1 & 0.022 & 0.000 & 0.000 & 24 & 0.510 & 0.292 & 0.690 & 47 & 11.505 & 6.467 & 55.606 & 70 & 262.370 & 0.000100 .000 \\
\hline 2 & 0.026 & 0.000 & 0.000 & 25 & 0.584 & 0.458 & 1.155 & 48 & 13.246 & $6.87 \mathrm{~b}$ & 62.484 & 71 & 300.518 & 0.000100 .000 \\
\hline 3 & 0.029 & 0.000 & 0.000 & 26 & 0.669 & 0.435 & 1.590 & 49 & 15.172 & 6.847 & 60.331 & 72 & 344.206 & $0.000100,000$ \\
\hline 4 & 0.034 & 0.000 & 0.000 & 27 & 0.766 & 0.500 & 2.090 & 50 & 17.377 & 6.380 & 75.711 & 73 & 394.244 & 0.000100 .000 \\
\hline s & 0.039 & 0.000 & 0.000 & 28 & 0.877 & 0.499 & 2.589 & 51 & 19.904 & 5.618 & 61.329 & 74 & 451.556 & 0.000100 .000 \\
\hline 6 & 0.044 & 0.000 & 0.000 & 29 & 1.005 & 0.635 & 3.224 & 52 & 22.797 & 4.724 & 66.053 & 75 & 517.200 & 0.000100 .000 \\
\hline 7 & 0.051 & 0.000 & 0.000 & 30 & 1.151 & 0.881 & 4.108 & 53 & 26.111 & 3.820 & 80.860 & 76 & 692.387 & 0.000100 .000 \\
\hline 8 & 0.058 & 0.000 & 0.000 & 31 & 1.318 & 1.215 & 5.320 & 54 & 29.907 & 2.003 & 92.873 & 77 & 678.504 & 0.000100 .000 \\
\hline 9 & 0.057 & 0.000 & 0.000 & 32 & 1.510 & 1.400 & 6.729 & 55 & 34.255 & 2.261 & 25.134 & 78 & 777.141 & 0.000100 .000 \\
\hline 10 & 0.076 & 0.000 & 0.000 & 33 & 1.729 & 1.603 & 8.332 & 56 & 39.234 & 1.649 & 96.784 & 79 & 890.116 & 0.000100 .000 \\
\hline 11 & 0.007 & 0.000 & 0.000 & 34 & 1.981 & 2.067 & 10.399 & 57 & 44.938 & 1.165 & 97.948 & 80 & 1019.515 & 0.000100 .000 \\
\hline 12 & 0.100 & 0.000 & 0.000 & 35 & 2.269 & 2.107 & 12.506 & 58 & 51,471 & 0.790 & 98.748 & 81 & 1167.725 & 0.000100 .000 \\
\hline 13 & 0.115 & 0.000 & 0.000 & 38 & 2.599 & 2.200 & 14.786 & 59 & 58.953 & 0.535 & 99.283 & 82 & 1337.481 & 0.000100 .000 \\
\hline 14 & 0.131 & 0.000 & 0.000 & 37 & 2.976 & 2.365 & 17.152 & 60 & 67.523 & 0.350 & 92.633 & 63 & 1531.914 & $0,000100,000$ \\
\hline 15 & 0.150 & 0.000 & 0.000 & 38 & 3.409 & 2.451 & 19.603 & 61 & 77.339 & 0.225 & 99.58 & 84 & 1754.613 & 0.000100 .000 \\
\hline 16 & 0.172 & 0.000 & 0.000 & 30 & 3.905 & 2.521 & 22.124 & 62 & 68.583 & 0.142 & 100.000 & 85 & 2000.000 & 0.000100 .000 \\
\hline 17 & 0.197 & 0.000 & 0.000 & 40 & 4.472 & 2.652 & 24.776 & 63 & 101.460 & 0.000 & 100.000 & & & \\
\hline 18 & 0.226 & 0.000 & 0.000 & 41 & 5.122 & 2.836 & 27.612 & 64 & 116.210 & 0.000 & 100.000 & & & \\
\hline 19 & 0.259 & 0.000 & 0.000 & 42 & 5.857 & 3.122 & 30.734 & 65 & 139.103 & 0.000 & 100.000 & & & \\
\hline 20 & 0.296 & 0.000 & 0.000 & 43 & 6.720 & 3.550 & 34.284 & 66 & 152.453 & 0.000 & 100.000 & & & \\
\hline 21 & 0.339 & 0.000 & 0.000 & 44 & 7.097 & 4.156 & 38.440 & 07 & 174.616 & 0.000 & 100.000 & & & \\
\hline 22 & 0.380 & 0.122 & 0.122 & 45 & 8.616 & 4.941 & 43.361 & 63 & 200.000 & 0.000 & 100.000 & & & \\
\hline 23 & 0.445 & 0.282 & 0.404 & 46 & 10.097 & 5.757 & 49.136 & 69 & 229.075 & 0.000 & 100.000 & & & \\
\hline
\end{tabular}

Grculation Speed : 3

$\begin{array}{ll}\text { Ullora sonic } & : 00: 13(7) \\ \text { laser Th\% } & : 75.8 \%(\%)\end{array}$

lamp T\% $: 74.9(\%)$

Calc. Level 130

R.R. Index :1800010t

Variance : 124.86( $\left.\mathrm{um}^{2}\right)$

S.D. : $11.1743(1 \mathrm{~mm})$

CV : 87.7603

Geo. Mean: 6.4415(um)

Chi-2:0.006617

Diameter on $\%$ $: 850.0$ (um)- $100.000(\%) \quad 150.0$ (um) $100.000(\%)$ $600.0(\mathrm{~m})-100.000(\%) \quad 106.0(\mathrm{~mm})-100.000(\%)$ 425.0 (um)- $100.000(\%) \quad 75.00(\mu \mathrm{m})-93.807(\%)$ 300.0 (um)- $100.000 \%$ ) $\quad 53.00$ (um)- $98.863(\%)$ $2120(\mathrm{~m})-100.000(\%) \quad 38.00(\mathrm{~m})-96.395(\%)$ 


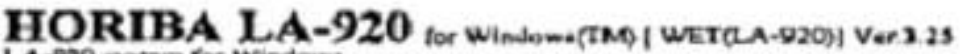

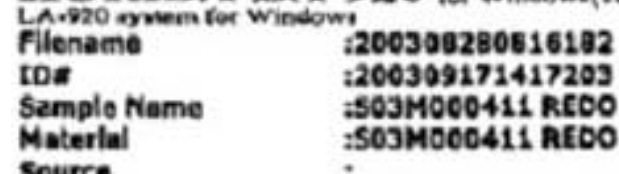

Source

Lot Number

Form of Distribution istandard

Dutituten Boss Nolume

Sonoling Tires

:1000 24hr's

S.f. Aras : $1629 \mathrm{~s}\left(\mathrm{~cm}^{2} \mathrm{fow}^{2}\right)$

Nedan i i.10(x) ain)

Nean $t 10.063 i(y m)$

Mode; 12.313t(um)

Span : 2.3226

Hen Diameter

$105.000(4)+1.034(4)$ (2) 1000 (\%) 1.5640\%)

(3)20.00(4) - 264tum)

(4)0000 (\%) 4.164.0m)

(5) $40.09(\%)+6.509(\mathrm{vm})$
110

(6)50.00 (4) $10.13 \times(u m)$ (7) (6)a.00 (us) is.32iun) (9) $30.00($ w) $20.558(\mathrm{ym})$ (10955.00 (45) 26.4314 ,o)
Horlbe Labenatory

Laboratery Haneser

17671 Armutrong Avenue

Irvinu, CA 92614

Phane ( 600$) 446-7422$

Fox: (eis) $230-0024$

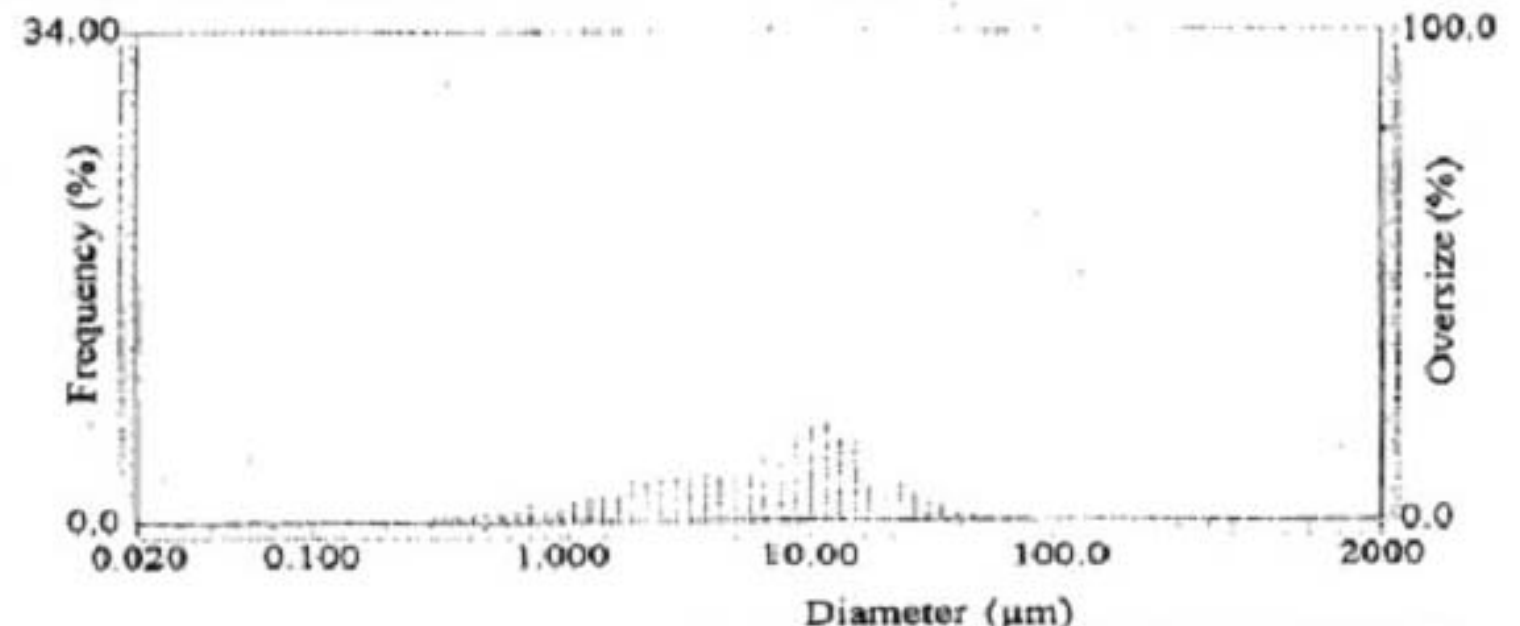

Orculuon speed :
Uevasoric $\quad 00: 19(7)$
User Th $\quad: 555(\mathrm{~s})$
unp Tto is4.2(
Cuic Levei 30
R.R. Index tadaoosol
Variante i s0.9810mi J
S.D. : E. Evon(um)
Cr i 02.602
Cea rean i 6.6206tum)
ON-2 i a.005622

Dlameter en 4

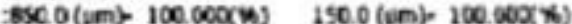

6000 (unt $10000(4) \quad 106.0$ (um) 100.00044$)$

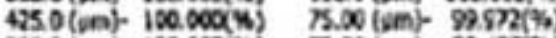

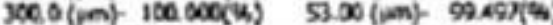

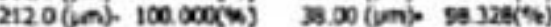

\begin{tabular}{|c|c|c|c|c|c|c|c|c|c|c|c|c|c|c|c|}
\hline Nio & neter & & 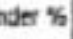 & No. & Diankter & & $\ln 0 \mathrm{er} \mathbf{x}$ & Na. & Duatukn & & Unds $2 \times$ & No & Dlomber & & Under $x$ \\
\hline 1 & aote & 0000 & 0000 & 24 & $\cos 10^{\circ}$ & 0762 & $12 \mathrm{~m}$ & 47 & 11505 & 2871 & $-66565^{-}$ & 75 & 262.216 & crtos & 100.600 \\
\hline 2 & 0020 & 0000 & 0000 & 25 & 0.504 & $0.07 t$ & 1.903 & 40 & 13246 & 6.774 & 72.259 & 71 & \%OS.511 & $c 000$ & $\operatorname{sab} c 00$ \\
\hline 3 & 0020 & 0,000 & 0000 & 26 & 0651 & 0.564 & 2.542 & 40 & 15.172 & 0.245 & Toest & 72 & 344.200 & 0.000 & 100.000 \\
\hline 4 & 0034 & 0000 & 0000 & 27 & 0.768 & 0.073 & 2.222 & 50 & 1737 & 5346 & $\cos 7$ & 7 & 304.144 & 0.000 & 100.000 \\
\hline a & 0000 & 9000 & 0.000 & 20 & 0.97 & Dees & 3.887 & Bt & 19.904 & 4273 & 00230 & 74 & 451,554 & 8.000 & 100,000 \\
\hline a & 0.044 & 0000 & 0.000 & 20 & 1.005 & $\operatorname{asc} 2$ & 6.748 & 02 & 22.707 & 2264 & 02.475 & 25 & 517200 & 0.000 & 100000 \\
\hline 7 & 0051 & 0.000 & 0.000 & 30 & 1.151 & 1.209 & 5051 & 53 & 24.111 & $2.3 \% 4$ & 04640 & 78 & 502.347 & 0.000 & 100.000 \\
\hline c) & 0.068 & 9.600 & 0.600 & 21 & 1.318 & 1045 & 7.500 & 54 & 29007 & 1 eas & 00.607 & $\eta$ & 610.504 & 0.000 & 100.090 \\
\hline$\theta$ & $0.00 \%$ & 0.000 & 0.000 & 72 & 1.510 & tees & 2.461 & 55 & 34255 & 1.178 & 97.712 & 76 & 777.141 & 0.000 & 190.000 \\
\hline 10 & 0.078 & 0.000 & D. 600 & 33 & 1.720 & 2074 & 11.595 & 50 & 29234 & 0.066 & $00.918^{\prime}$ & 70 & 496.116 & 0.000 & 100.000 \\
\hline 11 & Q osy & 0.000 & D. 000 & 24 & 1.001 & 2.050 & 14.173 & 57 & 44938 & 0.540 & 00.007 & 20 & 5010.515 & 0.060 & 100.000 \\
\hline 12 & 0.100 & 0.000 & $c .000$ & 95 & 2.262 & 2.641 & 16814 & 58 & 51471 & 0374 & 09.442 & e1 & 1187 rzs & 0.000 & 100.000 \\
\hline 13 & 0115 & 0600 & 0.000 & 96 & 2.599 & 2.810 & 10.032 & 50 & 59053 & 0.251 & 60000 & 62 & 1297,461 & 0.000 & 400.000 \\
\hline 14 & 0.131 & 0,000 & 0.000 & 37 & 2.976 & 2.604 & 22.515 & eo & 07.523 & 0.176 & 00.470 & E) & 1531,014 & 0.000 & 700.000 \\
\hline 15 & 0.150 & 0.000 & 0.900 & $\$ 6$ & 2400 & 2.057 & 25.473 & 64 & 77,330 & 0124 & 100000 & 64 & 1754.513 & 0,000 & 700000 \\
\hline 10 & 0472 & 0000 & 0.000 & 30 & 3.005 & 3023 & 28407 & 82 & cases & 9000 & $100.000^{\prime}$ & 65 & 2605000 & 0003 & 100.000 \\
\hline 17 & 0.107 & 0000 & 0000 & 40 & 4.472 & 3.172 & $31.60 \%$ & Es & 101.460 & 0.000 & 100,000 & & & & \\
\hline 18 & 0.220 & 0.000 & 0.000 & 41 & 5.122 & 3567 & 55010 & 64 & $\operatorname{tta210}$ & 0.000 & 100.000 & & & & \\
\hline 10 & 0250 & 0000 & 2.000 & 42 & 5.897 & 3.720 & 38776 & Es & 133.109 & 0.000 & 100.000 & & & & \\
\hline 20 & 0.200 & 0.000 & 0.600 & 43 & 0.720 & 4203 & 42.479 & $E 6$ & 152.453 & 0000 & 100.000 & & & & \\
\hline 21 & 0339 & a.115 & 0.115 & 44 & 7697 & 4659 & 47.929 & er & $\$ 74616$ & 0000 & $1 c c .000$ & & & & \\
\hline$n$ & 0.069 & 0.200 & 0.221 & 45 & 0416 & 5.680 & 59.48 & na & 200000 & 0000 & 160.000 & & & & \\
\hline 23 & 0445 & 0.494 & 6.615 & 46 & 10007 & 6.321 & 50.000 & 52 & 220075 & 0000 & 100000 & & . & & \\
\hline
\end{tabular}




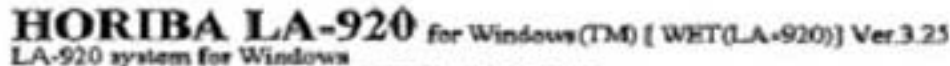

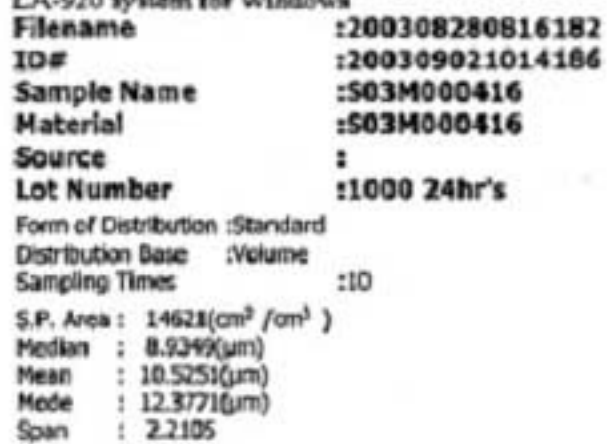

(6) $60.00(\%)-11.010(\mathrm{~m})$ 6) 70.00 (\%) - $11.346 \mathrm{um}$ (8) 60000 (\%) $16.390 \mathrm{gm}$ (9) 50.00 (\%) 21.435ym) (1095.00(n) 26.613 (um)
Horiba Laboratory

Lbsestory Manager

17671 Armstrong Avenue

Invine, CA 92614

Phope: ( 800$) 466-7422$

Fá́ (949)2so-cmat

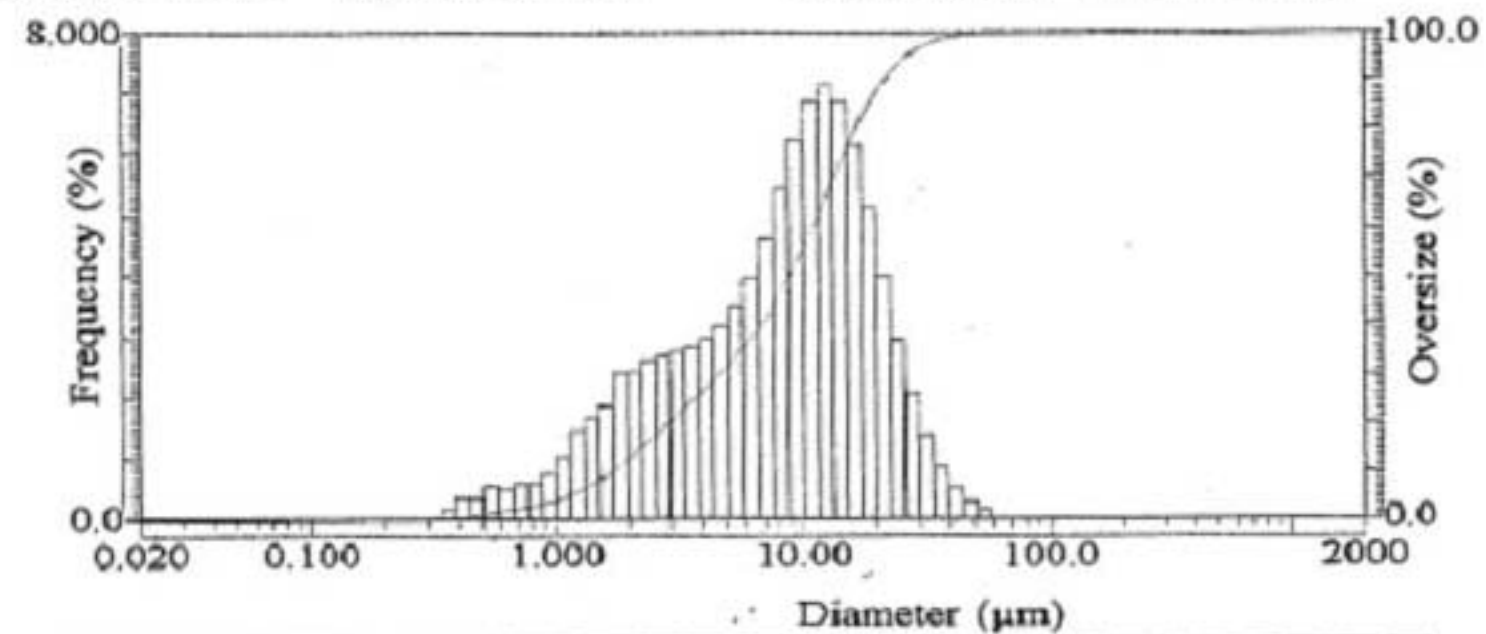

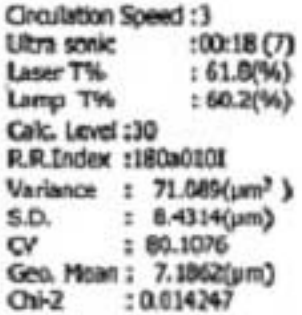

\begin{tabular}{|c|c|c|c|c|c|c|c|c|c|c|c|c|c|c|}
\hline No. & Dianteler & & Under 4 & No. & Dianeler & & Unset \& & Na. & Diemctor & & Under $\%$ & No. & Dameter & Under $x$ \\
\hline 1 & 0.02 & 0000 & 0000 & 24 & 0.510 & 0365 & 0060 & 47 & 11.565 & 6.877 & 02.421 & 78 & 252376 & 0000100000 \\
\hline 2 & 0.028 & 0.000 & 0.000 & 25 & 0.584 & 0.568 & 1.445 & 48 & 13.245 & 7.136 & 60.629 & 71 & 500.510 & 0.060100 .000 \\
\hline 3 & 0.020 & 0.000 & 0.000 & 26 & 0.689 & 0.513 & 1.963 & 49 & 15.172 & $6 . m$ & 76.507 & 72 & 344.200 & 0,000100000 \\
\hline 4 & 0.034 & 0.060 & 6.000 & 27 & 0.730 & asol & 2.551 & 50 & 1737 & 5.137 & 82844 & $n$ & 334244 & 0.060100000 \\
\hline 5 & 0.039 & 0.000 & 0.000 & 20 & 0877 & 0.580 & 3.139 & 51 & 19504 & 5.107 & 67.751 & 74 & 451.656 & 0.000100 .000 \\
\hline 0 & 0.044 & 0.000 & 0.000 & 29 & 1005 & 0753 & 3.9.97 & 52 & 22797 & 2.607 & 01.748 & 75 & 517.200 & $0.000100,000$ \\
\hline 7 & 0.051 & 0.000 & 0.000 & 30 & 1.151 & 1.000 & 4957 & 69 & 20.111 & 2.600 & 04.700 & 70 & 502397 & 0.000100 .000 \\
\hline a & 0.058 & 0.000 & 0.000 & 31 & 1.310 & 1.450 & 0.416 & 54 & 29.907 & 2.976 & 90.700 & $\pi$ & $678.50-4$ & 0.000100 .000 \\
\hline 9 & 0.067 & 0.000 & 0.000 & 32 & 1.510 & 1.073 & 0.009 & 55 & 34.255 & 1.380 & 90.107 & 70 & 77.141 & $0.000+100.000$ \\
\hline 10 & 0.078 & 0.000 & 0.000 & 33 & 1.720 & 1883 & 9.672 & 56 & 39234 & 0.358 & 99034 & 79 & 890.110 & 0.000100 .000 \\
\hline 11 & 0.007 & 0,000 & 0.603 & 34 & 1.931 & 2,412 & 12.384 & 57 & 44.938 & 0.517 & 99.551 & 60 & 1012.515 & 0.000100 .020 \\
\hline 12 & 0.100 & 0.000 & 0.000 & 58 & 2200 & 2.435 & 14.819 & 58 & 51.471 & 0.292 & 99.843 & 81 & 1168.725 & 0.000100 .020 \\
\hline 12 & 0.115 & 0,000 & 0.000 & 26 & 2.590 & 2016 & 17.434 & 50 & 58.653 & 0.167 & 100.000 & B2 & 1737.481 & 0.000100000 \\
\hline 14 & 0.131 & 0.000 & 0.000 & 97 & 2976 & 2092 & 20.126 & 60 & 62.529 & 0.000 & 100.000 & 80 & 1591.914 & $0.000100,000$ \\
\hline 15 & 0.190 & 0.002 & 0.000 & 30 & 2,402 & 2773 & 22.1999 & 61 & 77.393 & 0.000 & 100.000 & 84 & 1754.613 & 6.000100 .000 \\
\hline 18 & 0.122 & 0.000 & 0.000 & 39 & 3505 & 2860 & 25740 & 62 & 60.553 & 0.000 & 100000 & es & 2000.000 & 0.000100 .000 \\
\hline 17 & 0.197 & 0.000 & 0.000 & 40 & 4.472 & 2900 & 20.720 & 63 & 101.460 & 0.000 & 100.000 & & & \\
\hline 18 & 0.226 & 0.000 & 0.000 & 41 & 5.122 & 3.180 & 31.900 & 64 & 116210 & 0000 & 100.080 & & & \\
\hline 16 & 0.250 & 0.000 & 0.000 & 42 & 5667 & 2.490 & 35.302 & 65 & 132.103 & 0.000 & 100000 & & & \\
\hline 20 & 0.256 & 0.000 & 0.000 & 43 & 2720 & $905 A$ & 30.340 & $e s$ & 152.453 & 0.000 & 100000 & & & \\
\hline 21 & 9.390 & 0.000 & 0.000 & 44 & 7.697 & 4600 & 49.954 & 67 & 174618 & 0.000 & 100.000 & & & \\
\hline 22 & 0.309 & 0.154 & 0.154 & 45 & 0.810 & 6.428 & 49.383 & 69 & 200.000 & 0.000 & 100.000 & & & \\
\hline 23 & 0.445 & 0.363 & 0.523 & 40 & 10.997 & 6.232 & 56.615 & 60 & 229015 & 0.000 & 100.000 & & & \\
\hline
\end{tabular}




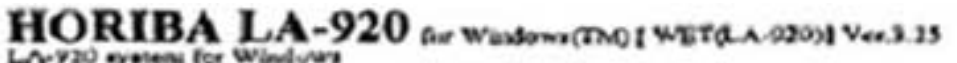

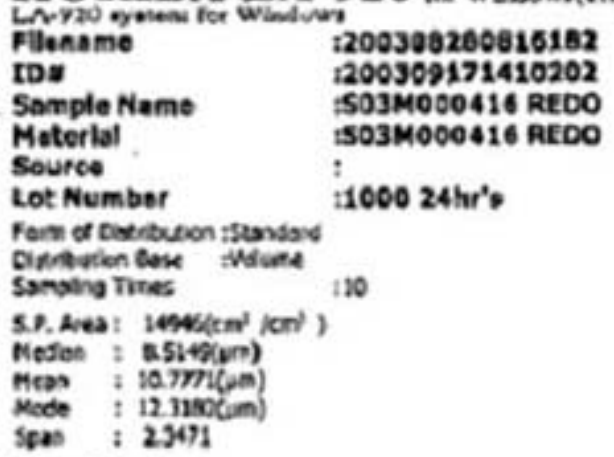

(c)enos)- 1053 (un) C) 00 (w) $12034 \mathrm{~m})$ (6) 06.00 (\%) - is vesum) 990.00(7)- 21. $60 \%$ in

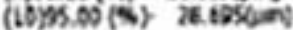

Herne Lowwetery

Labetetery Managet

1767 Normens Aveturt trins, cavio14

phone $(600) 446-7422$

Fox (200)250-0004

Orovilon Speve 3

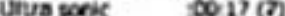
Laver The the

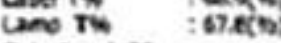
Cakl Lued 00
R. D. Inser vecuoles
vatance : 10728 (ind')
s.o. i 25357(4)
CV : $50: 000$
Gea. Mean: 7.050040$)$
OH-2 i, 0006250

\section{Diameter on $\boldsymbol{h}$}

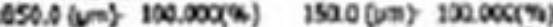

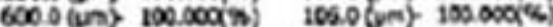

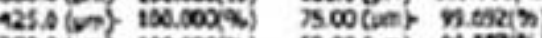

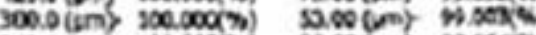

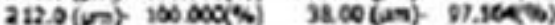

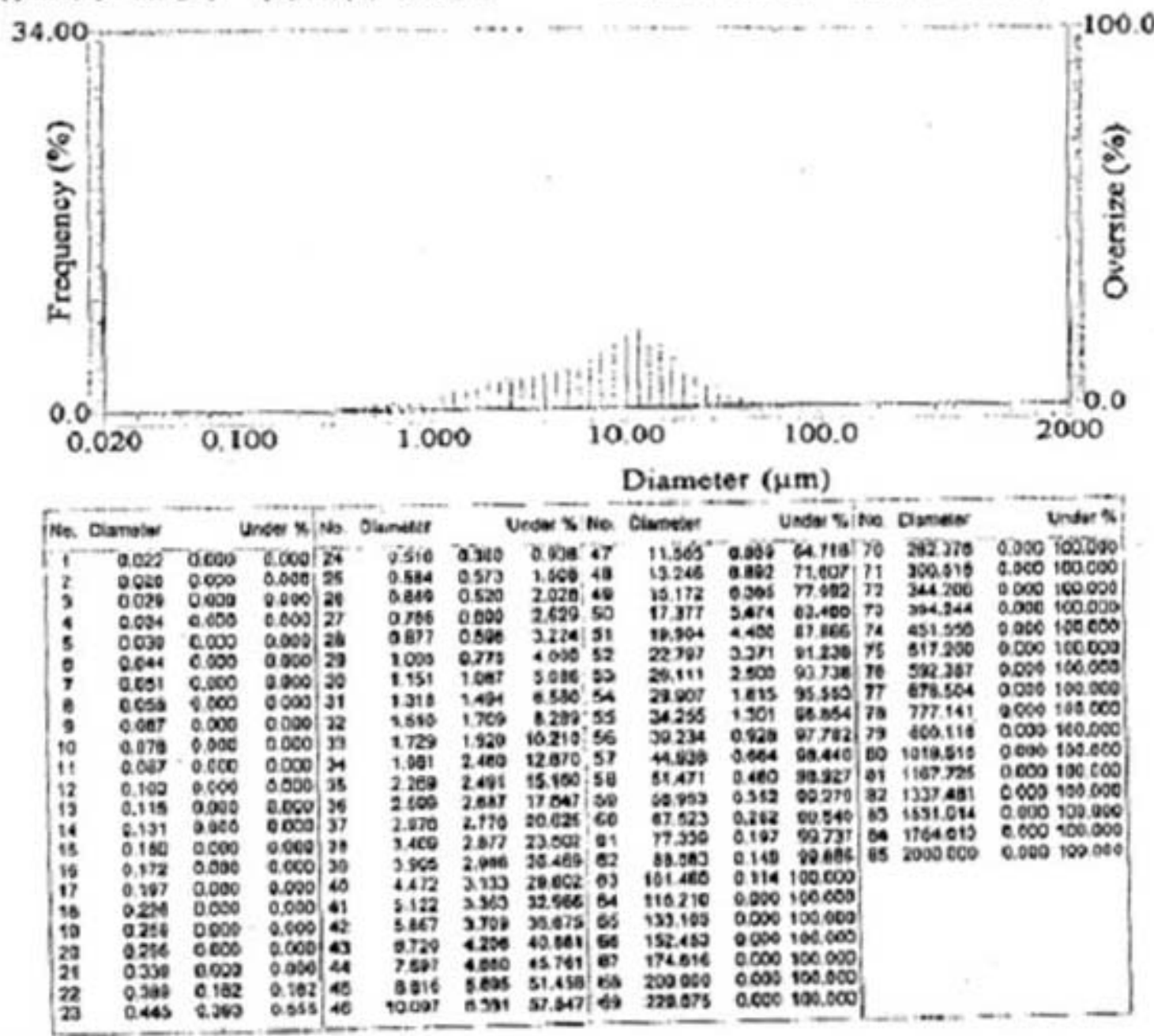


HORIBA LA-920 for Windows(TMo [ WET $\alpha-A-920$ )] Ver.3.25

LA-920 system for Windows

Filename

ID\#

Sample Name

Material

Source

Lot Number

Form of Distribution :Standard

Distribution Base :Nolume

Sampling Times

\section{:200308280816182}

:200309021021187

:S03M000412

:S03M000412

:

\$1000 24hr's

S.P. Area : $9921.4\left(\mathrm{~cm}^{2} / \mathrm{cm}^{3}\right)$

Median : 13.2895(um)

Mean : $13.2034(\mathrm{um})$

Mode : 16.2781(um)

Span : 1.5041

$\%$ on Diameter

(1) 5.000 (\%) $1.558(\mu \mathrm{m})$

(2) 10.00 (\%) $\quad 2.698(\mathrm{um})$

(3) $20.00(\%)-6.037(\mu \mathrm{m})$

(4) $30.00(\%) .9 .037(\mu \mathrm{m})$

(5) $40.00(\%)-11.304(\mu \mathrm{m})$
(6) $60.00(\%)-15.175(\mu \mathrm{m})$

$(7) 70.00(\%)-17.145(\mu \mathrm{m})$

(8) $90.00(\%)=19.466(y \mathrm{~m})$

(9)90.00 (\%)- 22.686( $1 \mathrm{~m})$

$(10) 95.00(\%)-25.577(\mu \mathrm{m})$
Horiba Laboratory

Laboratory Manager 17671 Armstrong Avenue Irvine, CA 92614 Phone: (800)446-7422 Fax: (949)250-0924

Groulation Speod $: 3$

Ultra sonic $\quad: 00: 12(7)$

Laser T\% $\quad: 99.1(\%)$

Lamp T\% : : $98.8 \%$

Calc. Levei :30

R.R.Index :1800010I

Variance : $54.177\left(u^{2}\right)$

S.D. : 7.3605(um)

CV $\quad: 55.7469$

Gea. Mean : $10.2462(\mu \mathrm{m})$

Ohi-2 :0.144217

Dlameter on $\%$

$850.0(\mu \mathrm{m})-100.000(\%) \quad 150.0(\mu \mathrm{m})-100.000(\%)$

600.0 (um)- $100.000(\%) \quad 106.0(\mu \mathrm{m})-100.000(\%)$

425.0 (um)- 100.000 (\%) $\quad 75.00(\mu \mathrm{m})-100.000 \times \%)$

$300.0(\mu \mathrm{m})-100.000(\%) \quad 53.00(\mu \mathrm{m})-100.000 \%)$

$212.0(\mathrm{jm})-100.000(\%) \quad 38.00(\mathrm{jm})-99.925(\%)$

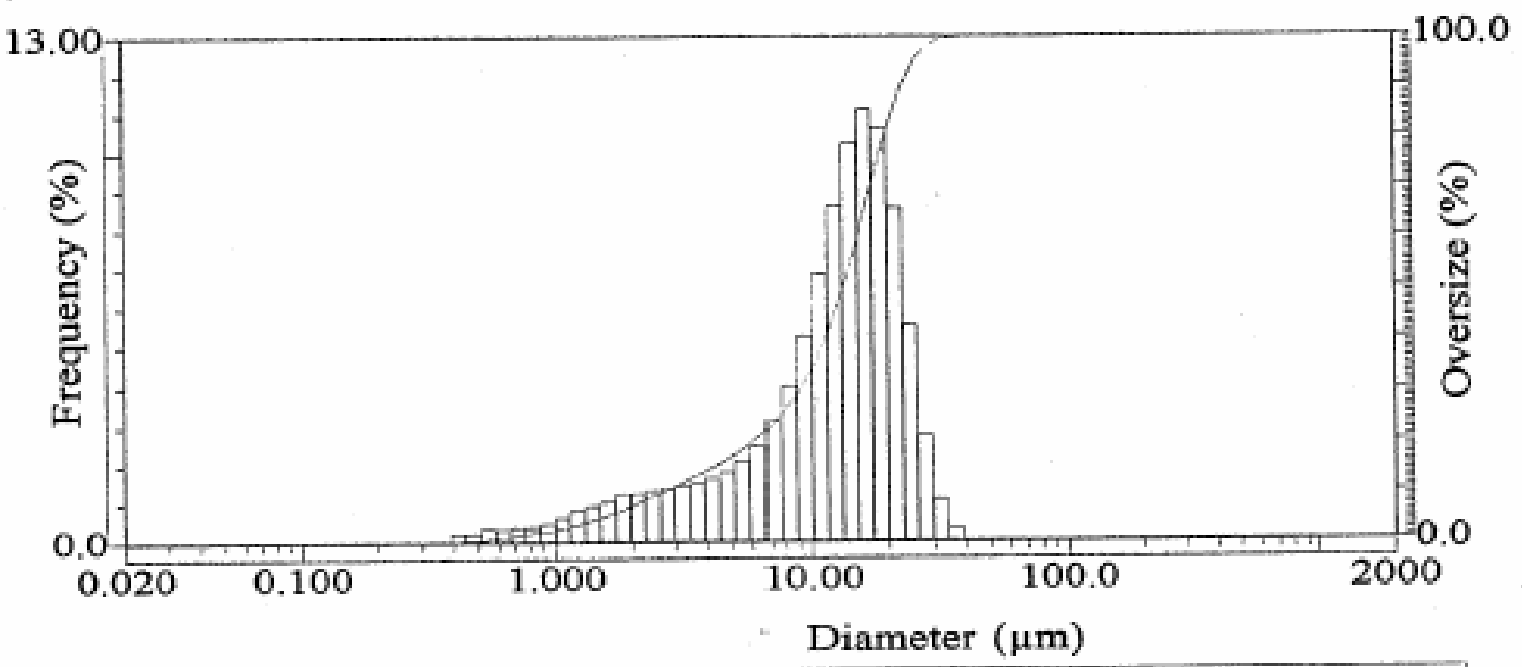

\begin{tabular}{|c|c|c|c|c|c|c|c|c|c|c|c|c|c|c|}
\hline Na. & Diameter & & nder $\%$ & $\mathrm{No}$. & Diameter & & Under $\%$ & No. & Diameler & & Under \% & No. & Diameler & Under $\%$ \\
\hline 1 & 0.022 & 0.000 & 0.000 & 24 & 0.510 & 0.224 & 0.447 & 47 & 11.585 & 6.837 & 41.149 & 70 & 262.376 & 0.000100 .000 \\
\hline 2 & 0.026 & 0.000 & 0.000 & 25 & 0.584 & 0.363 & 0.810 & 48 & 13.246 & 8.605 & 49.754 & 71 & 300.518 & 0.000100 .000 \\
\hline 3 & 0.029 & 0.000 & 0.000 & 26 & 0.669 & 0.343 & 1.153 & 49 & 15.172 & 10.229 & 59.983 & 72 & 344.205 & $0.000 \quad 100.000$ \\
\hline 4 & 0.034 & 0.000 & 0.000 & 27 & 0.766 & 0.387 & 1.540 & 50 & 17.377 & 11.121 & 71.103 & 73 & 394.244 & 0.000100 .000 \\
\hline 5 & 0.039 & 0.000 & 0.000 & 28 & 0.877 & 0.385 & 1.925 & 51 & 19.804 & 10.641 & B1.744 & 74 & 451.556 & 0.000100 .000 \\
\hline 6 & 0.044 & 0.000 & 0.000 & 29 & 1.005 & 0.471 & 2.396 & 52 & 22.797 & 8.562 & 90.307 & 75 & 517.200 & 0.000100 .000 \\
\hline 7 & 0.051 & 0.000 & 0.000 & 30 & 1.151 & 0.626 & 3.022 & 53 & 26.111 & 5.537 & 25.843 & 76 & 592.387 & 0.000100 .000 \\
\hline 8 & 0.058 & 0.000 & 0.000 & 31 & 1.318 & 0.822 & 3.844 & 54 & 29.907 & 2.775 & 98.618 & 77 & 678.504 & 0.000100 .000 \\
\hline 9 & 0.067 & 0.000 & 0.000 & 32 & 1.510 & 0.922 & 4.766 & 55 & 34.255 & 1.063 & 99.682 & 78 & 777.141 & 0.000100 .000 \\
\hline 10 & 0.076 & 0.000 & 0.000 & 33 & 1.729 & 1.016 & 5.782 & 56 & 39.234 & 0.318 & 100.000 & 79 & 890.116 & 0.000100 .000 \\
\hline 11 & 0.087 & 0.000 & 0.000 & 34 & 1.981 & 1.250 & 7.032 & 57 & 44.906 & 0.000 & 100.000 & 80 & 1019.515 & 0.000100 .000 \\
\hline 12 & 0.100 & 0.060 & 0.000 & 35 & 2.269 & 1.254 & 8.287 & 58 & 51.471 & 0.000 & 100.000 & B1 & 1167.725 & 0.000100 .000 \\
\hline 13 & 0.115 & 0.000 & 0.000 & 35 & 2.599 & 1.333 & 9.619 & 59 & 58.953 & 0.000 & 100.060 & 82 & 1337.481 & 0.000100 .000 \\
\hline 14 & 0.131 & 0.000 & 0.000 & 37 & 2.976 & 1.376 & 10.996 & 60 & 67.523 & 0.000 & 100,000 & 83 & 1531.914 & 0.000100 .000 \\
\hline 15 & 0.150 & 0.000 & 0.000 & 38 & 3.409 & 1.436 & 12.432 & 61 & 77.339 & 0.000 & 100.000 & 84 & 1754.613 & 0.000100 .000 \\
\hline 16 & 0.172 & 0.000 & 0.000 & 39 & 3.906 & 1.508 & 13,940 & 62 & 88.583 & 0.000 & 100.000 & 85 & 2000.000 & 0.000100 .000 \\
\hline 17 & 0.197 & 0.000 & 0.000 & 40 & 4.472 & 1.636 & 15.576 & 63 & 101.460 & 0.000 & 100.000 & & & \\
\hline 18 & 0.226 & 0.000 & 0.000 & 41 & 5.122 & 1.815 & 17,392 & 64 & 116.210 & 0.000 & 100.000 & & & \\
\hline 19 & 0.259 & 0.000 & 0.000 & 42 & 5.867 & 2,094 & 19.478 & 65 & 133.103 & 0.000 & 100.000 & & & \\
\hline 20 & 0.286 & 0.000 & 0.000 & 43 & 6.720 & 2.485 & 21.981 & 66 & 152.453 & 0.000 & 100.000 & & & \\
\hline 21 & 0.339 & 0.000 & 0.000 & 44 & 7.697 & 3.090 & 25.051 & 67 & 174.616 & 0.000 & 100,000 & & & \\
\hline 22 & 0.389 & 0.000 & 0.000 & 45 & 8.816 & 3986 & 29.036 & 68 & 200.000 & 0.000 & 100.000 & & & \\
\hline 23 & 0.445 & 0.222 & 0.222 & 46 & 10.097 & 5.276 & 34.312 & 69 & 229.075 & 0.000 & 100.000 & & & \\
\hline
\end{tabular}


HORIBA LA-920 for Windowa(TMO [ WETC.A-920)] Ver.3.23

Herlba Laborabery

coboratory Manager 17671 Armatrong Avenue

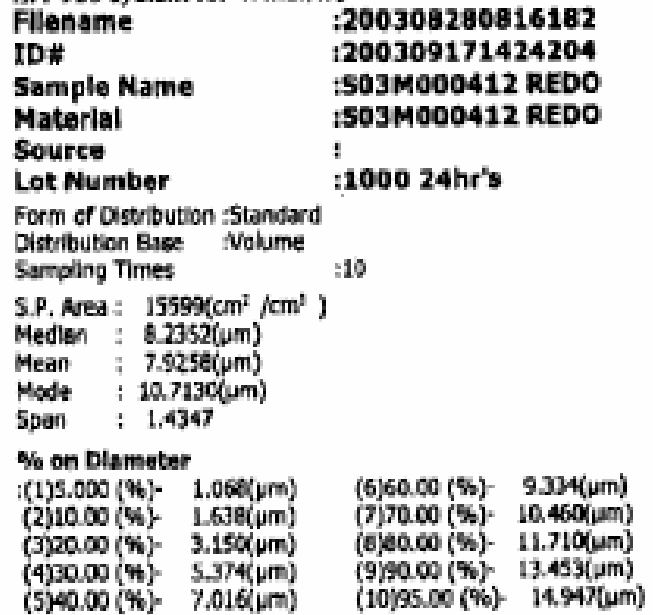

Orculation Speod: 3

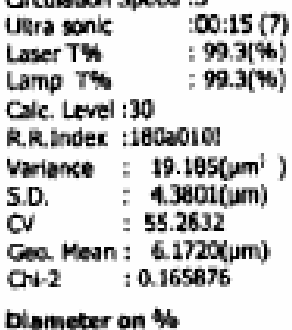

$650.0(\mathrm{jr})-100.000(\%) \quad 150.0(j \mathrm{~m})-100.000(4)$

$600.0(\mu \mathrm{m})-100.000 \% \mathrm{~s}) \quad 106.0(\mu \mathrm{m})=100.000(\mathrm{~s})$

$425.0(\mu \mathrm{m})-100.000(\$ 6) \quad 75.00(\mu \mathrm{m})-100.000 \%)$

300.0 (um) $100.000 \%$ ) $\quad 53.00(\mu \mathrm{m})-100.000 \%$

$2120(\mathrm{sm}) \cdot 100.000(\%) \quad 38.00(1 \mathrm{~m}) \cdot 100.000(\%)$

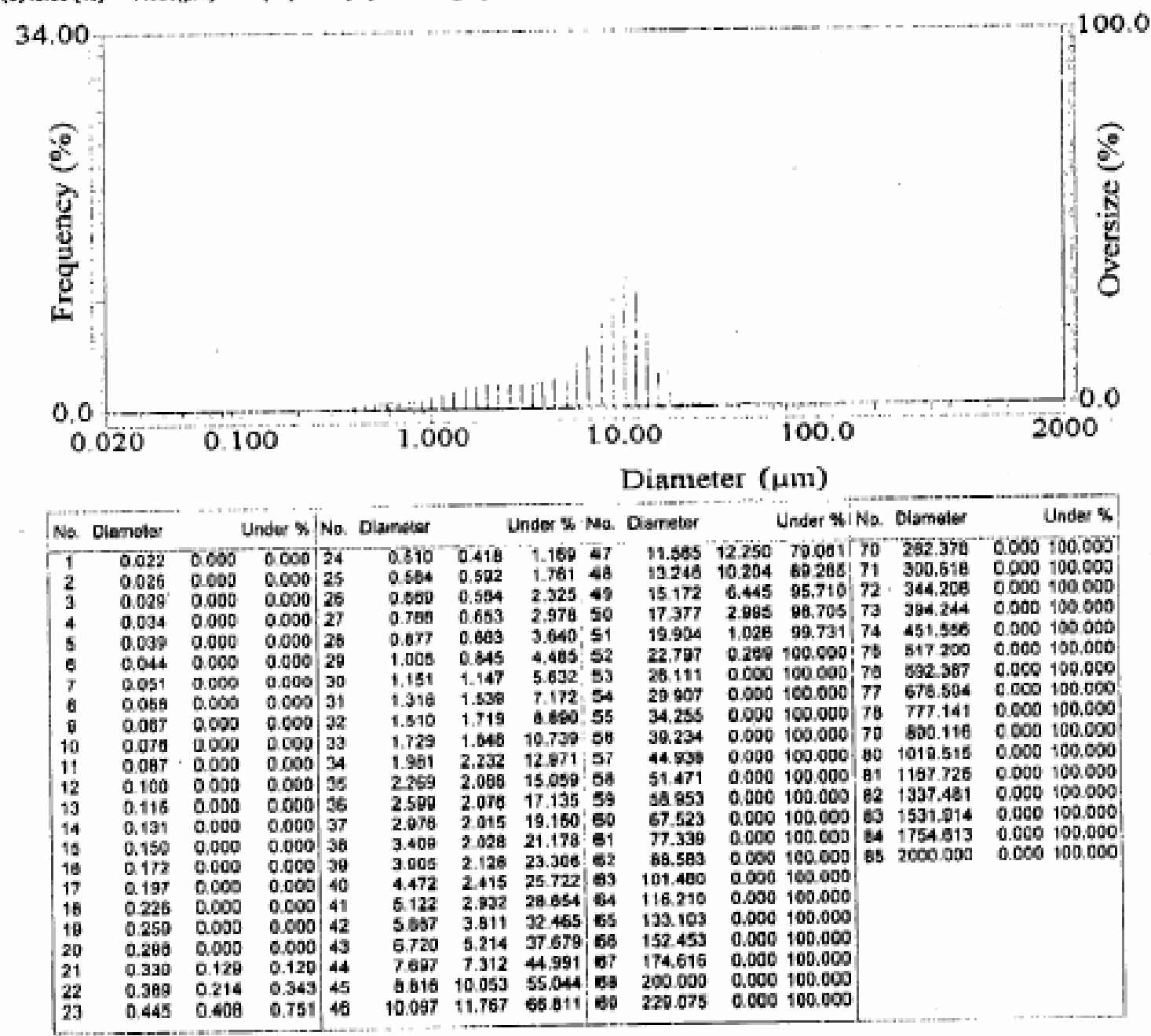


HORIBA LA-920

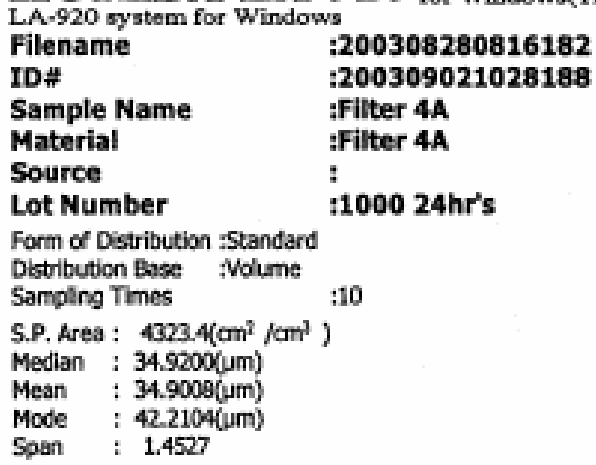

$(6) 60.00(\%)-39.898(\mu m)$ (7) $70.00(\%)$ - 45.050 (um) (8) $60.00(\%)$ - 51.020(um) (9)90.00 (\%) $59.520(\mu \mathrm{m})$ $(10) 95.00(\%)-65.905(\mu \mathrm{m})$
Horiba Laboratory

Laboratory Manager

17671 Armstrong Avenue Irvine, C192614 Phone: (800)446-7422 Fax: (949)250-0924

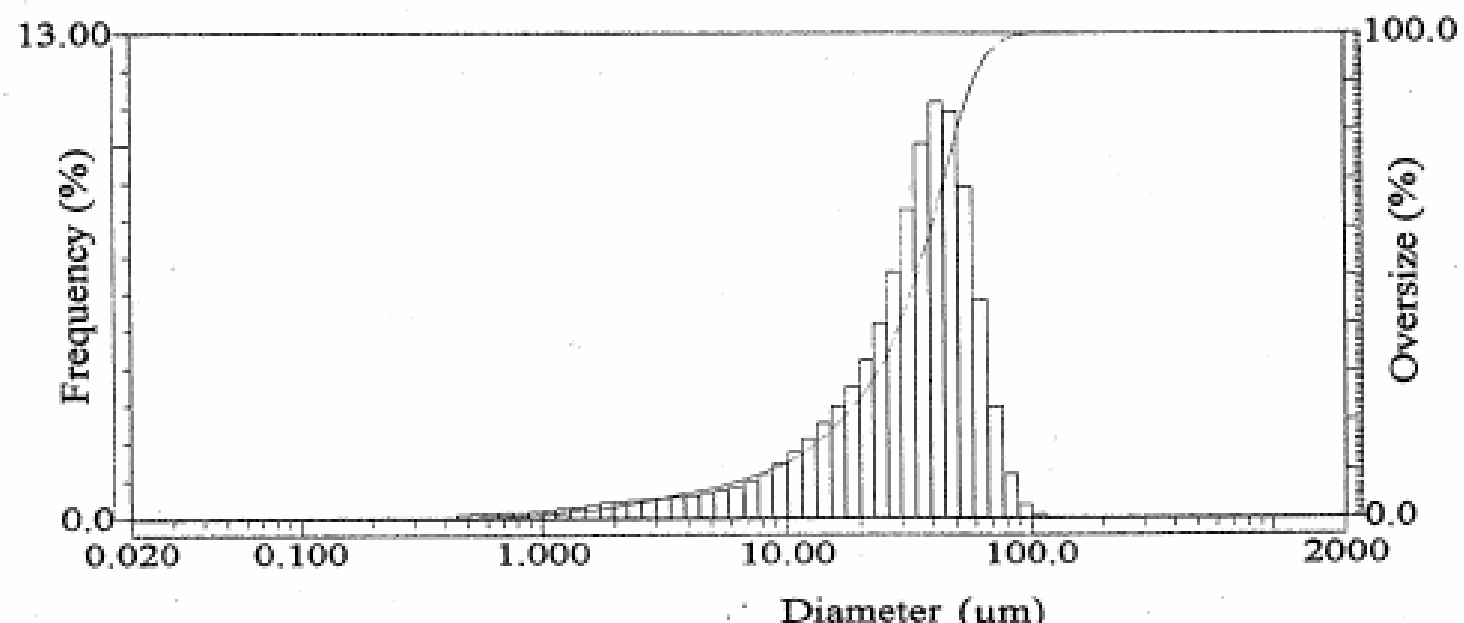

Groulation Speed :

Utra sonic :00:10 (7)

Laser T\% : $: 98.9(\%)$

Calc. Level : 30

R.R.Index :180a010I

Vartance : $367.77\left(\mu^{2}\right)$

S.D. : $19.1773(\mu \mathrm{m})$

CV : 54.9480

Geo. Mean : $27.0764(\mu \mathrm{m})$

Chi-2: 0.156942

Diameter on $\%$

$850.0(\mu \mathrm{m})-100.000(\%) \quad 150.0(\mu \mathrm{m})-100.000(\%)$

$600.0(\mu m)-100.000(\%) \quad 106.0(\mu m)-99.928(\%)$

$425.0(\mu \mathrm{m})-100.000 \%) \quad 75.00(\mu \mathrm{m})-97.67 \%(5 \%)$

$300.0(\mathrm{~mm})-100.000(\%) \quad 53.00(\mu \mathrm{m})-82.623(\%)$

$\begin{array}{ll}300.0(\mathrm{~mm})-100.000(\%) & 33.00(\mu \mathrm{m})-82.623(\%) \\ 212.0(\mathrm{~m})-100.000(\%) & 38.00(\mu \mathrm{m})-56.253(\%)\end{array}$

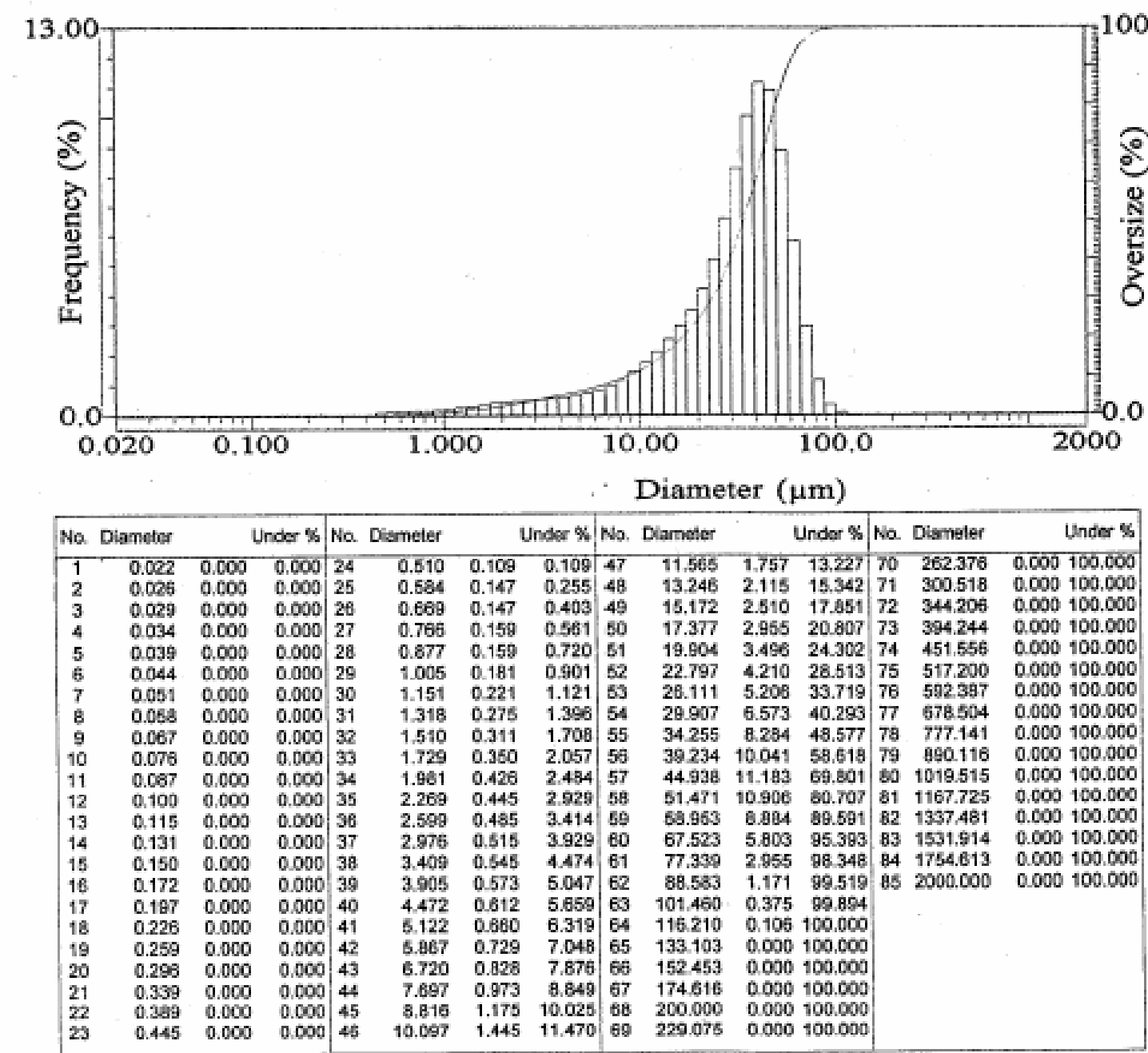


HORIBA LA-920 for Windows(TMo [ WET(L.A-920)] Ver. 3.25

LA-920 system for Windows

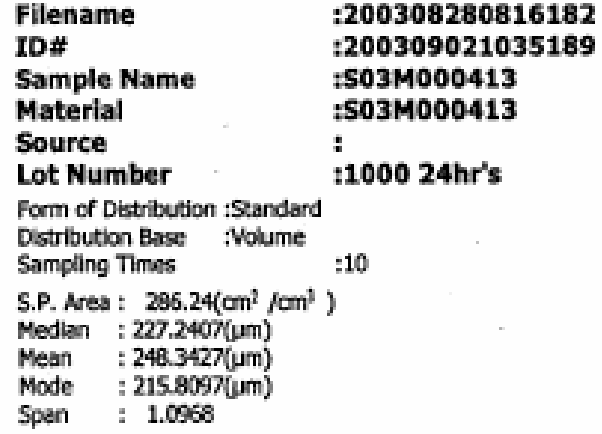

$\%$ on Dlameter

:(1)5.000 (\%)-117,183(رm) (2) $1000(\%)-136.611(\mu \mathrm{m})$ (3) $20.00(\%)-163.345(1 \mathrm{~mm})$ $(4) 30.00(\%)-185.434(\mathrm{\mu m})$ (5) $40.00(\%)-206.297(\mu \mathrm{m})$

(6) $60.00(\%)-250.538(\mu \mathrm{m})$ (7) $70.00(\%)-273.837(\mu \mathrm{m})$ (8) 80.00 (\%)- $317.527(\mu \mathrm{m})$ ( 9 ) $90.00(\%)-385.842$ (um) (10) $95.00(\%)-461.298(\mathrm{Hm})$
Horiba Laboratory

Laboratory Manager 17671 Armstrong Avenue Irvine, CA 92614

Phone: (800)446-7422

Fax: (949) 250-0924

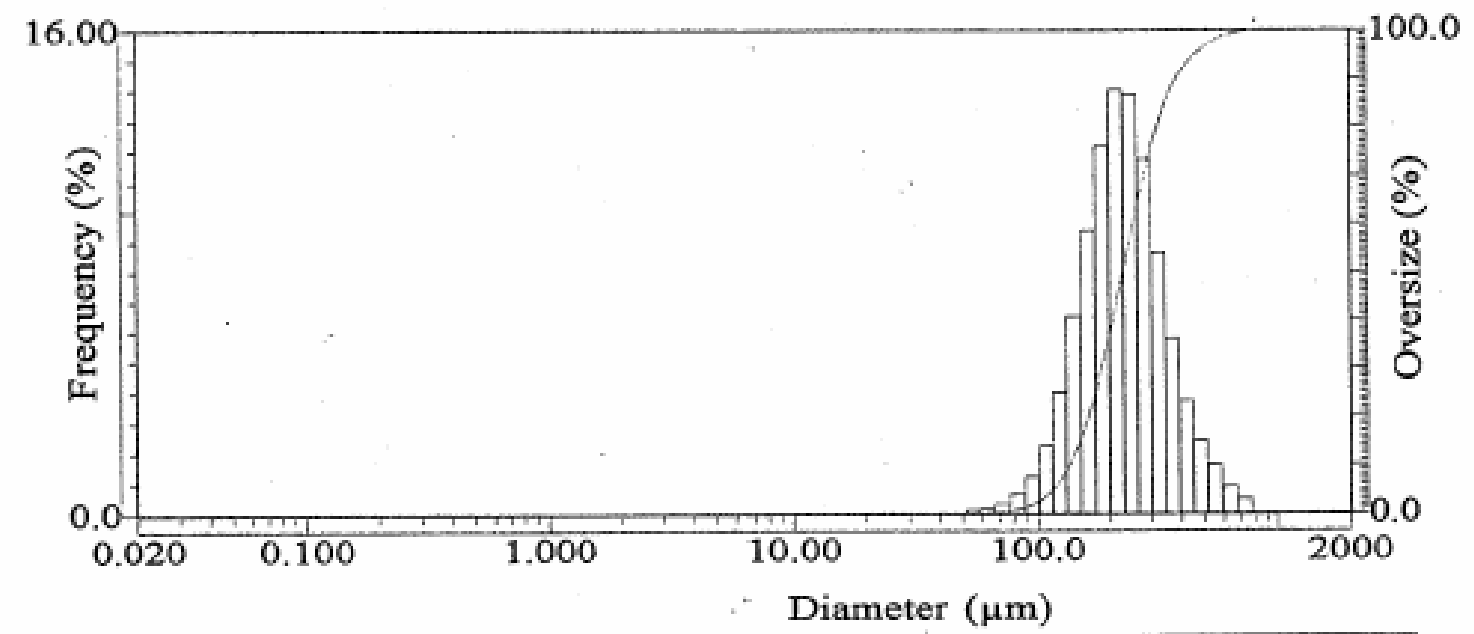

\begin{tabular}{|c|c|c|c|c|c|c|c|c|c|c|c|c|c|c|c|}
\hline No. & Diameter & & inder \% & No. & Diemeter & & Under \% & No. & Diameter & & Inder $\%$ & No. & Diameter & & Under \% \\
\hline 1 & 0.022 & 0.000 & 0.000 & 24 & 0.510 & 0.000 & 0.000 & 47 & 11.365 & 0.000 & 0.000 & 70 & 262.376 & 13.895 & 64,726 \\
\hline 2 & 0.026 & 0.000 & 0.000 & 25 & & 0.000 & 0.000 & 48 & 13.246 & 0.000 & 0.000 & 71 & 300.518 & 11,764 & 76.490 \\
\hline 3 & 0.029 & 0.000 & 0.000 & 26 & 0.669 & 0.000 & 0.000 & 49 & 15.172 & 0.000 & 0.000 & 72 & 344.205 & 8.653 & 86.143 \\
\hline 4 & 0.034 & 0.000 & 0.000 & 27 & 0.766 & 0.000 & 0.000 & 50 & 17.377 & 0.000 & 0.000 & 73 & 394,244 & 5.773 & 90.916 \\
\hline 5 & 0.039 & 0.000 & 0.000 & 28 & 0.877 & 0.000 & 0.000 & 51 & 19.904 & 0.000 & 0.000 & 74 & 451,558 & 3.707 & 94.623 \\
\hline 6 & 0.044 & 0.000 & 0.000 & 29 & 1.005 & 0.000 & 0.000 & 52 & 22.797 & 0.000 & 0.000 & 75 & 517,200 & 2.398 & 97.021 \\
\hline 7 & 0.061 & 0.000 & 0.000 & 30 & 1.151 & 0.000 & 0.000 & 53 & 28.111 & 0.000 & 0.000 & 76 & 592387 & 1.598 & 96.619 \\
\hline 8 & 0.068 & 0.000 & 0.000 & 31 & 1.318 & 0.000 & 0.000 & 54 & 29.607 & 0.000 & 0.000 & $\pi 7$ & 67 b. 504 & 0.888 & 89.507 \\
\hline 9 & 0.067 & 0.000 & 0.000 & 32 & 1.510 & 0.000 & 0.000 & 55 & 34.255 & 0.000 & 0.000 & 78 & 777.141 & 0.493 & 100.000 \\
\hline 10 & 0.076 & 0.000 & 0.000 & 33 & 1.729 & 0.000 & 0.000 & 56 & 39.234 & 0.000 & 0.000 & 79 & 890.116 & 0.000 & 100.000 \\
\hline 11 & 0.087 & 0.000 & 0.000 & 34 & 1.981 & 0.000 & 0.000 & 57 & 44.938 & 0.000 & 0.000 & 80 & 1019.515 & 0.000 & 100.000 \\
\hline 12 & 0.100 & 0.000 & 0.000 & 35 & 2.269 & 0.000 & 0.000 & 58 & 51.471 & 0.000 & 0.000 & 81 & 1167.725 & 0.060 & 100.000 \\
\hline 13 & 0.115 & 0.000 & 0.000 & 38 & 2.599 & 0.000 & 0.000 & 59 & 58.953 & 0.126 & 0.126 & 82 & 1337.481 & 0.000 & 100.000 \\
\hline 14 & 0.131 & 0.000 & 0.000 & 37 & 2.976 & 0.000 & 0.000 & 60 & 67.523 & 0.199 & 0.325 & 83 & 1531.914 & 0.000 & 100.000 \\
\hline 15 & 0.150 & 0.000 & 0.000 & 38 & 3.409 & 0.000 & 0.000 & 81 & 77.339 & 0.346 & 0.672 & 84 & 1754.613 & 0.000 & 100.000 \\
\hline 16 & 0.172 & 0.000 & 0.000 & 39 & 3.905 & 0.000 & 0.000 & 62 & 88.583 & 0.642 & 1.314 & 85 & 2000.000 & 0.000 & 100.000 \\
\hline 17 & 0.197 & 0.000 & 0.000 & 40 & 4.472 & 0.000 & 0.000 & 63 & 101,460 & 1.213 & 2.527 & & & & \\
\hline 18 & 0.226 & 0.000 & 0.000 & 41 & 5. 122 & 0.000 & 0.000 & 64 & 116.210 & 2.227 & 4.754 & & & & \\
\hline 19 & 0.259 & 0.000 & 0.000 & 42 & 5.867 & 0.000 & 0.000 & 65 & 133.103 & 4.003 & 8.757 & & & & \\
\hline 20 & 0.298 & 0.000 & 0.000 & 43 & 6.720 & 0.000 & 0.000 & 66 & 152.453 & 6.488 & 15.243 & & & & \\
\hline 21 & 0.339 & 0.000 & 0.000 & 44 & 7.697 & 0.000 & 0.000 & 67 & 174.616 & 9.355 & 24.599 & & & & \\
\hline 22 & 0.389 & 0.000 & 0.000 & 45 & 8.816 & 0.000 & 0.000 & 68 & 200.000 & 12.195 & 35.794 & & & & \\
\hline 23 & 0.445 & 0.000 & 0.000 & 45 & 10.097 & 0.000 & 0.000 & 69 & 229.075 & 14.037 & 50.831 & & & & \\
\hline
\end{tabular}

Gradation Speed : 3

Uttra sonic :00:20 (7)

Laser T\% : $\quad 89.0 \%$

Lamp T\% : :91.6(\%)

Calc. Level $: 30$

R.R.Index : $180 \mathrm{a} 0101$

Varlance : $11564\left(\mu \mathrm{m}^{2}\right)$

S.D. : $107.5371(\mu \mathrm{m})$

: 43.3019

Gea. Mean : $228.1476($ um)

Chi-2 : 0.036716

Diameter on $\%$

$=850.0(\mu \mathrm{m})-100.000(\%) \quad 150.0(\mu \mathrm{m})-14.468(\%)$

600.0 (um) $98.702(\%) \quad 106.0$ (um) $\quad 3.245(\%)$

$425.0(\mu \mathrm{m})-92.968(\%) \quad 75.00(\mathrm{\mu m})-0.593(\%)$

$3000(\mu \mathrm{m})-76.341 \%) \quad 53.00(\mathrm{\mu m})-0.027(\%)$

$3000(\mu \mathrm{m})-76.341(\%) \quad 53.00(\mu \mathrm{m})-0.02 \pi(\%)$ 
HORIBA LA-920 let Windowernol wistan-920)! ves. 3.23

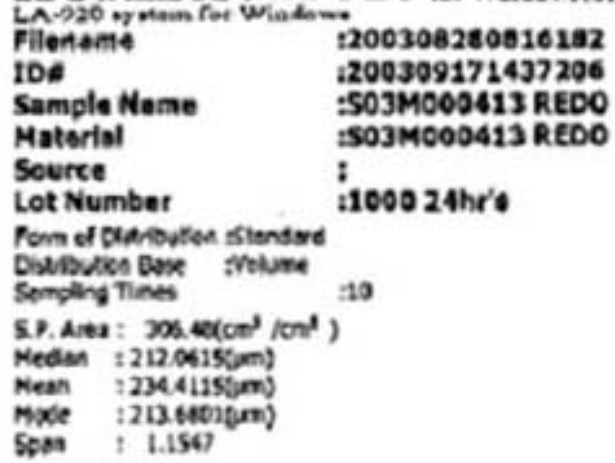

(6)00.00 (m) 294.sncun)

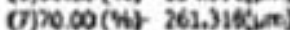
$6000.00(\mathrm{~W})-299.0 \mathrm{x} \times \mathrm{um}$ )

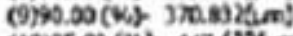
(10)05.00 (4) $447.6396 \mathrm{~m})$
Hortbe Lablewry Lobsotery Manager 17893 A rematgeno Avenue tovine, CA n2614 Dhonat (300) 44a-702? Fax: $(\mathrm{M}+\mathrm{y}) 250-0924$

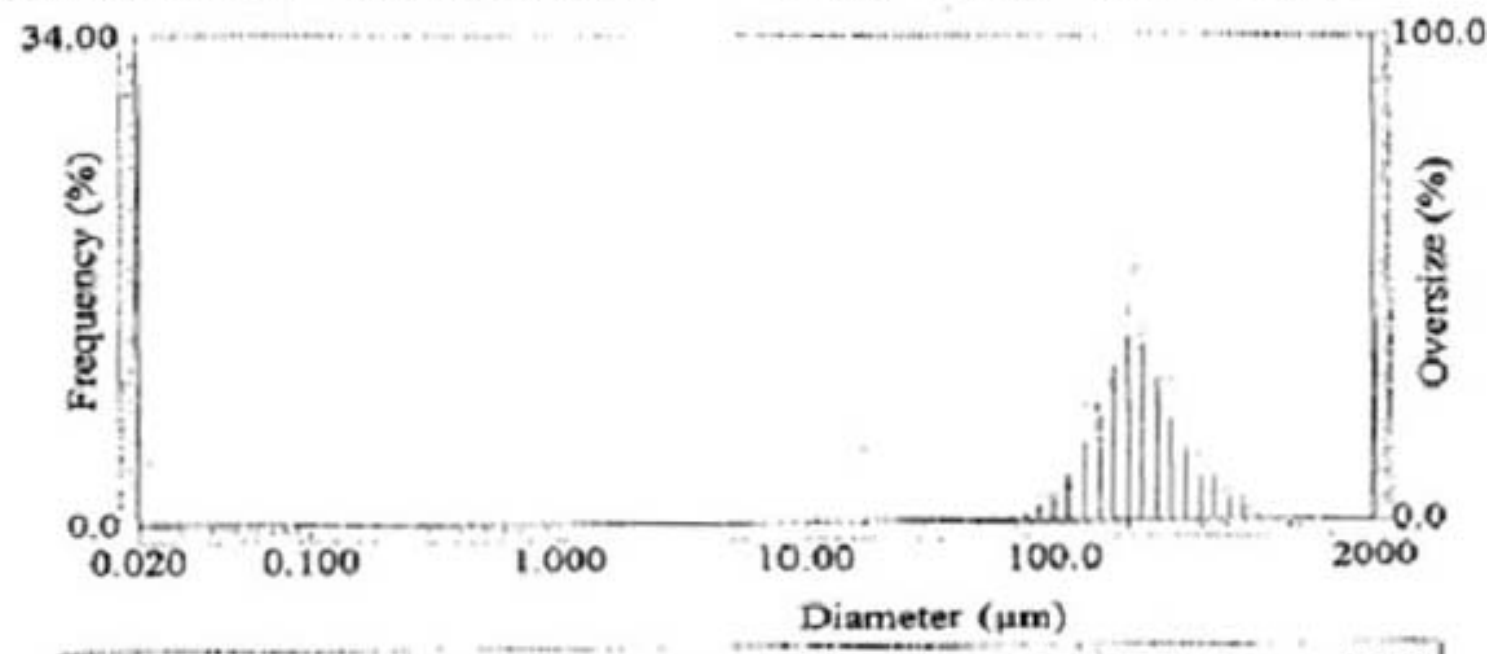

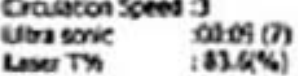

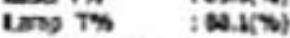

Cec. Level 30

Ratndex :ikcosict

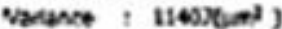

5.0. $\quad t 10.8000(\mathrm{~nm})$

CV it 455021

Geo. Mean : 213 s4a6n)

Ol-2:0023900

Dismeter on $\%$.

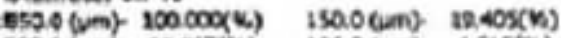

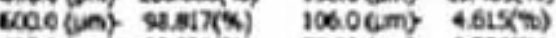

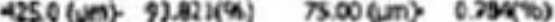

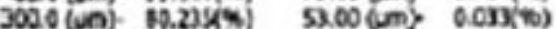

2120 (un) $42.97(x) \quad 39.006 \mathrm{~m}) \quad 0.000(6)$

\begin{tabular}{|c|c|c|c|c|c|c|c|c|c|c|c|c|c|c|c|}
\hline 160 & moret & & $d e x$ & la. & arelat & & ort & Nor & Cimeiner & & $n d r \times$ : & Nie. & Ditmeler & & Under s? \\
\hline 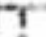 & 0.922 & 0006 & 0000 & 24 & $0 \leqslant 10$ & $0050^{\circ}$ & 0000 & 47 & 13.505 & 600 & 6000 & 70 & 200318 & $12: 600$ & тมבร: \\
\hline 2 & 0020 & 0,000 & 0,000 & 25 & osse & 0.003 & 0.000 & 49 & 13.245 & 0.000 & 0.000 & $\pi 1$ & 300.513 & 0.107 & as.ac2 \\
\hline 2 & 0.029 & 0,000 & 0,000 & 28 & 0.059 & 0.009 & 0.060 & 19 & 15.172 & 0.000 & 0.000 & $n$ & 342.200 & 7.005 & 8. 427 \\
\hline 4 & 0034 & 0,000 & 0.000 & 27 & 0.760 & 0.000 & 0.050 & 50 & 17.377 & 0.900 & 0.000 & $n$ & $904: 244$ & 460 & 02,114 \\
\hline s & 0.020 & 0.000 & 9.000 & 20 & 0.47 & 0.000 & 0.050 & 51 & 19504 & 0.000 & $0000^{\circ}$ & 74 & 451.656 & 2.034 & 95.195 \\
\hline a & 0.044 & a.c00 & a.cos & 20 & 1.009 & 0.060 & $0.000^{\prime}$ & Sa & 22797 & 0.000 & $\cos$ & 78 & 517.290 & 2.906 & 67214 \\
\hline 7 & 0.051 & 0.000 & 0.000 & 20 & 1.151 & 0.060 & 0.640 & 53 & 26.111 & 0.000 & $\csc 0$ & 76 & 502397 & 1.467 & 00.741 \\
\hline 3 & 0.058 & 0.000 & 0,000 & 21 & 1.314 & 0.000 & o ceco & 54 & 29.007 & 0,000 & 0.000 & $\pi$ & 673.504 & 0.400 & 00.550 \\
\hline$D$ & 0.007 & 0.000 & 0.000 & 12 & 1.510 & 0.000 & $0,000^{\circ}$ & 55 & 34.256 & 0.000 & 0.000 & 70 & $m .141$ & 0.450 & $1 \mathrm{cocec}$ \\
\hline 10 & 0.076 & 0.000 & 0.000 & 25 & 1.720 & 0000 & 0000 & 50 & 97.234 & 0.000 & 0.000 & 73 & 600.110 & 0.000 & 100000 \\
\hline 11 & 0.687 & $=0.060$ & 0.500 & 24 & 1.251 & 0000 & 0.000 & 57 & 44.938 & 0.000 & 0.000 & 0 & 1012515 & 0.000 & 100.06 \\
\hline 12 & 2.100 & 0.060 & 0,000 & 35 & 2.269 & 0000 & $4.000^{\prime}$ & 50 & 51,47 & 0.000 & 0.000 & 31 & $1107 \mathrm{ng}$ & 0.000 & 100090 \\
\hline 12 & 0.115 & 0.600 & 0500 & 20 & 2.567 & 0050 & 000 & 50 & 52.552 & Q.152 & Q.152 & $\boldsymbol{n}$ & 1397.491 & 0.060 & 100.050 \\
\hline 14 & 0.131 & 0.600 & 0.000 & y & 2.970 & 0039 & 0.000 & 60 & 07.573 & 0250 & 0.412 & 09 & 1031914 & & 100.050 \\
\hline 15 & 0.160 & 0.000 & 0,000 & 34 & 3.400 & 0009 & $0.000^{\circ}$ & 61 & n.390 & 0.452 & 0.000 & $* 4$ & 1784019 & & 100.030 \\
\hline 16 & 0.172 & 0.000 & 0000 & 9 & 2.020 & 0000 & 0.000 & 02 & 28 59 & 0.50 & 1.023 & es & 2000.000 & 0000 & 100.000 \\
\hline 17 & 0.197 & 0.095 & 0000 & 40 & 4.42 & 0000 & $0.000^{\circ}$ & 63 & 101.460 & 1.70 & 3.502 & & & & \\
\hline te & 0.223 & 0.000 & 0000 & 41 & 5.122 & 0000 & 0.000 & 64 & 116210 & 3.171 & 0.703 & & & & \\
\hline 10 & 0.250 & 000 & 0.000 & 42 & 569 & 0.000 & 0,000 & 65 & 132.103 & 5.46 & 12.212 & & & & \\
\hline 20 & 0.265 & $0 . \infty 0$ & 0,000 & 43 & 6720 & 0.009 & 0.000 & et & 152.453 & e.tea & 20360 & & & & \\
\hline 21 & 0.959 & 0.000 & 0,000 & 44 & 7628 & 0000 & 0009 & ef & 174016 & 90.181 & 31.102 & & & & \\
\hline 22 & 0.260 & 0.090 & 0.030 & 45 & 0.016 & $\cos$ & & 6 & 200000 & 12024 & 4005 & & & & \\
\hline 22 & 2.445 & 0.090 & 0,000 & es & 10607 & $\cos$ & $0.000:$ & 60 & nods & 13.762 & 07.754 & & & & \\
\hline
\end{tabular}


HORIBA LA-920 for Windows(TM) [ WETCAA-920)] Ver.3.25

LA-920 system for Windows

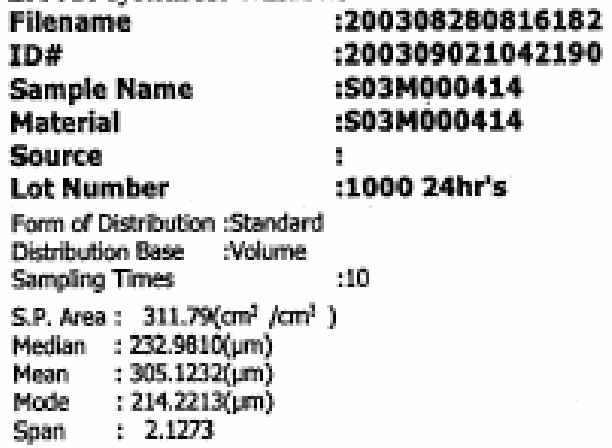

\section{:200308280816182}

is03M000414

:S03M000414

:

:1000 24hr's$$
10
$$

$(6) 60.00(\%)-269.138(\mu \mathrm{m})$
$(7) 70.00(\%)-320.606(\mu \mathrm{m})$
$(8) 00.00(\%)-411.342(\mu \mathrm{m})$
$(9) 90.00(\%)-615.016(\mu \mathrm{m})$
$(10) 95.00(\%)-805.258(\mu \mathrm{m})$

$(6) 60.00(\%)-269.138(\mu \mathrm{m})$
$(7) 70.00(\%)-320.606(\mu \mathrm{m})$
$(8) 60.00(\%)-411.342(\mu \mathrm{m})$
$(9) 90.00(\%)-615.016(\mu \mathrm{m})$
$(10) 95.00(\%)-805.258(\mu \mathrm{m})$

$(6) 60.00(\%)-269.138(\mu \mathrm{m})$
$(7) 70.00(\%)-320.606(\mu \mathrm{m})$
$(8) 90.00(\%)-411.342$ (um)
$(9) 90.00(\%)-615.016(\mu \mathrm{m})$
$(10) 95.00(\%)-805.258(\mu \mathrm{m})$

$(6) 60.00(\%)-269.138(\mu \mathrm{m})$
$(7) 70.00(\%)-320.606(\mu \mathrm{m})$
$(8) 60.00(\%)-411.342(\mu \mathrm{m})$
$(9) 90.00(\%)-615.016(\mu \mathrm{m})$
$(10) 95.00(\%)-805.258(\mu \mathrm{m})$

$(6) 60.00(\%)-269.138(\mu \mathrm{m})$
$(7) 70.00(\%)-320.606(\mu \mathrm{m})$
$(8) 90.00(\%)-411.342(\mu \mathrm{m})$
$(9) 90.00(\%)-615.016(\mu \mathrm{m})$
$(10) 95.00(\%)-805.258(\mu \mathrm{m})$

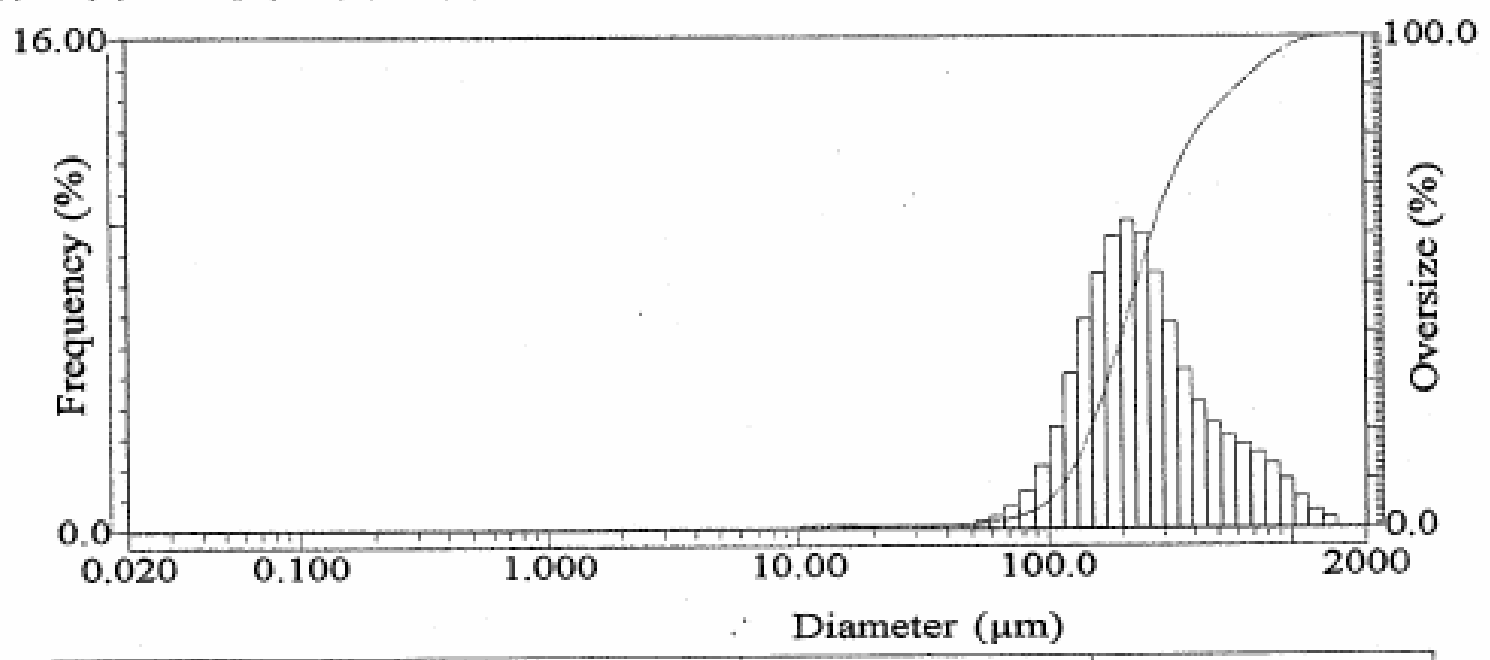

Graulation Speed : 3

$\begin{array}{ll}\text { Ultra soric } & : 00: 12(7) \\ \text { Laser T\% } & : 80.3(\%)\end{array}$

Lamp T\% $: 85.6(\%)$

Calc. Level :30

R.R.Index :180a010I

Varlance : 50707 (uma')

S.D. : $225.1814(\mathrm{um})$

CV : 73.8002

Geo. Mean : $245.7035(\mathrm{\mu m})$

Oni-2 :0.060973

\section{Diameter on $\%$}

850.0 ( $\mu \mathrm{m})-95.836(\%) \quad 150.0(\mu \mathrm{m})-20.096(\%)$

$600.0(\mu \mathrm{m})-89.501(\%) \quad 106.0(\mu \mathrm{m})-6.748(\%)$

$425.0(\mu \mathrm{m})-80.988(\%) \quad 75.00(\mu \mathrm{m})-2.256 \%$

$300.0(\mu \mathrm{m})-66.692(\%) \quad 53.00(\mu \mathrm{m})-1.130 \%)$

$212.0(\mu \mathrm{m})=43.060(\%) \quad 38.00(\mu \mathrm{m})-0.755(\%)$

\begin{tabular}{|c|c|c|c|c|c|c|c|c|c|c|c|c|c|c|c|}
\hline No. & Diameter & & Inder \% & $\mathrm{Na}$ & Diameter & & nder $\%$ & No. & Diameler & & Under $\%$ & No. & Diameter & & Under * \\
\hline 1 & 0.022 & 0.000 & 0.000 & 26 & 0.510 & 0.000 & 0.000 & 47 & 11.565 & 0.102 & 0,102 & 70 & 262376 & 9.631 & 58.431 \\
\hline 2 & 0.026 & 0.000 & 0.000 & 25 & 0.584 & 0.000 & 0.000 & 48 & 13.246 & 0.114 & 0.216 & 71 & 300.518 & 8.367 & 66.798 \\
\hline 3 & 0.029 & 0.000 & 0.000 & 26 & 0.669 & 0.000 & 0.000 & 49 & 15.172 & 0.120 & 0.338 & 72 & 344.206 & 6.716 & 73.514 \\
\hline 4 & 0.034 & 0.000 & 0.000 & 27 & 0.766 & 0.000 & 0.000 & 50 & 17,377 & 0.119 & 0.455 & 73 & 394.244 & 5.201 & 78.716 \\
\hline 5 & 0.039 & 0.000 & 0.000 & 28 & 0.877 & 0.000 & 0.000 & 51 & 19.904 & 0.113 & 0.568 & 74 & 451,566 & 4.106 & 82.822 \\
\hline 6 & 0.044 & 0.000 & 0.000 & 29 & 1.005 & 0.000 & 0.000 & 52 & 22797 & 0.105 & 0.673 & 75 & 517,200 & 3.415 & 86.236 \\
\hline 7 & 0.051 & 0.000 & 0.000 & 30 & 1.151 & 0.000 & 0.000 & 53 & 26.111 & 0.000 & 0.673 & 76 & 692.357 & 3.007 & 89.243 \\
\hline 8 & 0.058 & 0.000 & 0.000 & 31 & 1.318 & 0,000 & 0.000 & 54 & 29.907 & 0.000 & 0.673 & $\pi$ & 678.504 & 2.740 & 91.983 \\
\hline$\theta$ & 0.067 & 0.000 & 0.000 & 32 & 1.510 & 0.000 & 0.000 & 55 & 34.255 & 0.000 & 0.673 & 78 & 777.141 & 2.467 & 94.450 \\
\hline 10 & 0.076 & 0.000 & 0.000 & 33 & 1.729 & 0.000 & 0.000 & 56 & 39.234 & 0.107 & 0.780 & 79 & 890.116 & 2.009 & 96.560 \\
\hline 11 & 0.087 & 0.000 & 0.000 & 34 & 1.981 & 0.000 & 0.000 & 57 & 44.938 & 0.128 & 0.908 & 80 & 1019.515 & 1.560 & @6.130 \\
\hline 12 & 0.100 & 0.000 & 0.000 & 35 & 2.269 & 0.000 & 0.000 & 58 & 51.471 & 0.169 & 1.077 & 81 & 1167.725 & 1.003 & 89.133 \\
\hline 13 & 0.115 & 0.000 & 0.000 & 36 & 2.699 & 0.000 & 0.000 & 59 & 58.953 & 0.248 & 1.325 & 82 & 481 & 0.557 & 99.690 \\
\hline 14 & 0.131 & 0.000 & 0.000 & 37 & 2.976 & 0.000 & 0.000 & 80 & 67.523 & 0.400 & 1.724 & 83 & .914 & 0.310 & 100.000 \\
\hline 15 & 0.150 & 0.000 & 0.000 & 38 & 3.409 & 0.000 & 0.000 & 61 & 77.339 & 0.687 & 2.411 & 84 & 1754.613 & 0.000 & 100.000 \\
\hline 16 & 0.172 & 0.000 & 0.000 & 39 & 3.805 & 0.000 & 0.000 & 62 & 88.583 & 1.206 & 3.617 & 85 & 2000.000 & 0.000 & 100.000 \\
\hline 17 & 0.197 & 0.000 & 0.000 & 40 & 4.472 & 0.000 & 0.000 & 63 & 101.460 & 2.064 & 5.681 & & & & \\
\hline 18 & 0.226 & 0.000 & 0.000 & 41 & 5.122 & 0.000 & 0.000 & 64 & 116.210 & 3.309 & ช.990 & & & & \\
\hline 19 & 0.259 & 0.000 & 0.000 & 42 & 5.857 & 0.000 & 0.000 & 65 & 133.103 & 5.060 & 14.070 & & & & \\
\hline 20 & 0.296 & 0.000 & 0.000 & 43 & 6.720 & 0.000 & 0.000 & 66 & 152,463 & 6.844 & 20.914 & & & & \\
\hline 21 & 0.339 & 0.000 & 0.000 & 44 & 7.697 & 0.000 & 0.000 & 67 & 174.816 & 8.336 & 29.248 & & & & \\
\hline 22 & 0.389 & 0.000 & 0.000 & 45 & 8.8 & 0.000 & 0.000 & 68 & 200.000 & 9.509 & 38.750 & & & & \\
\hline 23 & 0.445 & 0.000 & 0.000 & 46 & 10.097 & 0.000 & 0.000 & 69 & 222.075 & 10.042 & 48.800 & & & & \\
\hline
\end{tabular}




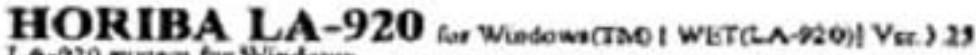

LA-720 my nom tor Windows.

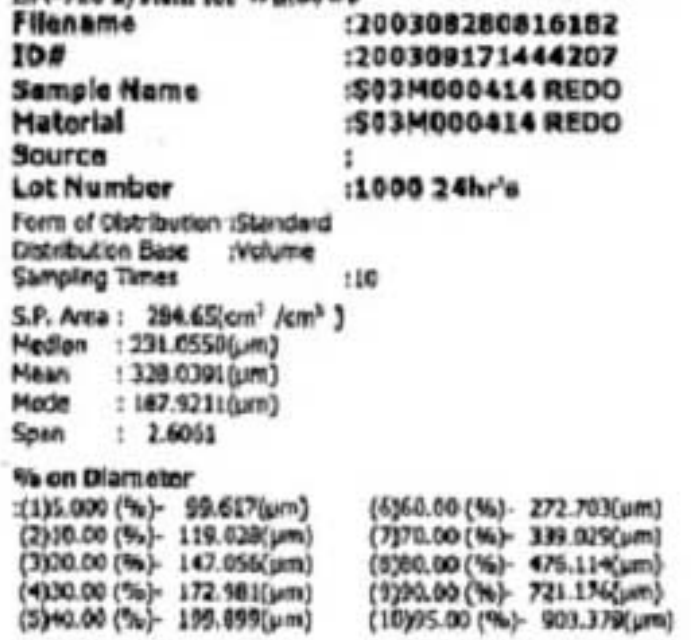

Morlba Laborstory

Laberatery Nanagar 17071 Amiationg Avencie Ivine, CA 92614

Dhone (sco) 456-7422 Fan (949)250-0924
Oreulaton Speed 3

Utua soric 00:10 (7)

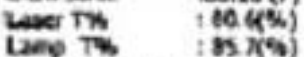

Citc inel 10

R.R.inder :160eosen

Vailance : essazfum' )

SD. $\quad$ 208.7009(un)

Cy $\$ \mathbf{n 2 0 0 6}$

Ces. Hean : 2585710 me?

ONe2 0.13794

Dlameter on $\mathrm{W}$

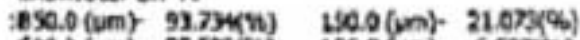

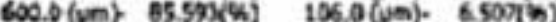

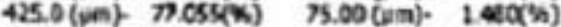

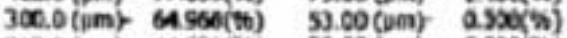

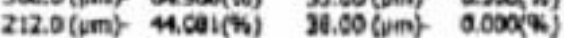

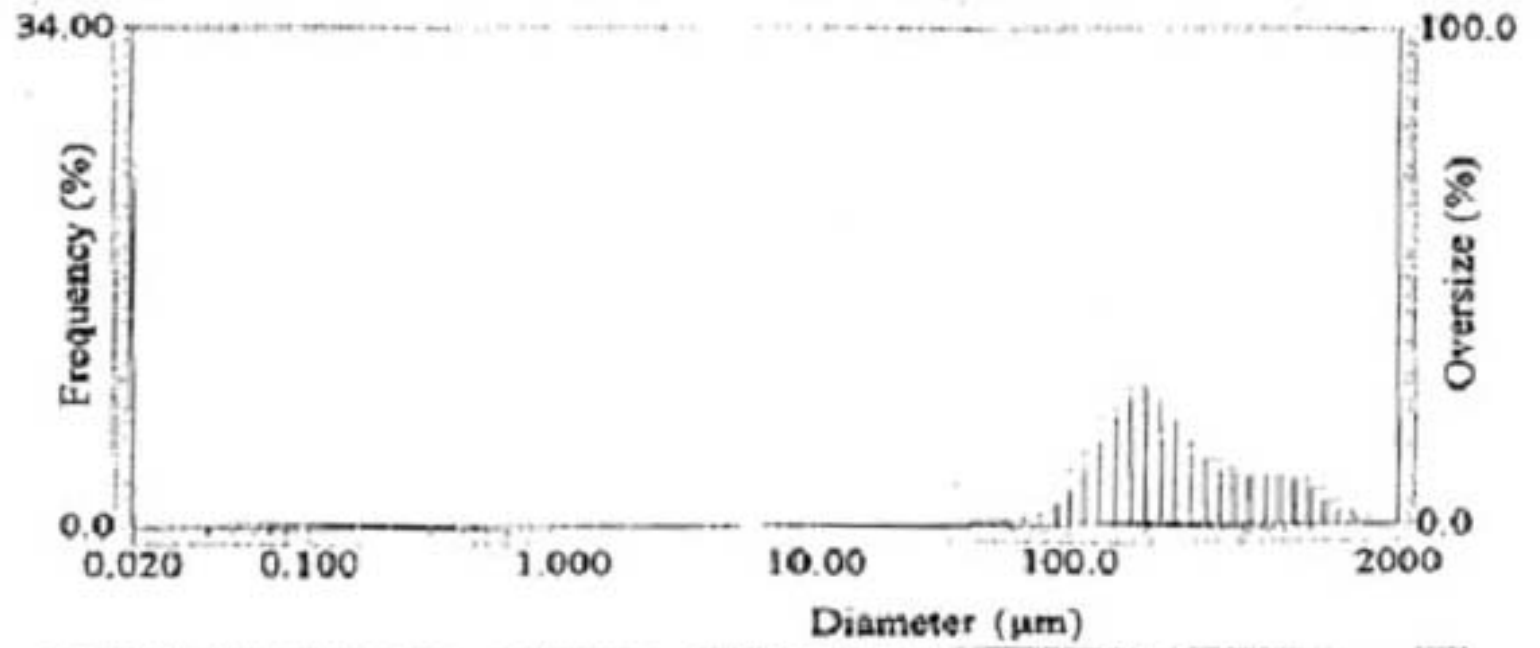

\begin{tabular}{|c|c|c|c|c|c|c|c|c|c|c|c|c|c|c|c|}
\hline Nie. & Digmeier & & $n d e=2$ & No & Olarnetet & & neer \&s & Na. & Oateler & & neer $\mathbf{N}$ & No & Ciancior & & teser \% \\
\hline 1 & 0022 & 0,000 & 0000 & 24 & $0.510^{\circ}$ & 0.000 & 9.000 & 47 & 31305 & 0.000 & 0000 & 70 & $202.37 e^{\circ}$ & $8: 531$ & 87.096 \\
\hline 2 & 0.025 & 0000 & 0000 & 25 & 0554 & 0.000 & 0000 & 48 & 13245 & 0.000 & 0.000 & 71 & 200518 & 7,068 & 65.058 \\
\hline$\partial$ & 0.026 & 0000 & 0.000 & 20 & 0659 & 0.000 & 0.000 & 40 & 15,172 & 0,000 & 0.600 & 72 & 244206 & 6. 504 & 70.621 \\
\hline 4 & 0034 & 0.000 & 0.000 & 27 & 0.755 & 0.060 & 0.000 & 50 & 17.377 & 0000 & 0.000 & 73 & 284244 & 4.365 & 76.090 \\
\hline 5 & 0000 & 0.000 & c. 600 & 20 & 0.977 & 0.000 & 0.000 & 37 & 18.604 & 0003 & 0.000 & 74 & 451.556 & 2.76 & 76698 \\
\hline E & 0044 & 0.000 & 6000 & 29 & 1.005 & 0.000 & 0,000 & 22 & 22757 & 0.000 & 0.000 & 75 & 517.200 & 2300 & 02.095 \\
\hline 7 & 0.051 & 0.060 & 0.000 & 30 & 1.151 & 0.000 & 0.009 & 00 & 26,141 & 0.000 & 0.000 & 76 & 592.287 & 3.200 & 65200 \\
\hline a & 0.058 & 0.000 & 0.000 & 31 & 1310 & 0.000 & $0.000^{\prime}$ & 54 & 29.067 & 0.000 & ecco & 77 & 576.004 & 3.256 & es.55i \\
\hline 0 & 0.067 & 0.000 & 0.000 & 92 & 1510 & 0.000 & 0.000 & 35 & 34.255 & 0,000 & 0.000 & 78 & 777.141 & 3.226 & 01.710 \\
\hline 10 & 0.076 & 0.000 & 0.000 & $\mathbf{3 9}$ & inz & 0.000 & 0. & Se & 36.234 & 0.000 & 0.000 & 70 & 890.110 & 2.500 & 96.742 \\
\hline 11 & 0.007 & -0.000 & 0.000 & 34 & 1.991 & 0.090 & $0,000^{\prime \prime}$ & 57 & 4986 & 0.100 & 0.100 & $\theta 0$ & 1910.213 & 2371 & 07.113 \\
\hline 12 & e. 100 & $c .000$ & 00 & 26 & 22 & 0000 & 0.000 & 56 & 51.471 & e.151 & 0.267 & 61 & 1697.726 & 1584 & 8067 \\
\hline 13 & 0.11 & 0.000 & 0.900 & B & 2500 & 0000 & 0.00 & $\infty$ & 54.759 & c. 2299 & 0.465 & 82 & 1397.461 & 0.05 ! & n.52t \\
\hline 14 & 0.131 & 0.000 & 0.000 & 37 & 2873 & 0000 & 0.000 & 60 & 57,523 & 0.411 & 0.960 & 63 & 1531.914 & 0.473 & 109000 \\
\hline 15 & 0.150 & 0.000 & 0.000 & 30 & 3.460 & 0000 & 0000 & 61 & 77.395 & 0.742 & 1.540 & eu & 1754.613 & 0.060 & 100.000 \\
\hline 19 & 0.112 & 0.000 & 0000 & 39 & 3005 & 0000 & 0.000 & 62 & 06569 & 1363 & 2.001 & 85 & 2000000 & 0000 & 102.000 \\
\hline$\rightarrow$ & 0.157 & 0.000 & 0000 & 40 & 4472 & 2.000 & 0000 & 63 & 101.460 & 2.322 & 5314 & & & & \\
\hline 1e & 0.226 & 0.000 & 0000 & 41 & 5.122 & 0 coo & 0000 & 64 & 316210 & 2.669 & 0.019 & & & & \\
\hline 10 & 0.269 & 0.000 & 0000 & 42 & 5. vat & 0000 & 0.000 & 05 & 130.109 & 5.554 & 14607 & & & & \\
\hline 20 & 0.206 & 0.000 & 0000 & 43 & 6. 120 & 0000 & 0.060 & $\theta 0$ & 152.450 & 734 & 21.060 & & & & \\
\hline 21 & 0.390 & 0.000 & 0.000 & 44 & 7.697 & 0.000 & 0.000 & 67 & 174 oie & 6.048 & 32000 & & & & \\
\hline 22 & 0.399 & $0.0 \%$ & 0000 & 45 & 0.16 & $0 \times 00$ & & 06 & 200600 & 0.498 & 49036 & & & & \\
\hline 23 & 0.445 & 2000 & 0000 & 40 & 10.087 & 0.000 & 0.000 & Es & 229075 & 2024 & 49459 & & & & \\
\hline
\end{tabular}




\section{Distribution}

No. of

$\underline{\text { Copies }}$

3 DOE Office of River Protection

Dennis Irby

Yusuf Noorani

Jian-Shun Shuen

8 CH2M HILL Hanford Group

Dan Baide

Blaine Barton

Paul Branson

John Harris III

Dan Reynolds

John Schofield

Dave Smet

Ryan Smith
No. of

Copies

1 Fluor Hanford

H6-60

H6-60

H6-60

10 Pacific Northwest National Laboratory

Sheila Bennett

K7-90

Jim Huckaby (5)

$\mathrm{K} 7-15$

John Glissmeyer

K3-45

Paul Gray

K3-54

Information Release (2)

S7-12

S7-90

S7-90

S7-12

S7-65

S7-90 